UNIVERSIDADE DE SÃO PAULO

Escola de Artes, Ciências e Humanidades

Thiago Adriano Coleti

Um ambiente de avaliação da usabilidade de software apoiado por técnicas de processamento de imagens e reconhecimento de fala

São Paulo

2014 
Thiago Adriano Coleti

\section{Um ambiente de avaliação da usabilidade de software apoiado por técnicas de processamento de imagens e reconhecimento de fala}

Dissertação apresentada à Escola de Artes, Ciências e Humanidades da Universidade de São Paulo para obtenção do título de Mestre em Ciências. Programa: Sistemas de Informação.

Versão corrigida contendo as alterações solicitadas pela comissão julgadora. A versão original encontra-se disponível na Escola de Artes, Ciências e Humanidades.

Orientador(a): Prof. Dr. Marcelo Moran$\operatorname{dini}$

São Paulo 
Autorizo a reprodução e divulgação total ou parcial deste trabalho, por qualquer meio convencional ou eletrônico, para fins de estudo e pesquisa, desde que citada a fonte.

\section{CATALOGAÇÃO-NA-PUBLICAÇÃO}

\section{Biblioteca}

Escola de Artes, Ciências e Humanidades da Universidade de São Paulo

Coleti, Thiago Adriano

Um ambiente de avaliação da usabilidade de software apoiado por técnicas de processamento de imagens e reconhecimento de fala / Thiago Adriano Coleti : orientador, Marcelo Morandini. - São Paulo, 2014. [155]f.: il.

Dissertação (Mestrado em Ciências) - Programa de PósGraduação em Sistemas de Informação, Escola de Artes, Ciências e Humanidades, Universidade de São Paulo, em 2013.

Versão corrigida.

1. Interface homem-computador. 2. Usabilidade de software Avaliação. 3. Teste e avaliação de software. 4. Reconhecimento de imagem. 5. Reconhecimento de voz. I. Morandini, Marcelo, orient. II. Título 
Folha de Aprovação

Dissertação sob o título "Um ambiente de avaliação da usabilidade de software apoiado por técnicas de processamento de imagens e reconhecimento de fala", defendida por Thiago Adriano Coleti e aprovada em 17 de dezembro de 2013, em São Paulo, Estado de São Paulo, pela banca examinadora constituída pelos doutores:

Prof. Dr. Marcelo Morandini Orientador

Prof. Dr. Junia Coutinho Anacleto Universidade Federal de São Carlos

Prof. Dr. João Luiz Bernardes Jr. Universidade de São Paulo 
Dedico este trabalho a meu pai, que muito me apoiou no começo deste curso, mas que por vontade de Deus partiu cedo e com certeza esteve ao meu lado nesta caminhada. 
Agradeço primeiramente a Deus e a Nossa Senhora Aparecida por permitir que eu realizasse mais esta etapa, me proporcionando forças para nunca desistir. Agradeço a minha esposa Claudete, pela compreensão, apoio e principalmente paciência com todas as minhas viagens, ausências e muitas vezes, nervosismos, com as tarefas a realizar. Obrigado por todo carinho, dedicação, você foi fundamental para conclusão deste trabalho. Ao meu grande orientador, Prof. Marcelo Morandini, pela confiança, por todas as orientações, pelos ensinamentos, pela amizade, por ter me apresentado ao mundo da pesquisa científica e por todas as oportunidades. Muito Obrigado por tudo! Ao meu pai (in memoriam), minha mãe, avós e todos os familiares, por sempre me apoiarem neste trabalho e por todo esforço realizado para me ajudar a chegar até aqui. Agradeço aos meus amigos, alunos e demais professores que, de alguma forma, contribuíram para conclusão deste trabalho. 
Sabei que o Senhor é Deus: ele nos fez, e a Ele pertencemos. Somos o seu povo e as ovelhas de seu rebanho (Salmo 99:3) 


\section{Resumo}

COLETI, Thiago Adriano. Um ambiente de avaliação da usabilidade de software apoiado por técnicas de processamento de imagens e reconhecimento de fala. 2014. 155 f. Dissertação (Mestrado em Ciências) - Escola de Artes, Ciências e Humanidades, Universidade de São Paulo, São Paulo, 2013.

A filmagem e a verbalização são métodos de teste de usabilidade considerados fundamentais para apoiar a avaliação da usabilidade de software, pois permitem ao avaliador coletar dados reais da capacidade de interação de um sistema e sua influência sobre o usuário. Os testes são, geralmente, realizados com usuário reais do software para que os mesmos possam submeter a interface as mais diversas situações. Embora eficazes, a filmagem e a verbalização são pouco eficientes, pois necessitam de muito trabalho para análise dos dados coletados e identificação de problemas de usabilidade. Pesquisas já realizadas na área apontam para um tempo de análise de duas a dez vezes o tempo do teste. Este trabalho teve como objetivo desenvolver um ambiente computacional que utilizava eventos de pronuncia de palavras chave e reações faciais para apoiar o processo de coleta, análise e identificação de interfaces com possíveis problemas de usabilidade de forma rápida e segura. O ambiente foi composto por um aplicativo que monitorava (em segundo plano) a utilização de um determinado aplicativo registrando palavras chave pronunciadas pelo participante e imagens faciais em determinados intervalos de tempo. Além destes dados, imagens das telas do sistema (snapshots) também eram registrados a fim de indicar quais interfaces eram utilizadas no momento de um determinado evento. Após a coleta, estes dados eram organizados e disponibilizados para avaliador com destaques para eventos que poderiam indicar insatisfação do participante ou possíveis problemas na utilização. Foi possível concluir que os eventos relacionados à verbalização com palavras chave foram eficazes para apoiar a tarefa de análise e identificação de interfaces problemáticas, pois as palavras estavam relacionadas com classificadores que indicavam satisfação ou insatisfação por parte do usuário. A atividade de verbalização se mostrou mais eficiente quando a análise de seus dados foi aplicada em conjunto com as imagens faciais, pois permitiram uma análise mais confiável e abrangente. Nesta análise, o avaliador teve condições de identificar quais interfaces do sistema foram mal classificadas pelo usuário e qual era o foco de visão/utilização do usuário no momento do evento. Para análises efetuadas com utilização de palavras chave com/sem utilização de imagens, o tempo gasto para identificar as interfaces e possíveis problemas foi reduzido para menos de duas vezes o tempo de teste.

Palavras-chave: Avaliação da Usabilidade, Teste de Usabilidade, Processamento de Fala, Processamento de Imagens, Análise de Dados. 


\section{Abstract}

COLETI, Thiago Adriano. An enviornment to support usability evaluation using image processing and speech recognition. 2014. 155 p. Dissertation (Master of Science) - School of Arts, Sciences and Humanities, University of São Paulo, São Paulo, 2013.

Filming and verbalization are considered fundamental usability test methods to support software usability evaluation, due to the reason that allows the evaluator to collect real data about the software interaction capacity and how it influences the user. The tests are, usually, performed by real software users because they can submit the system to several situations that were not presupposed by evaluator in the labs. Although effective, the filming and the verbalization are not efficient due to the reason that require a long time to analyzing the data and identify usability problems. Researches performed in the area present that the time to data analysis is two to ten times the test time. This research aimed to develop an environment that used events as words pronounced and face reactions to support the collect, analysis and identification of interfaces with usability problems easily and safe. The environment is composed by a software to monitoring (background) of the user activities. The software collects key words pronounced by the participant and face images in specific time intervals. Besides these data, snapshots of the interfaces were registered in order to present which interfaces were in used in the event moment. After the collect stage, these data were processed and available to the evaluator with highlights to events that could indicate unsatisfactory events or potential utilization problems. In this research, was possible to conclude that the verbalization events using key words were effective to support the analysis and identification of problematic interfaces because the words were related to specific context that indicated the user opinion. The verbalization activities were more effective in the moments that the data analysis was performed using the face images to support it, allowing more reliable and comprehensive data analysis. In this analysis, the evaluator was able to identify which interfaces were classified negatively by the participant and which was the user focus of view/use in the event moment. In analysis performed using key words and/or not using the face images, the time to identifying the interfaces and potentials usability problems was reduced to less than twice the time of test.

Keywords: Usability Evaluation, Usability Test, Speech Processing, Image Processing, Data Analysis. 


\section{Lista de Figuras}

1 Modelo de qualidade em uso da ISO $25010 \ldots \ldots$. . . . . . . . 25

2 Laboratório de usabilidade . . . . . . . . . . . . . . . . . . . . . . . . . 29

3 Imagem de aplicação de filtro de suavização com base na vizinhança. Fonte: (NUNES, 2011) . . . . . . . . . . . . . . . . . . . . . . 44

4 Imagem de aplicação de filtro de realce (NUNES, 2011) . . . . . . . . . . . . 44

5 Atividades do processamento de imagens (GONZALEZ; WOODS, 2000) . . 46

6 Histograma de uma imagem em tons de cinza . . . . . . . . . . . . . . 48

$7 \quad$ Vetores de características de uma imagem . . . . . . . . . . . . . 49

8 Atividades de Processamento de Fala . . . . . . . . . . . . . . . . . . 53

9 Linhas de código para acesso a funções da ferramenta Coruja . . . . . . . . 54

10 Abordagem do sistema EvaLogger (BALAGTAS-FERNANDEZ; HUSSMANN,

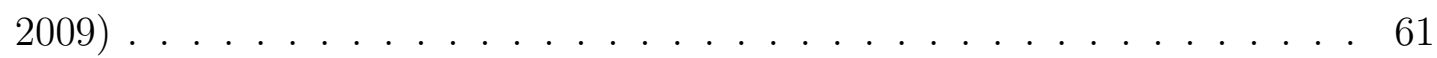

11 Abordagem de Avaliação da Usabilidade de Hasan, Morris e Probets (2013) 67

12 Modelo de Cartão de emoções de Fernández et al. (2012) . . . . . . . . . . 68

13 Resultados dos experimentos de Fernández et al. (2012) . . . . . . . . . . . 69

14 Resultados da análise de emoções de Fernández et al. (2012) . . . . . . . 70

15 Comparação dos resultados da abordagem de Fernández et al. (2012) com os Critérios Ergonômicos . . . . . . . . . . . . . . . 71

16 Configuração de testes para o aplicativo Morae . . . . . . . . . . . . . 73

17 Tela do aplicativo Morae Observer http://www.techsmith.com . . . . . . . 74

18 Abordagem do sistema ErgoMonitor (MORANDINI, 2002) . . . . . . . . 76

19 Arquivos de configuração do Coruja . . . . . . . . . . . . . . . . 81 
20 Interface do protótipo de teste da ferramenta Coruja . . . . . . . . . . . 82

21 Reconhecimento facial com OpenCV (OLIVEIRA; JAQUES, 2008) . . . . . . 85

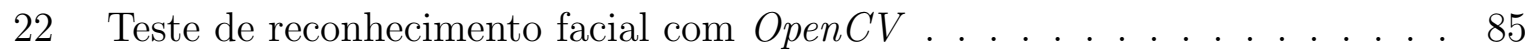

23 Diagrama de Caso de Uso do ErgoSV . . . . . . . . . . . . . . . . . 87

24 Diagrama de Caso de Uso do ErgoSV . . . . . . . . . . . . . . . . . . 88

25 Diagrama de Classe ErgoSV . . . . . . . . . . . . . . . . . . . . . . 89

26 Interface de registro de participantes do ErgoSV . . . . . . . . . . . . 91

27 Tela inicial do sistema $\operatorname{ErgoSV} \ldots \ldots$. . . . . . . . . . . . . . 92

28 Fluxograma de inicialização de testes com o ErgoSV . . . . . . . . . . . . . 93

29 Fluxograma de reconhecimento de fala . . . . . . . . . . . . . . . . 94

30 Fluxograma de reconhecimento de face . . . . . . . . . . . . . . 95

31 Tela inicial do sistema ErgoSV Analyzer . . . . . . . . . . . . . . . 96

32 Tela para funcionalidade de processamento de imagens faciais . . . . . . 97

33 Tela para análise de dados de fala - módulo Complete Informations . . . . 100

34 Tela para funcionalidade de processamento de imagens faciais . . . . . . . 102

35 Imagens da tela de apresentação de gráficos . . . . . . . . . . . . . . 103

36 Tela com a relação de imagens descartadas . . . . . . . . . . . . . . . . 104

37 Interface de seleção de intervalos de tempo . . . . . . . . . . . . . 105

38 Interface de visualização de imagens de interface . . . . . . . . . . . 106

39 Interface de visualização de imagens faciais . . . . . . . . . . . . . . . 107

40 Gráficos de valores das características . . . . . . . . . . . . . . . 108

41 Imagem padrão X Não padrão . . . . . . . . . . . . . . . . . . . . 115

42 Variação dos valores das características . . . . . . . . . . . . . . . . 122

43 Imagem padrão X Imagem candidata e suas respectivas características . . . 122

44 Estrutura de análise dos dados . . . . . . . . . . . . . . . . . . . 124

45 Gráficos de palavras pronunciadas para análise . . . . . . . . . . . . 125 
46 Seleção de palavra e intervalo . . . . . . . . . . . . . . . 126

47 Estrutura de seleção de imagens de tela por palavra . . . . . . . . . . . . . 127

48 Interface reprovada por diversos participantes . . . . . . . . . . . . 127

49 Tela do PEM com muitos recursos . . . . . . . . . . . . . . . . . . . . 129

50 Tela do PEM classificada como Bom . . . . . . . . . . . . . . . . . . . 129

51 Lista de registro de imagens com valores de similaridade . . . . . . . . . . 132

52 Imagens com expressões faciais relevantes X Não identificáveis . . . . . . . 133

53 Tela do ErgoSV com dados de similaridade . . . . . . . . . . . . . 136

54 Árvore do ambiente do teste no momento de uma reação . . . . . . . . . 137

55 Imagem facial e imagem de tela com possível local de insatisfação . . . . . 139

56 Imagem facial e imagem de tela com possível local de insatisfação . . . . . 139

57 Comparativo de tempo de análise com dados de fala . . . . . . . . . . 141

58 Comparativo de tempo de análise com dados de fala e dados de imagem . . 144 


\section{Lista de Tabelas}

1 Contagem geral de artigos da Revisão Bibliográfica Específica . . . . . . . 56

2 Contagem dos artigos incluídos na Revisão Bibliográfica Específica . . . . . 57

3 Relação de artigos analisados . . . . . . . . . . . . . . . . . . . . . 59

4 Relação de artigos incluídos manualmente . . . . . . . . . . . . . . . . 60

$5 \quad$ Problemas identificados pela abordagem de Fernández et al. (2012) . . . 71

6 Resultados dos testes da ferramenta Coruja . . . . . . . . . . . . . . . 83

$7 \quad$ Características das imagens extraídas pelo $\operatorname{ErgoSV}$ Analyzer . . . . . . . . 98

8 Características dos participantes dos experimentos . . . . . . . . . . . 113

9 Quantidade de testes por aplicativo . . . . . . . . . . . . . 116

10 Lista de experimentos da abordagem . . . . . . . . . . . . . 117

11 Estatísticas dos teste . . . . . . . . . . . . . . . 117

12 Quantidade de dados registrados . . . . . . . . . . . . . . 118

13 Quantidade de palavras registradas . . . . . . . . . . . . . 119

14 Quantidade de imagens registradas versus imagens descartadas . . . . . . . 119

15 Tempos utilizados para parâmetros para análise . . . . . . . . . . . 123

16 Valores de similaridade por expressão facial . . . . . . . . . . . . . . . 133

17 Classificação de valores de similaridade por teste . . . . . . . . . . . . . . 134

18 Tempos utilizados para parâmetros para análise . . . . . . . . . . . . 145 


\section{Sumário}

1 Introdução 16

1.1 Considerações Iniciais . . . . . . . . . . . . . . . . . . 16

1.2 Objetivos . . . . . . . . . . . . . . . . . . . . 18

1.3 Justificativa . . . . . . . . . . . . . . . . . . . . . . . 19

1.4 Organização do Trabalho . . . . . . . . . . . . . . . . . . . 20

2 Conceitos Fundamentais 21

2.1 Considerações Iniciais . . . . . . . . . . . . . . . . . . . . . . 21

2.2 Interação Humano Computador . . . . . . . . . . . . . . . . 21

2.3 Usabilidade . . . . . . . . . . . . . . . . . . . . . 23

2.4 Avaliação da Usabilidade . . . . . . . . . . . . . . . . . . . . 26

2.4.1 Avaliação em Laboratório . . . . . . . . . . . . . . . . . . . 29

2.4.2 Avaliação em Ambiente Real . . . . . . . . . . . . . . . . . . . . . . 30

2.4 .3 Técnicas de Observação do Usuário . . . . . . . . . . . . . . . . . . . 31

2.4.3.1 Verbalização $($ Think aloud $)$. . . . . . . . . . . 32

2.4.3.2 Registros de Imagens . . . . . . . . . . . . . . . . . . 37

2.4.3.3 Monitoramento por Arquivos de Logs . . . . . . . . . . . . 38

2.5 Processamento de Imagens . . . . . . . . . . . . . . . . . . . . . . . 41

2.5.1 Conceitos Fundamentais . . . . . . . . . . . . . . . . 41

2.5.2 Ferramentas de Apoio ao Processamento de Imagens . . . . . . . . 46

2.5.3 Recuperação de Imagens Baseada em Conteúdo . . . . . . . . . . . 47

2.5.3.1 Extratores..................... 48 
2.5.3.2 Funções de Similaridade . . . . . . . . . . . . . . . . . . . 50

2.5.4 Considerações Finais sobre Processamento de Imagens ..... . 50

2.6 Processamento de Fala . . . . . . . . . . . . . . . . . . . . . . . . . 51

2.6.1 Aplicativos de Processamento de Fala . . . . . . . . . . . . . . . 53

2.6.2 Considerações Finais sobre Processamento de Fala . . . . . . . . . . 55

2.7 Frameworks para Avaliação da Usabilidade . . . . . . . . . . . . . . . . . 55

2.7.1 Revisão Bibliográfica Específica . . . . . . . . . . . . . 56

2.7.2 Ambientes de teste de usabilidade . . . . . . . . . . . . . . . 60

2.7.2.1 EvaLogger . . . . . . . . . . . . . . . . . 61

2.7.2.2 Monitoramento por Arquivos de Logs - ErgoMonitor . . . 63

2.7.2.3 Eye Tracking. . . . . . . . . . . . . . . . 64

2.7.2.4 Avaliação para E-Commerce . . . . . . . . . . . 66

2.7.2.5 Modelo de Avaliação da Usabilidade para Model Driver Development . . . . . . . . . . . . . . . 67

2.7.2.6 Considerações Finais sobre Ambientes de Avaliação .. . 71

2.8 Ferramentas de Avaliação da Usabilidade . . . . . . . . . . . . . . . . . . . 72

2.8 .1 Morae .............................. 72

2.8.2 ErgoMonitor . . . . . . . . . . . . . . . . . 75

2.8 .3 ErgoCoin . . . . . . . . . . . . . . . . 76

$\begin{array}{lll}3 & \text { Metodologia de Pesquisa } & 78\end{array}$

3.1 Definição da Estrutura do Sistema . . . . . . . . . . . . . . . . 78

3.1.1 Componentes para o desenvolvimento da aplicação . . . . . . . . 79

3.1.1.1 Ambiente de Desenvolvimento e Linguagem de Programação 79

3.1.1.2 Projeto Coruja - Projeto Fala Brasil . . . . . . . . . . . 79

3.1.2 Testes com a ferramenta Coruja . . . . . . . . . . . . . . 81

3.1.2.1 Biblioteca OpenCV . . . . . . . . . . . . . . 83 
3.1.2.2 Considerações Finais sobre a Seleção de Recursos Computacionais . . . . . . . . . . . . . 85

3.1.3 Definição e Modelagem das Funcionalidades . . . . . . . . . . . . 86

3.1.4 Considerações finais sobre a Estrutura do Sistema . . . . . . . . . . 90

3.2 Estratégias de Uso da Abordagem e da Aplicação . . . . . . . . . . . . . . 90

3.2 .1 Coleta de Dados . . . . . . . . . . . . . . . . . . . 90

3.2 .2 Análise de Dados e Geração de Informações . . . . . . . . . . . . . 95

3.2.2.1 Processamento/Comparação Facial . . . . . . . . . . . . . 97

3.2.2.2 Vizualização de Dados e Informações . . . . . . . . . . . . 99

3.2.2.3 Aba Words ..................... . . 99

3.2.2.4 Aba Face Images . . . . . . . . . . . . . . . . . . . . . . . 101

3.2 .2 .5 Aba Charts ...................... . . 102

3.2.2.6 Aba Discarted Images . . . . . . . . . . . . . . . . . . . 103

3.2.2.7 Visualização de Imagens das Telas/Face . . . . . . . . . . 104

3.2.2.8 Função Features Charts . . . . . . . . . . . . . . . . . 107

3.2.3 Considerações Finais sobre a Estratégia de Uso da Aplicação . . . . 108

3.3 Validação da Abordagem . . . . . . . . . . . . . . . . . . . . . . 109

3.3.1 Aplicativos Selecionados . . . . . . . . . . . . . . 109

3.3.1.1 Experimentos no WEC . . . . . . . . . . . . 109

3.3.1.2 Experimentos no WPG . . . . . . . . . . . 110

3.3.1.3 Experimentos no PEM . . . . . . . . . . . . . . 111

3.3.1.4 Considerações finais sobre a escolha dos aplicativos . . . 112

3.3.2 Seleção de Participantes . . . . . . . . . . . . . . . . . . . . 112

3.3.3 Estratégias de Validação da Abordagem . . . . . . . . . . . . . 113

3.3.4 Experimentos . . . . . . . . . . . . . . 116

3.3.4.1 Coleta de Dados . . . . . . . . . . . . . 116 
3.3.5 Pré Processamento dos Dados . . . . . . . . . . . . . . . . . 119

3.3 .6 Análise dos Dados . . . . . . . . . . . . . . . . . . 123

3.3.6.1 Análise Somente com Dados de Voz . . . . . . . . . . . . . 124

3.3.6.2 Análise Somente com Dados de Imagens . . . . . . . . . . 130

3.3.6.3 Análise com Dados de Voz e Imagens . . . . . . . . . . . . 136

3.4 Resultados da Validação . . . . . . . . . . . . . . . . . . . . . . . . 140

3.4.1 Análise dos dados de voz . . . . . . . . . . . . . . . . . . . . 140

3.4 .2 Análise com dados de imagem . . . . . . . . . . . . . . . . . . 142

3.4.3 Considerações Finais dos Resultados . . . . . . . . . . . . . . . . 143

4 Conclusão $\quad 147$

4.1 Contribuições . . . . . . . . . . . . . . . . . . . . 147

4.2 Limitações . . . . . . . . . . . . . . . . . . . . . . . . . . . . . . . . . . . . 148

4.3 Trabalhos Futuros . . . . . . . . . . . . . . . . . . . . . 148

4.4 Publicações . . . . . . . . . . . . . . . . . . . . . . . . . . . . . . 149

Referências $\quad 151$ 


\section{Capítulo 1}

\section{Introdução}

\subsection{Considerações Iniciais}

O desenvolvimento de interfaces gráficas para sistemas computacionais se tornou uma das principais atividades do processo de desenvolvimento de software e vem recebendo atenção especial de empresas e instituições de ensino que atuam na área de Interação Humano Computador (IHC). Interfaces são recursos computacionais que permitem a interação do usuário com o sistema, ou seja, permitem sua utilização em tarefas diversas. A importância dispensada nas atividades de design de interfaces levou ao aumento de investimentos na área e o surgimento/crescimento de empresas, laboratórios de pesquisa, cursos, métodos e técnicas com objetivo de desenvolver sistemas com usabilidade (CYBIS; BETION; FAUST, 2010).

O termo usabilidade refere-se ao principal objetivo daqueles que atuam na tarefa da concepção da IHC de um produto. A usabilidade é definida como a capacidade que um sistema interativo oferece a seu usuário dentro de um determinado contexto de realizar suas tarefas com eficácia (completitude), eficiência (melhores recursos) e satisfação (bem estar do usuário) (ISO9241, 2002). Por se tratar de um conceito que remete, de forma geral, a qualidade de interação de um sistema e a capacidade que o mesmo oferece a seu usuário de realizar suas tarefas, a usabilidade se tornou fator crítico de sucesso e aceitação do produto por seus usuários (CYBIS; BETION; FAUST, 2010; PREECE; BORGES; SHARP, 2005; ROCHA; BARANAUSKAS, 2003).

O processo realizado por equipes de designers para alcançar altos níveis de usabilidade compreende atividades como: identificação do contexto e da necessidade do usuário, produção de protótipos para elucidar requisitos, desenvolvimento do produto final e avaliação da usabilidade. Todas as atividades citadas são de suma importância no processo de design e nenhuma delas deve ser ignorada. Entretanto, a atividade de avaliação da usabilidade deve ser considerada por desenvolvedores como uma das mais importantes neste processo devido à capacidade de gerar informações sobre a usabilidade do sistema 
por ser realizada em todos os estágios do desenvolvimento da interface. Esta característica pode evitar que sistemas venham a ser entregues com problemas de interação que comprometam a capacidade de utilização e levem a rejeição por parte de seus usuários (CYBIS; BETION; FAUST, 2010; NIELSEN, 1993; PREECE; BORGES; SHARP, 2005).

A avaliação da usabilidade pode ser realizada de duas formas: inspeção de usabilidade e teste de usabilidade. A primeira refere-se a atividades que visam verificar se uma interface está de acordo com um determinado padrão de qualidade como os Critérios Ergonômicos de Dominique Scapin e Christian Batien (SCAPIN; BASTIEN, 1997) ou as Heurísticas de Jakob Nielsen (NIELSEN, 1993); a segunda refere-se a atividades sistemáticas com objetivo de verificar como uma pessoa ou um grupo de pessoas interagem com a aplicação e como a mesma interfere positiva ou negativamente em suas atividades, ou seja, tem como principal intenção verificar a capacidade de interação oferecida pela interface ao seu usuário. (CYBIS; BETION; FAUST, 2010; NIELSEN, 1993; PREECE; BORGES; SHARP, 2005).

Os testes de usabilidade permitem ao avaliador identificar problemas de interação do sistema com o usuário e devido a isso é realizado, na maioria dos casos, com a participação de pessoas diretamente envolvidas com a utilização final do software, citados neste trabalho como "usuários tradicionais" ou "participantes". Observar o usuário durante a utilização da aplicação compreende um método amplamente utilizado por avaliadores e pode ser apoiado por técnicas como a filmagem e a verbalização, esta última também conhecida por Think Aloud. Enquanto a primeira técnica consiste na utilização de uma ou várias câmeras de vídeo posicionadas estrategicamente para coletar imagens do participante realizando suas tarefas, a verbalização consiste em solicitar ao participante que verbalize (fale) sua opinião a respeito do sistema, e assim, expresse seus pensamentos pela voz, para registro em gravadores de áudio ou papel e consequentemente possam ser utilizados para gerar informações sobre a usabilidade do aplicativo testado (CYBIS; BETION; FAUST, 2010; NIELSEN, 1993). Ambas as técnicas são consideradas eficazes, porém demoradas e de alto custo (pouco eficiente). Estes pontos negativos ocorrem devido ao fato do avaliador precisar revisar todos os registros de vídeo e/ou de fala mais de uma vez para encontrar possíveis indicadores de problemas de usabilidade e de acordo Nielsen (1993) esta atividade pode levar, no mínimo, de duas a dez vezes o tempo da avaliação. Portanto, um teste que demorou quinze minutos para ser realizado pelo usuário comum, um avaliador pode levar, no mínimo, 30 minutos para identificar questões de usabilidade.

Esta pesquisa foi desenvolvida com objetivo de implementar uma melhoria na abor- 
dagem de observação apoiada por técnicas de filmagem e verbalização. As modificações focam-se na coleta e processamento automatizado dados. Os dados referem-se a eventos proporcionados pelos participantes tais como pronuncia de palavras chave e reações faciais. Estes dados foram utilizados na geração de informações de qual(is) momento(s)do teste o usuário pode ter demonstrado insatisfação ou não com o produto e assim, permitir que o avaliador visualize de forma rápida e prática qual(is) interface(s) estavam em uso no momento de determinado evento reduzindo o tempo para análise e identificação de possíveis problemas de usabilidade.

\subsection{Objetivos}

Esta pesquisa teve como objetivo desenvolver uma abordagem para apoiar testes da usabilidade utilizando eventos de verbalização e reações faciais para geração de dados e recursos de processamento de imagens, reconhecimento facial e reconhecimento de fala para processamento dos dados e geração de informações. As informações tiveram como foco a criação de insumos de forma automatizada que auxiliassem um avaliador na análise, identificação de interfaces e tomada de decisão de forma rápida, prática e segura. Dentre essas informações se destacam a indicação de momentos no qual o participante proporcionou eventos como reações adversas, que poderiam indicar problemas na interface, ou reações de satisfação, que indicassem estruturas que deveriam ser mantidas e/ou replicadas no software. Com o indicativo desses momentos a abordagem disponibilizou acesso a imagens das interfaces utilizadas no momento do evento específica, momentos antes e momentos após tal evento a fim de permitir uma análise de toda situação relacionada à tal reação.

A redução do tempo na identificação dos eventos negativos, na análise das interfaces utilizadas e na geração de informações básicas era o principal objetivos desta pesquisa.

Para atingir este objetivo geral os seguintes objetivos específicos necessitaram ser alcançados:

- levantamento das principais vantagens e desvantagens da metodologia de observação do usuário utilizando filmagem e verbalização;

- levantamento de pesquisas realizadas a fim de identificar soluções para melhorar a capacidade e agilidade do processamento e geração de informações em testes feitos com filmagem e verbalização; 
- seleção os recursos de software adequados para aplicar na pesquisa a fim de melhor o processamento e a geração de informações em testes de usabilidade;

- identificação, teste e seleção de recursos tecnológicos para apoiar a pesquisa;

- desenvolvimento de um aplicativo dividido em dois módulos que recebeu o nome de ErgoSV e foi utilizado para coleta, processamento e geração de informações sobre os testes;

- realização de testes em aplicativos utilizando usuários tradicionais;

- analise do comportamento da abordagem de teste durante os experimentos a fim de verificar a eficácia e eficiência do mesmo para a atividade fim;

- considerando os resultados dos testes, efetuar a classificação da abordagem proposta como adequada ou inadequada para apoiar testes de usabilidade utilizando filmagem e verbalização.

Na próxima seção será apresentada a justificativa para a realização desta pesquisa.

\subsection{Justificativa}

A necessidade de utilização de software por usuários com as mais diversas características somadas a grande quantidade de atividades que podem ser executadas e a importância que estas tem para o dia a dia das pessoas fez com que a experiência do usuário se tornasse uma preocupação constante para desenvolvedores de IHC.

Considerar a opinião do usuário final em relação à qualidade da interface é fundamental para determinar o fator de sucesso para o sistema e para isso a realização de testes de usabilidade se faz necessária para identificar, qualificar e/ou quantificar a qualidade da interação entre usuário e sistema.

Enquanto a inspeção de usabilidade permite identificar se a interface está de acordo com algum padrão de qualidade e normalmente é realizada por especialistas da área, o teste de usabilidade permite ao avaliador analisar a capacidade de interação do sistema com o usuário provendo dados para a elaboração de um parecer de como o aplicativo se comporta perante todas as situações nas quais é submetido, como os diversos usuários se comportam frente ao sistema e como fatores externos influenciam na interação. 
A dificuldade na realização do teste de usabilidade principalmente no que diz respeito à análise e geração de informações pode levar designers e avaliadores a optarem pela não realização do procedimento deixando de identificar possíveis erros na aplicação e consequentemente entregar sistemas com péssima qualidade de IHC dificultando a utilização final.

A presente pesquisa se justifica pelo fato de desenvolver uma abordagem que facilite a execução de testes de usabilidade, principalmente na fase de análise e identificação de problemas. A abordagem foi apoiada por um sistema utilizado para coletar, processar e gerar informações. Estes recursos podem servir de incentivo para equipes de desenvolvimento de IHC (em centros de pesquisas e fábricas de software) realizarem testes em aplicativos em fase de desenvolvimento e/ou já finalizados (produto final) com usuários tradicionais devido, principalmente, a redução de tempo e a facilidade para identificação de dados que indiquem insatisfação do participante.

Na próxima seção é apresentação a organização desta dissertação.

\subsection{Organização do Trabalho}

Estas atividades estão organizadas de forma a apresentar a pesquisa realizada para que os objetivos apresentados fossem atingidos e contempla os tópicos: Introdução, Fundamentação Teórica, Metodologia, Resultados e Discussão e Considerações Finais.

Neste primeiro capítulo são apresentadas a contextualização, objetivos gerais e específicos, justificativa e esta organização do trabalho.

No segundo capítulo será apresentada a Fundamentação Teórica na qual se descreve os conceitos fundamentais dos assuntos que norteiam este trabalho tais como Interação Humano Computador, Usabilidade, Avaliação da Usabilidade, Processamento de Imagens, Reconhecimento Facial e Reconhecimento de Fala, assim como uma pesquisa bibliográfica específica sobre a utilização de processamento de imagens e reconhecimento de fala para apoiar a avaliação da usabilidade.

No terceiro capítulo será explicado o processo de desenvolvimento do ambiente de avaliação (ErgoSV), sua estrutura e seus diagramas UML (GUEDES, 2009), estratégias de teste, hóteses e resultados obtidos.

No último capítulo serão apresentadas as conclusões, contribuições, limitações e trabalhos futuros para esta pesquisa. 


\section{Capítulo 2}

\section{Conceitos Fundamentais}

\subsection{Considerações Iniciais}

Neste capítulo serão apresentados os conceitos sobre IHC, Usabilidade e Avaliação da Usabilidade relacionados à área principal desta pesquisa. Serão apresentados também conceitos sobre processamento de imagens, reconhecimento facial e reconhecimento de fala, temas abordados como apoio aos processos de avaliação da usabilidade.

Uma pesquisa bibliográfica específica contendo abordagens de teste de usabilidade já existentes e aplicados também é apresentada e discutida neste capítulo.

\subsection{Interação Humano Computador}

O termo Interação Humano-Computador (IHC) surgiu no início dos anos 80 e inicialmente estava relacionado ao software e hardware, ou seja, com os recursos que o usuário utilizava para interagir com o computador. Atividades relacionadas à pesquisas e desenvolvimento de recursos destinados e interação entre usuário e software evoluíram para uma nível no qual a preocupação com o usuário, principalmente no aspecto físico, cognitivo e emocional, é uma constante. Os aplicativos passaram a ser criados visando reduzir a carga de trabalho física e mental do usuário e como resultado proporcionarem maior satisfação, permitindo ao mesmo tempo a realização de tarefas com completitude e qualidade (CYBIS; BETION; FAUST, 2010; ROCHA; BARANAUSKAS, 2003).

Embora tratada em muitos casos de forma errônea, simplesmente como o ato de posicionar componentes nas interfaces dos sistemas, suas atividades vão muito além, pois tratam de questões como entendimento dos requisitos do usuário, análise, prototipagem, desenvolvimento e testes de recursos de interação dos sistemas. Na realização destas tarefas, questões relacionadas à saúde, bem estar, limitações e experiências do usuário final devem ser consideradas prioridades por parte dos designers (ROCHA; BARANAUSKAS, 2003). 
O processo de desenvolvimento de sistemas interativos sempre foi um desafio para o profissional de computação e esse desafio vem aumentando a cada ano devido aos diversos recursos que surgem, resultados de extensas e complexas pesquisas e atividades de desenvolvimento. Além da vasta quantidade de recursos, a diversidade de usuários incrementa as dificuldades a estes desafios (CYBIS; BETION; FAUST, 2010; NIELSEN, 1993; PREECE; BORGES; SHARP, 2005) .

No final da década de setenta e início da década de 80 os usuários de computadores estavam restritos a profissionais da área, bem preparados e que desenvolviam recursos para sua própria utilização e sempre observando seus próprios limites. Com o passar dos anos, mais exatamente após a década de noventa e após o surgimento de recursos como a Internet, computadores mais baratos e aplicativos dotados de recursos diversos, fez com que o número de usuários de computadores aumentasse significativamente. Os recursos computacionais passaram a ser utilizados por todos os tipos de pessoas e com as mais diversas habilidades. Atualmente, há casos em que o desenvolvedor cria uma aplicação sem saber o perfil exato de seus usuários finais, sabendo somente que podem variar muito. Por exemplo, um sistema de caixa eletrônico pode ser acessado por pessoas com vasto conhecimento em informática e também por pessoas que não tem nenhuma instrução específica na área e esse nível de conhecimento pode estar distribuído em jovens, adultos, idosos e cada um com suas possíveis limitações tais como visão, movimentos ou leitura (CYBIS; BETION; FAUST, 2010; PRESSMAN, 2011).

A grande variedade de usuários se tornou uma preocupação constante de desenvolvedores de IHC devido ao fato que designers precisam criar recursos completos (que contemplem todas as atividades) e que possam ser utilizados pelo seu público. Características como cor, tamanho de fonte, formato da interface, quantidade de informações exibidas em tela devem ser consideradas por um desenvolvedor de IHC. A reutilização de interfaces para fins diferentes deve ser analisada de forma cuidadosa pelo desenvolvedor porque uma interface pode ser adequada para uma classe de usuário e não ser boa para outra classe. Características das regras de negócios também devem ser tratadas com extrema atenção, por exemplo, em um sistema de controle contábil o objetivo final do seu usuário pode ser a execução das tarefas de forma rápida e por completo, entretanto em um sistema de trafego aéreo a execução de forma rápida pode não ser prioridade, mas sim a execução de forma segura. Já em um sistema de caixa eletrônico a execução da tarefa deve ser simples e prática permitindo que qualquer pessoa possa utilizá-lo (CYBIS; BETION; FAUST, 2010; NIELSEN, 1993; PREECE; BORGES; SHARP, 2005). 
O principal objetivo da área de IHC é entregar produtos com capacidade de interação otimizada e que permitam que seus participantes realizem suas tarefas com eficácias, eficiência e consequentemente tenham satisfação. Este conceito remete a definição de usabilidade, que será explicado na próxima seção.

\subsection{Usabilidade}

Segundo Nielsen (1993) a usabilidade é um requisito de qualidade de software necessário e exigido para atingir a qualidade de um sistema computacional permitindo que o mesmo seja utilizável e fácil de aprender. Um sistema que tenha boas taxas de usabilidade permite que seus usuários o utilizem de forma satisfatória, agradável e produtiva e assim, atinja seu objetivo. A definição de usabilidade é apresentada pela ISO 9241, como a capacidade que um sistema interativo oferece a seu usuário de realizar suas tarefas com eficácia, eficiência e satisfação. Ainda segundo a norma, os três parâmetros que sustentam a usabilidade são definidos como:

- Eficácia: relacionada à completitude e precisão na qual uma tarefa é executada;

- Eficiência: refere-se a quantidade e a forma de utilização de recursos disponíveis para atingir determinada meta;

- Satisfação: relacionada ao bem-estar do usuário, ou seja, o quanto o mesmo esta satisfeito com o resultado do sistema.

Um aplicativo com boa usabilidade evita que seu usuário tenha que aprender procedimentos complexos, ajuda na memorização das atividades no sistema, orienta na exploração de seu conteúdo, protege contra erros e facilita procedimentos e reduz a carga física e mental da pessoa, além da diminuir o tempo gasto para realizar uma tarefa (CYBIS; BETION; FAUST, 2010).

É importante destacar que a usabilidade não é uma característica intrínseca da interface, mas um conjunto de atributos que, atuando de forma coerente, levam uma aplicação a ter altos níveis de usabilidade e estes fatores podem variar de acordo com o usuário e o contexto de aplicação. Por exemplo, em um sistema de Home Banking a gestão de erros é uma característica de suma importância, pois visa evitar os erros do usuário e o possível comprometimento da integridade financeira, porém somente essa característica não seria o suficiente para uma boa utilização, recursos tais como boa visibilidade das informações, 
design adequado para todas as idades, termos e palavras de fácil entendimento agregam qualidade a interface do sistema e conquentemente aumentam o nível de usabilidade da aplicação (CYBIS; BETION; FAUST, 2010; NIELSEN, 1993; PREECE; BORGES; SHARP, 2005).

Da mesma forma que um aplicativo com bons níveis de usabilidade facilita a vida de seus usuários, a falta desse requisito pode levar a sérios problemas que vão desde a dificuldade de encontrar um componente na tela ou de memorizar determinada tarefa até sérios problemas de saúde tais como fortes cargas de stress e palpitações. Fatores psicológicos podem ser afetados e provocar situações como falta de motivação, medo ou sensação de inferioridade. Questões técnicas, físicas ou psicológicas podem ser fortemente influenciadas pelo nível de usabilidade, tanto para mais quanto para menos, mas é fato que afetam diretamente a qualidade de vida dos usuários de sistema (CYBIS; BETION; FAUST, 2010).

A verificação da usabilidade de um software pode ser realizada por meio da avaliação da usabilidade que se trata de um conjunto de métodos e técnicas sistemáticas que apóiam o avaliador na coleta e geração de informações sobre a usabilidade (CYBIS; BETION; FAUST, 2010; NIELSEN, 1993; PREECE; BORGES; SHARP, 2005). Porém, é comum surgir a pergunta: Quais os atributos devem existir em um sistema para que o mesmo possa ter usabilidade? A norma ISO 9241 apresenta uma lista com quatro atributos que caracterizam um sistema com usabilidade e Cerrato (2012) apresenta também uma pergunta para cada atributo, que visa direcionar o leitor a uma reflexão sobre a usabilidade de uma aplicação. Os quatro atributos e suas respectivas perguntas são:

- Facilidade de uso: É fácil para os usuários aprenderem como usar seu sistema?

- Eficiente para usar: Os usuários conseguem encontrar e obter informação rapidamente e efetivamente em seu produto?

- Memorizável: Um usuário que retorne ao seu aplicativo conseguiu reter alguma experiência de aprendizado por ter visitado anteriormente?

- Erros dos usuários: É uma falha do programador ou projetista do software quando o usuário experimenta um erro?

Recentemente o termo usabilidade recebeu uma atualização em sua definição com a norma ISO 25010 publicada em 2012 e que segundo Cerrato (2012) substituiu a norma ISO 9126. 
A norma ISO 25010 apresenta um modelo de qualidade de software que divide os critérios de aplicação em dois: atributos internos de qualidade e atributos externos de qualidade (ISO 25010).

Os atributos internos referem-se a fatores internos e estáticos do sistema que normalmente não são influenciados por fatores como usuários ou contexto de operação tais como arquitetura do software, estruturas de dados e componentes utilizados no sistema. A validação e verificação desses atributos podem ser feitos por meio de testes nos algoritmos e nas estruturas de dados internas do sistema.

Já os atributos externos estão relacionados à características do sistema que influenciam seu comportamento e consequentemente o comportamento de seu usuário durante a tentativa de atingir determinados objetivos. Sua validação pode ser feita por meio de testes que simulem a utilização do aplicativo em ambiente real.

Dentro da ISO 25010 a usabilidade passou a ser definida como a medida que um sistema pela qual um produto pode ser usado por usuário específicos para atingir metas específicas com eficácia em uso, eficiência em uso e satisfação no uso em um contexto específico de operação.

A norma ISO 25010 também acrescenta a característica de usabilidade que descende da qualidade em uso mais duas características relacionadas à Flexibilidade e Segurança. A característica de Flexibilidade se refere a capacidade do sistema de adequar a diversas formas de uso dentro de determinado contexto e a Segurança arremete a capacidade do sistema em evitar erros que possam comprometer quaisquer atributos relacionados ao sistema tais como saúde do usuário, integridade dos dados e ambiente de uso. A Figura 1 apresenta o diagrama da característica de qualidade em uso.

Usabilidade em uso: Eficácia, eficiência e satisfação em uso.

Flexibilidade em uso: Contexto de conformidade, extensibilidade e acessibilidade em uso, observância da flexibilidade em uso

Segurança: saúde e segurança dos usuários, danos ambientais e comerciais em uso

Figura 1 - Modelo de qualidade em uso da ISO 25010 
Por fim, a usabilidade é uma característica (atributo) de uma aplicação que expressa a qualidade da IHC que permite que o software seja um produto utilizável dentro de determinado contexto facilitando as atividade de aprendizado, memorização e utilização de forma geral reduzindo carga mental e física do operador, proporcionando também eficácia e eficiência na realização das atividades e satisfação de seus usuários.

O processo de desenvolvimento de software com altos níveis de usabilidade é um processo complexo e requer atividades de verificação e validação constante. Esta validação pode ser realizada por meio da avaliação da usabilidade utilizando técnicas como os testes de usabilidade. Na próxima seção serão apresentados conceitos, métodos e técnicas sobre avaliação e teste de usabilidade.

\subsection{Avaliação da Usabilidade}

Desde a década de 80, quando surgiram os primeiros sistemas interativos e época na qual ocorreu uma expansão da utilização de software, existe a preocupação em avaliar a usabilidade de uma aplicação (HOLLINGSED; NOVICK, 2007). O surgimento e a popularização da Internet no início da década de 90 ajudou a expandir a ideia da avaliação da usabilidade, pois marca um período no qual o desenvolvimento de software passa de uma fase focada em especialistas da área de computação para um fase na qual muitos usuários, com diversos níveis de conhecimento, passaram a utilizar sistemas computacionais (PREECE; BORGES; SHARP, 2005).

Avaliar a usabilidade se tornou uma atividade fundamental no processo de design devendo ser realizada no início, durante e no final do processo de desenvolvimento, antes da entrega para a seu usuário final (NIELSEN, 1993; ROCHA; BARANAUSKAS, 2003)

A avaliação da usabilidade é um conjunto de métodos e técnicas que devem ser aplicadas a fim de inspecionar a qualidade do design de uma interface. Dentre questões analisadas pelos avaliadores estão: (1) a adequação da interface a determinados padrões de qualidade de interface tais como Critérios Ergonômicos, Avaliação Heurística e Regras de Ouro; (2) a capacidade de interação proporcionada pela interface a seu usuário, ou seja, o quanto esta interface permite o seu utilizador realizar suas tarefas e "conversar" com a aplicação; (3) adequação do design as tarefas do usuário; (4) capacidade de adaptação aos mais variados tipos de usuário, principalmente quando contempla em seus usuários candidatos pessoas com restrições físicas. Pontos negativos da interação são identificados para posterior correção e pontos positivos são replicados para demais pontos da aplicação 
visando melhorar o máximo possível a qualidade da interface do sistema (CYBIS; BETION; FAUST, 2010; NIELSEN, 1993; PREECE; BORGES; SHARP, 2005; ROCHA; BARANAUSKAS, 2003) .

Em resumo, efetuar a avaliação da usabilidade do software apóia na identificação de problemas no projeto de interação e apresenta ao projetista pontos que necessitam de correções ou que são consideradas bons e que possam ser replicadas a outros locais da aplicação.

Embora considerado um processo de teste e verificação, a avaliação da usabilidade não deve ser efetuada somente na fase final de desenvolvimento, mas sim durante todo o ciclo de criação do projeto. Para cada estágio de desenvolvimento há técnicas específicas de avaliação e que apresentam melhores resultados para análise. Por exemplo, na fase inicial pode-se avaliar a usabilidade de aplicativos semelhantes com objetivo de obter um repositório de práticas utilizadas com sucesso para replicação dentro do projeto. Em uma fase mais avançada do desenvolvimento podem ser efetuadas avaliações em laboratório com usuário e/ou especialistas a fim de identificar problemas nos requisitos de interface, problemas com padrões de qualidade e, se necessário, dar novo rumo ao projeto. Na fase final uma avaliação com o usuário final no ambiente real de utilização pode ajudar a identificar problemas de interação que afetam a utilização, além de interferências externas não identificadas na fase de projeto. Na fase inicial do desenvolvimento na qual há poucos insumos sobre o sistema, testes mais informais podem ser realizados com a finalidade de ajustar questões da qualidade da interação, porém, durante a fase final, avaliações formais e mais rigorosas são requeridas, principalmente com a participação dos usuários (CYBIS; BETION; FAUST, 2010; NIELSEN, 1993; ROCHA; BARANAUSKAS, 2003).

A avaliação é considerada por algumas organizações um custo adicional ao projeto e até mesmo um motivo de atraso nas entregas, porém, a não realização desta atividade pode levar a rejeição do software por parte do usuário final e um consequente insucesso do projeto (ROCHA; BARANAUSKAS, 2003).

O processo de avaliação da usabilidade pode variar de acordo com o contexto do software. Em uma aplicação que será utilizada em um caixa de supermercado para emissão de cupom fiscal, uma bateria de testes de alguns dias e talvez meses seria suficiente para checar e corrigir problemas de interação. Entretanto, em uma aplicação que tem por objetivo controlar o tráfego aéreo, uma avaliação da usabilidade pode demorar anos para ser realizada. Para cada contexto de teste existem técnicas que melhor se adaptam a eles, por exemplo, para o sistema de mercado a avaliação heurística pode ser suficiente, mas 
para o sistema de tráfego aéreo técnicas de testes de usabilidade utilizando observação do usuário podem ser utilizadas para agregar dados. Em certos casos pode haver a necessidade de unir ou mesmo adaptar duas ou mais técnicas de forma que atendam melhor a necessidade da avaliação (ROCHA; BARANAUSKAS, 2003).

A avaliação pode ser efetuada utilizando dois métodos: inspeção de usabilidade ou teste de usabilidade.

Nas inspeções a interface da aplicação é comparada com guidelines (guias de qualidade) tais como heurísticas e/ou critérios ergonômicos. As inspeções, porém, trazem maior benefício na detecção de problemas de usabilidade, em outras palavras, checar se o software está de acordo critérios de qualidade utilizados pela equipe de desenvolvimento (ROCHA; BARANAUSKAS, 2003).

Entretanto, os testes de usabilidade tem como foco a avaliação da qualidade das interações entre usuário e o sistema. Segundo Cybis, Betion e Faust (2010) não se trata da elaboração de relatório de checagem, mas sim, descobrir como um usuário utiliza determinada interação e medir o impacto sobre suas atividades identificando assim, causas de possíveis problemas na usabilidade.

O processo de avaliação da usabilidade (tanto inspeções como teste de usabilidade) de um sistema computacional pode ocorrer em um laboratório de usabilidade, utilizando um ambiente simulado e controlado, porém, próximo ou semelhante a realidade, ou no próprio ambiente real de utilização da aplicação. Ambos os métodos de avaliação podem ter seus resultados alterados de acordo com o local no qual são realizados, entretanto, a inspeção de usabilidade tende a alterar menos considerando que independente do local de testes as atividades se concentrarão na comparação da interface com um determinado critério (CYBIS; BETION; FAUST, 2010; NIELSEN, 1993) .

Quando considerados os testes de usabilidade, cuidados devem ser tomados pelo fato de que o teste pode sofrer mais interferências externas em um ambiente real em relação ao ambiente controlado. Além disso, em um ambiente real, o sistema é submetido a situações muitas vezes difíceis de simular ou mesmo de serem imaginadas pelo avaliador (CYBIS; BETION; FAUST, 2010).

Nos próximos tópicos será explicado como funcionam as avaliações em laboratórios e no ambiente real de utilização. 


\subsubsection{Avaliação em Laboratório}

Um laboratório de teste de usabilidade é dotado de uma sala especial com equipamentos que permitem o controle dos processos efetuados no software, dentre eles, câmeras de vídeo, microfones, telefones para simular um sistema de help desk, vidros espelhados e equipamentos de monitoramento para a equipe de avaliadores. Os vidros espelhados permitem que o usuário realize suas atividades sem o constrangimento de estar sob observação direta, embora os avaliadores acompanhem o teste, o usuário não pode visualizá-los. Além desses equipamentos, é comum a utilização de um facilitador, ou seja, uma pessoa para acompanhar o processo de avaliação, controlar as atividades a serem realizadas e resolver pequenos problemas que possam ocorrer durante o processo. O facilitador não tira dúvidas sobre o software, caso o usuário as tenha, deve fazer utilizando o simulador de suporte (telefone) (CYBIS; BETION; FAUST, 2010). A Figura 2, apresenta um conceito de laboratório de avaliação da usabilidade.

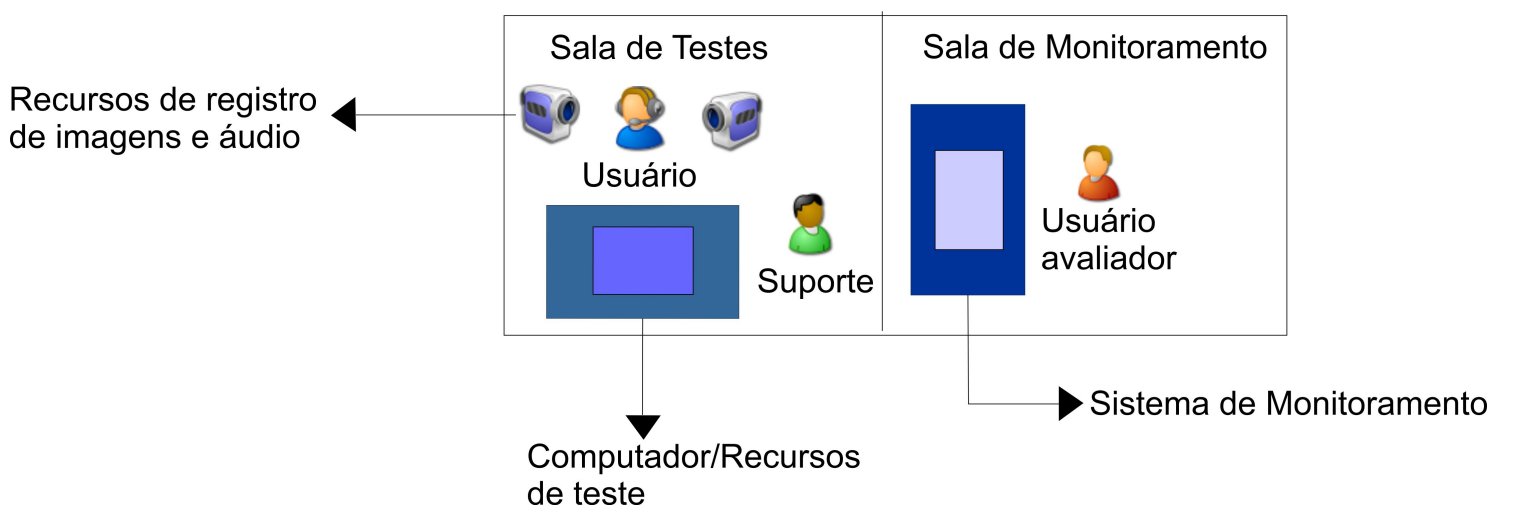

Figura 2 - Laboratório de usabilidade

O teste efetuado em laboratório é considerado ideal para software em seu estado de concepção. Durante a avaliação, a equipe de avaliadores realiza experimentos controlados simulando diversas situações como alterações nas interfaces, correção de erros, inserção de situações não planejadas, havendo possibilidade de efetuar alterações nas versões da interface e aplicar os testes novamente (CYBIS; BETION; FAUST, 2010).

O primeiro passo para efetuar um teste em laboratório é determinar uma hipótese a ser testada e todas as variáveis de interesse assim como seus resultados que podem ser validados estatisticamente, embora a validação de variáveis seja difícil e questionável quando envolve a utilização de seres humanos (ROCHA; BARANAUSKAS, 2003).

Essa abordagem é ideal para fornecer parâmetros do aplicativo em fase de desenvolvimento e em muitos casos dar um novo rumo ao processo de desenvolvimento, porém, a 
avaliação em laboratório não consegue simular $100 \%$ das situações que o sistema poderá ser submetido. Essas simulações podem ser efetuadas testando o software em ambiente real de utilização (CYBIS; BETION; FAUST, 2010; ROCHA; BARANAUSKAS, 2003).

Na próxima seção serão apresentados conceitos a respeito da avaliação no ambiente real de utilização.

\subsubsection{Avaliação em Ambiente Real}

O teste de usabilidade em laboratório simula situações controladas e hipotéticas. Embora permita a equipe de avaliação testar o software, impede de verificar como o aplicativo se integra com outras atividades em seu ambiente real.

Em um ambiente real de utilização o teste de usabilidade é feito visando submeter o aplicativo a situações que podem ocorrer no local de trabalho que será utilizado. Esse método permite verificar como o sistema vai se integrar com as demais atividades do usuário e, principalmente, avaliar como as ações ocorridas no ambiente de trabalho, por exemplo, telefonemas, interrupções por pessoas e outros agentes tecnológicos tais como Skype, MSN e E-mail podem induzir o usuário a erros ou dificuldades na utilização software (CYBIS; BETION; FAUST, 2010).

O ambiente de teste pode ser preparado utilizando câmeras de vídeo, microfones, arquivos de check list, porém não há o mesmo controle do laboratório, havendo a necessidade de um rigoroso estudo posterior dos resultados da avaliação (ROCHA; BARANAUSKAS, 2003).

A avaliação da usabilidade no ambiente real do software pode ocorrer com a presença de um avaliador in loco. Embora não possam ocorrer interferências, o mesmo pode acompanhar o processo de utilização e em muitos casos sanar dúvidas e problemas momentâneos dentro de sua alçada. Porém, o deslocamento de avaliadores pode ser custoso financeiramente, além de difícil devido à localização da organização, transporte, etc. Devido a esse fato, muitas avaliações passam a ser realizadas a distância sem a participação do avaliador no local. Esse conceito denomina-se Remote Usability Evaluation (RUE), em português, Avaliação Remota de Usabilidade. Na abordagem de RUE o avaliador e o usuário podem estar em locais, cidades e até mesmo países diferentes. O avaliador pode acompanhar remotamente e efetuar a análise dos dados em tempo real (Conceito Síncrono) ou receber e avaliar os dados em outra data/horário (Conceito Assíncrono) (RAMLI; JAAFAR, 2008; VARGAS; WEFFERS; ROCHA, 2010). 
Diversas técnicas podem ser utilizadas para apoiar os testes de usabilidade tanto local quanto remotamente e são aplicadas com o objetivo de coletar dados, processar e gerar informações sobre a interação entre o usuário e o sistema computacional. Na próxima seção serão apresentadas algumas técnicas utilizadas em testes de usabilidades e seus respectivos conceitos.

\subsubsection{Técnicas de Observação do Usuário}

Inspecionar se a interface atende a um determinado guideline pode apoiar no desenvolvimento de interações dentro de boas práticas de IHC, porém, um sistema interativo vai além disso, ele precisa prover a seus usuários a capacidade de interação que permita o mesmo realizar suas atividades com completitude, utilizando o menor e melhor número de recursos possíveis e como consequência, deixar o usuário satisfeito (CYBIS; BETION; FAUST, 2010; ROCHA; BARANAUSKAS, 2003) .

O teste de usabilidade visa identificar se existem problemas com a capacidade de interação oferecida pelo sistema a seu usuário dentro de um determinado contexto. Para avaliar essa questão existe a necessidade de observar o usuário interagindo com o aplicativo a fim de identificar tais problemas (CYBIS; BETION; FAUST, 2010).

Problemas de usabilidade podem ser identificados quando um sistema não esta de acordo com as necessidade do usuário e/ou não permite que o mesmo realize suas atividades com eficácia e eficiência e não atenda, portanto, os atributos da norma ISO 9241 (CYBIS; BETION; FAUST, 2010; ROCHA; BARANAUSKAS, 2003).

Por esse motivo, a utilização de usuários reais no processo de avaliação da usabilidade é fundamental para otimizar o processo de design de interface. Os usuários da aplicação podem desconhecer melhores práticas de usabilidade, como heurística e/ou critérios ergonômicos, porém, podem submeter o sistema a situações reais de utilização muitas vezes difíceis de serem levantadas nos requisitos e simuladas na implementação. Com esta abordagem de avaliação o sistema é colocado em situações que permitem a identificação de fatores externos que interferem na interação, por exemplo, telefones, comunicadores (MSN, skype, GTalk), interferência de outras pessoas e regras de negócio da organização, que normalmente não são conhecidas em sua totalidade por designer e avaliadores (CYBIS; BETION; FAUST, 2010; NIELSEN, 1993).

A observação do usuário pode ser efetuada em laboratório ou no ambiente real de utilização, porém, o ambiente real pode prover situações extremamente próximas ao que 
ocorre no dia a dia de um usuário, situações estas, que podem não ser simuladas em laboratório (CYBIS; BETION; FAUST, 2010). O ambiente de avaliação é importante para determinar qual o foco da observação. Preece, Borges e Sharp (2005) explicam que, no laboratório o foco da observação está nas atividades que o usuário desempenha e como fazer no software. No caso da observação de campo (ambiente real) o foco está em como as pessoas interagem uma com as outras, com a tecnologia, com o ambiente e como afetam ou são afetadas pelo sistema.

Observar o usuário utilizando o software pode inferir questões importantes a serem tratadas pela equipe de design. Há diversas formas de observar o usuário, mas é comum a utilização de técnicas que envolvem as seguintes atividades:

- arquivos com registro de sons e fala: registram a fala do usuário durante o processo de avaliação;

- arquivos de vídeo: registram as ações do usuário por meio de filmes. O número de câmeras e pontos a serem filmados pode variar de acordo com a equipe de avaliação e/ou contexto a ser avaliado.

- arquivos de logs de dados: contem informações sobre a utilização do software. Não se referem diretamente a imagens ou dados do usuário, mas sim aos dados sobre ações do usuário durante a utilização do sistema ou website avaliado.

A seguir serão apresentadas três técnicas utilizadas para observação das ações do usuário durante um teste de usabilidade de software, são elas: Verbalização também conhecida pelo termo Think aloud; Filmagem/Registro de Imagens e Monitoramento de Usabilidade por arquivos de Logs.

\subsubsection{Verbalização (Think aloud)}

A verbalização é um método amplamente utilizado para apoiar testes de usabilidade, porém o mesmo não surgiu na área de IHC e sim na psicologia (BOREN; RAMEY, 2000; HAAK; JONG; SCHELlENS, 2003). Segundo Boren e Ramey (2000) os primeiros estudos visando verbalização foram feitos por W. James e W. Wundt com objetivo de estudar teorias da mente humana.

Segundo Boren e Ramey (2000) pesquisadores da área de verbalização desenvolveram um modelo de Think Aloud que se tornou a base para técnicas utilizadas nos processos 
de teste de usabilidade. Esse modelo era dividido em três níveis de verbalização no qual cada um deles pode ser aplicado de forma diferenciada e se caracterizam, principalmente, pela diferença na carga mental do participante. Os três níveis são:

Nível 1:Nesse nível a verbalização ocorre de forma direta entre o que usuário está pensando e o que ele precisa falar, ou seja, não há a necessidade de uma transformação do pensamento em algo para se pronunciar. Um exemplo desse nível é pensar em um determinado número, esse número pode ser verbalizado sem a necessidade de uma grande carga mental para transformá-lo em palavra.

Nível 2: Neste nível ocorre a necessidade de uma atividade mental maior por parte da pessoa/usuário que está verbalizando. Isso ocorre porque há a necessidade de transformar o que está pensando em uma palavra para ser verbalizada. Por exemplo, se um usuário está utilizando um website e acha um recurso de interação agradável ele/ela precisa transformar essa ideia em uma palavra tal como bom, ruim ou regular.

Nível 3: Este nível requer um processamento mental adicional, pois é considerado o nível de verbalização mais complexo. Neste nível, o usuário/pessoa é forçado a tratar questões como, "verbalizar somente o que está relacionado ao assunto $X$ " ou verbalizar o resultado de um complexo cálculo matemático. Outra forma relacionada à este nível, é o fato do usuário recuperar informações ou comportamentos de sua memória após certo tempo do acontecimento.

Trabalhos relacionados à usabilidade e verbalização podem ser encontrados desde o início da década de noventa. Algumas pesquisas datadas entre 1990 e 2001 são apresentadas por Boren e Ramey (2000) relacionadas às áreas de verbalização e IHC. Estes trabalhos apresentaram a utilização da técnica de verbalização com diversos usuários que utilizavam um software para executar determinadas tarefas. As atividades se resumiram em utilizar aplicativos nos quais alguns usuários realizavam suas tarefas em silêncio e outros precisavam verbalizar todas as suas atividades.

Em um desses trabalhos Wright e Converse utilizaram um sistema de gerenciamento de arquivos. Durante os experimentos, alguns usuários permaneciam em silêncio e outros forneciam explicações sobre suas atividades. Os participantes que estavam em condição de verbalização deveriam pronunciar o que estavam pensando durante todo o processo. Se um participante demorasse mais de trinta segundos ou realizasse uma ação qualquer sem verbalizar, o mesmo era advertido. Como resultado, os usuários em condição de verbalização cometeram menos erros e consumiram menos tempo para realização das tarefas em relação aos usuários que permaneceram em silêncio. Os pesquisadores não 
identificaram diferenças relacionadas à facilidade de uso e/ou carga mental (WRIGHT; CONVERSE, 1992 apud HERTZUM; HANSEN; ANDERSEN, 2009).

Essas pesquisas mostraram que a verbalização é uma técnica eficiente para avaliação, porém, não há um padrão na interpretação dos resultados. No trabalho de Boren e Ramey (2000) é apresentada uma divergência entre as pesquisas em relação ao melhor nível de verbalização utilizado para avaliação, não havendo um destaque de determinado nível, mas os resultados variaram de acordo com o aplicativo testado, usuários e metodologia, ocorrendo, em determinados casos, sucesso dos níveis 1 e 2 e em outros, sucesso do nível 3.

A dificuldade na determinação de um padrão para avaliação da usabilidade utilizando verbalização foi comentada por Deffner que notou uma grande dificuldade em avaliar a eficiência da verbalização em fatores humanos e computacionais ocorre devido a grande diversidade de procedimentos empregados por diferentes pesquisas (DEFFNER, 1990 apud BOREN; RAMEY, 2000).

Atualmente a verbalização é um dos métodos mais utilizados para o teste de usabilidade (BOREN; RAMEY, 2000; HAAK; JONG; SCHELLENS, 2003; HERTZUM; HANSEN; ANDERSEN, 2009; NIELSEN, 1993). Uma pesquisa foi efetuada por McDonald, Edwards e Zhao (2011) com uma amostra de 207 participantes que utilizavam a verbalização para avaliar a usabilidade, contemplando praticantes, pesquisadores, estudantes e profissionais de desenvolvimento. Dessa amostragem 90\% dos pesquisadores e acadêmicos utilizam a verbalização com maior frequência e $76 \%$ de praticantes e desenvolvedores afirmaram a mesma situação.

A verbalização tem grande aceitação e utilização por parte da comunidade de IHC. Isto ocorre porque a verbalização é um método que fornece dados importantes a respeito da usabilidade do software. Isto ocorre, principalmente, porque o usuário, como conhecedor da regra de negócios, pode verbalizar suas atividades permitindo identificar opiniões, dificuldades e demais situações não planejadas e com estes dados o avaliador e a equipe de design podem identificar e corrigir possíveis problemas de interação. Duas técnicas de verbalização são defendidas por Cybis, Betion e Faust (2010), Nielsen (1993), Preece, Borges e Sharp (2005) são elas:

Verbalização Simultânea:nesta técnica o usuário/participante é constantemente convidado a verbalizar seus pensamentos ao mesmo tempo em que executa determinada tarefa. Esta técnica está relacionada aos níveis 1 e 2, definidos por Ericsson e Simons. Durante a avaliação o avaliador deve sempre convidar o participante a verbalizar com questões 
como:

- você poderia me dizer o que está pensando?

- o que você está tentando fazer?

- por que você fez isso?

A verbalização simultânea é considerada simples e eficiente porque o usuário está focado na atividade e com a opinião/pensamento ativo em sua mente, mas necessita de uma carga cognitiva maior por parte do participante porque o mesmo precisa dividir a atenção entre realizar as atividades no sistema, mentalizar e verbalizar a palavra. O avaliador/analista deve gerenciar o processo de teste para não causar sobrecarga cognitiva e com isso atrapalhar ou induzir o usuário ao erro (CYBIS; BETION; FAUST, 2010).

O avaliador, nesta abordagem, deve atuar como um gerente das atividades. Dentre suas atividades está a manutenção do foco do usuário nas tarefas evitando que assuntos não relacionados à avaliação interfiram, distraiam ou sobrecarreguem o participante. Manter o usuário verbalizando é outra tarefa do avaliador, ou seja, ele/ela deve sempre alertar o participante quando o mesmo deixa de verbalizar advertindo o mesmo caso permaneça de 15 a 60 segundos em silêncio e deve fazê-lo de forma adequada para que o alerta não seja interpretado de forma ameaçadora ou abusiva. Segundo Cybis, Betion e Faust (2010), o avaliador pode chamar a atenção com uma simples frase, por exemplo, "Continue falando".

Durante a verbalização simultânea de um website de compras o usuário pode pronunciar frases ou palavras que auxiliam o avaliador a identificar problemas ou qualidades da interface, por exemplo:

- estou com dificuldade para encontrar o produto;

- recurso de busca bem simples;

- que ruim!!;

- legal!!;

- quais informações são obrigatórias??

Verbalização Consecutiva: Nesta técnica o usuário é submetido a uma entrevista após a realização do teste e encorajado a verbalizar sobre determinada atividade ao mesmo 
momento tempo em que assiste a algum registro de sua performance como um vídeo ou arquivo de áudio. Durante a realização da tarefa o usuário pode permanecer em silêncio sendo obrigado a dialogar somente quando solicitado (após a tarefa). Os comentários consecutivos podem apresentar boas sugestões relacionadas à usabilidade, porém, requer uma carga mental maior por parte do usuário, levando em conta que o mesmo deverá lembrar porque realizou tal atividade daquela forma. Outra desvantagem é o tempo para realização da avaliação que poderá duplicar em relação à verbalização simultânea. Os dados para análise podem ser registrados em arquivos de vídeo e áudio.

Para exemplificar, podemos apresentar o mesmo exemplo da verbalização simultânea em um website de compras, o usuário pode verbalizar utilizando termos como:

- ocorreu dificuldade para realizar tal atividade;

- não gostei da interface;

- não identifiquei informações obrigatórias;

- ficou muito bom este recurso;

Outra questão importante a ser tratada na verbalização são os fillers ou preenchimentos, em português. Os fillers são termos verbais utilizados para "preencher" uma frase como ("um", "ah", "eh") além do silêncio do participante. Estes termos e o silêncio, embora não sejam ideais para a verbalização, não devem ser desconsiderados no momento da análise. Psicólogos apontam que preenchimentos verbais e silêncio podem ocorrer quando há uma sobrecarga mental e o usuário necessita priorizar uma atividade ou porque o usuário está realizando processamentos mentais muito grandes (COOKE, 2010).

Por fim, a verbalização é uma técnica para apoiar os testes usabilidade amplamente utilizada por pesquisadores e especialistas e tem eficácia comprovada, levando em consideração que os usuários são encorajados a falar sobre suas atividades e com isso emitem opiniões importantes a respeito da interatividade do software. Os dados são registrados em arquivos de áudio e/ou vídeo para uma posterior análise. O processo utilizado na verbalização pode variar de acordo com as características do teste ou do participante, porém mantém o fundamento de que o usuário deve verbalizar (falar) o que pensa a respeito de um sistema computacional.

Na próxima seção serão apresentados conceitos sobre a observação do usuário por meio de filmagens. 


\subsubsection{Registros de Imagens}

O registro de imagens dos testes é uma técnica bastante utilizada para avaliação e é considerada fundamental para avaliadores que necessitam registrar a interação do usuário com o sistema de forma detalhada, minuto a minuto, para posterior análise. A utilização de câmeras é comum em laboratórios de usabilidade onde testes são efetuadas de forma controlada simulando situações pré programadas por avaliadores (CYBIS; BETION; FAUST, 2010; NIELSEN, 1993).

Nielsen (1993) considerava a utilização de câmeras de vídeo uma ferramenta de apoio importante e barata, visto que, com uma única câmera era possível registrar todas as atividades, identificar problemas de usabilidade e assim, definir uma possível correção. Porém, o autor define a técnica como demorada devido a não automação do processo de análise da interação. Assistir aos vídeos com o objetivo de identificar problemas pode levar de 2 a 10 vezes o tempo de duração da avaliação. Por exemplo, se uma avaliação demorou trinta minutos para ser realizada, a análise de seu vídeo pode levar de noventa até trezentos minutos para análise. O autor explica também que, em muitos casos, equipes de avaliação gravam imagens somente para fins de conferência, pois um problema de usabilidade é tão visível que é possível localizá-lo na primeira vez que ocorre não havendo necessidade de assistir as imagens para identificá-los, porém é uma atitude de extremo risco, pois pode ocasionar a desconsideração de algum detalhe importante.

A técnica de filmagem consiste na utilização de uma ou mais câmeras de vídeo posicionadas de forma a capturar imagens do ambiente no qual o software é testado. O posicionamento e a quantidade de câmeras pode variar de acordo com a necessidade da equipe de avaliação, mas na maioria dos casos são posicionadas no rosto, visando identificar expressões faciais e acompanhar o foco do olhar na tela do computador, no teclado e mouse para identificar as ações realizadas nos dispositivos e se for necessário, no ambiente ao redor do participante. É comum a equipe registrar imagens da tela do computador como forma de relacionar os dados das câmeras com a funcionalidade testada (CYBIS; BETION; FAUST, 2010; NIELSEN, 1993).

A evolução do hardware e software trouxe significativas melhoras para estas técnica. Dispositivos atuais já provêm recursos que facilitam o registro de dados tais como webcam integrada e algoritmos que permitem fazer o sanapshot da interface enriquecendo a quantidade e qualidade dos dados registrados com esta técnica.

A evolução de recursos de vídeo também pode ser atribuída a evolução de componentes 
software, permitindo apoiar as atividades de coleta e processamento de imagens. Recursos como a biblioteca $O p e n C V$ foram desenvolvidas com a finalidade de auxiliar áreas como IHC, processamento de imagens, identificação de objetos, dentre outras. A OpenCV foi desenvolvida utilizando a linguagem de programação $\mathrm{C}++$ e pode ser utilizada em ambientes de desenvolvimento como Microsoft Visual Studio, Eclipse e outros. Com estas ferramentas, pesquisadores, desenvolvedores e avaliadores podem aplicar técnicas de processamento de imagens visando melhorar as atividades de design de interação (LIMA et al., 2008).

Em resumo, a filmagem é uma técnica utilizada para avaliação da usabilidade de software que permite gravar o comportamento do usuário durante a utilização da aplicação além de registrar imagens da tela e demais objetos/locais de interesse do avaliador. Por ser uma técnica que apóia a identificação de problemas de interação, é amplamente utilizada em laboratórios de usabilidade e atualmente tem se disseminado para avaliações no ambiente real de trabalho, tanto in loco quanto remotamente.

Na próxima seção serão apresentados conceitos sobre monitoramento de usabilidade por arquivos de logs.

\subsubsection{Monitoramento por Arquivos de Logs}

A utilização de um website é uma situação comum e é feita com a intenção de realizar uma série de atividades que vão desde o entretenimento até atividades comerciais e empresariais. As interfaces dos websites encontram-se em constante evolução e a preocupação com a usabilidade dessas aplicações é constante entre engenheiros e projetistas (MORANDINI, 2002).

Dentro da arquitetura utilizada para websites é possível que dados relacionados à utilização de um website possam ser registrados em arquivos chamados de Arquivos de Logs. Os registros contêm dados sobre a utilização de um sítio eletrônico e seus recursos tais como endereço solicitado, horário, dados do navegador dentre outros (CYBIS; BETION; FAUST, 2010; MORANDINI, 2002).

Os dados podem ser gerados no lado do servidor, local no qual ficam armazenados arquivos do website e onde são executados na Internet e/ou no lado do cliente (computador que solicita acesso ao site). No primeiro caso há uma economia de recursos porque os dados são gerados e armazenados no próprio servidor sem ocorrer a necessidade de transferência pela Internet, situação que ocorre quando o arquivo é gerado no lado cliente além de 
reduzir o risco de perda dos dados durante uma transmissão, situação obrigatória na coleta de dados no lado do cliente (CYBIS; BETION; FAUST, 2010).

Segundo Cybis, Betion e Faust (2010) e Morandini (2002), dentre as vantagens do monitoramento por arquivos de logs as duas que mais se destacam: são a capacidade de coletar dados a grandes distâncias; e o fato de não ser intrusivo. Os dados representam as atividades desempenhadas por um grande número de usuários espalhados pelo planeta que realizam atividades no seu navegador interagindo com uma aplicação web. Esta técnica é considerada pouco intrusiva devido ao fato que os dados são coletados em silêncio durante a realização das atividades do usuário no website. Um aplicativo executa uma série de atividades de seleção, coleta e envio dos dados sem atrapalhar em absolutamente nada quem utiliza o website.

O ponto fraco do monitoramento por logs é explicado por Cybis, Betion e Faust (2010) como a dificuldade em ter maiores informações sobre o usuário da aplicação. Os arquivos registram dados sobre o percurso do usuário na página, por exemplo, hyperlinks selecionados, botões acionados, duração da visita, páginas acessadas e horários, porém, não permitem ao avaliador identificar o que pode ter ocorrido com o usuário durante este período como interrupções e/ou reações emocionais do usuário.

Os logs são escritos em arquivos configuráveis e necessitam de ferramentas específicas para leitura e interpretação desses dados. Os logs files são criados pelo servidor no momento em que processa uma solicitação de um computador cliente. Os dados registrados em um arquivo variam de acordo com o tipo de servidor utilizado e com o padrão adotado, mas em geral. Cybis, Betion e Faust (2010), Morandini (2002) apresentam que um arquivo contém os seguintes dados:

- endereço IP do computador que solicitou um serviço;

- data e horário da requisição;

- $U R L$ requisitada;

- tamanho do arquivo solicitado;

- protoloco empregado na requisição;

- navegador e sistema operacional utilizado;

Um exemplo de um registro gravado em um log file pode ser apresentado como: 135.217.50.100 - [16/Jun/2012:13:57:10 - 0000] "GET/ergosv/cadastro.aspx HTTP/1.1"200 
743 " ergosv/cadastrocliente.aspx"”Mozilla/4.0 [en](Win'; I).

Um arquivo pode conter vários registros e sua interpretação depende de ferramentas especializadas como o Fast Stats Analyzer, ErgoMonitor (MORANDINI, 2002) ou o ErgoParser (CERRATO, 2012). Essas ferramentas tem a capacidade de ler e interpretar os dados contidos em arquivos de log e gerar métricas de usabilidade para apoiar a análise dos websites.

O número de registros em um arquivo não significa, necessariamente, a quantidade de requisições. Devido ao cache do lado do cliente, páginas carregadas são armazenadas na memória da máquina do cliente por determinado tempo e de acordo com o espaço de memória disponível. Morandini (2002) exemplifica utilizando os comandos de Back (Voltar uma Página) e Foward (Próxima Página). Estes comandos não são registrados em log files por estarem arquivados na memória da máquina, porém, um comando de Reload (Recarregar Página) é registrado no arquivo.

A técnica de monitoramento da usabilidade por análise de arquivos de logs se tornou fundamental, principalmente para equipes de desenvolvimento de websites. Esta técnica é amplamente utilizada tanto para monitorar a experiência do usuário na aplicação quanto para pesquisas de publicidade, propaganda e dados estatísticos de acesso a conteúdos do website (CYBIS; BETION; FAUST, 2010).

Segundo Cybis, Betion e Faust (2010), Morandini (2002) as medidas fornecidas por ferramentas de monitoramento podem ser divididas em quatro grupos:

1. visitas: quantidade de visitas (novas e frequentes), taxa de repique (visitas rápidas), duração das visitas, quantidade de páginas visitadas por visita, localização geográfica do visitante e dados sobre seu ambiente tecnológico;

2. referência: lista de websites de onde partem as visitas, termos utilizados em ferramentas de buscas, percentual de usuário que acessaram digitando o endereço da página diretamente no navegador;

3. conteúdo: páginas mais visitadas;

4. navegação: caminhos internos utilizados pelos usuário para acessar determinada página ou realizar determinada tarefa.

Em resumo, a técnica de monitoramento utilizando arquivos de logs tornou-se incontornável para equipes que visam o desenvolvimento de páginas interativas para Internet. 
Como se trata de um recurso pouco intrusivo e com ampla capacidade de cobertura nos testes, permite que avaliadores submetam o sistema a situações reais de utilização em diversas partes do planeta, por diversos usuários a um custo relativamente baixo. A tecnologia pode ser implementada do lado servidor, coletando dados sobre o comportamento do usuário no website sem que o mesmo saiba do monitoramento. A única consideração negativa encontrada a respeito desta técnica é o fato da mesma monitorar as ações do usuário no programa sem identificar comportamento emocional da pessoa e o que acontece no ambiente em que o usuário se encontra e que pode ocasionar erros de manipulação.

Nas próximas seções serão apresentados os conceitos sobre processamento imagens e processamento de fala.

\subsection{Processamento de Imagens}

Esta seção apresenta conceitos básicos sobre Processamento de Imagens além de definições de técnicas utilizadas para extração de características e cálculo de similaridade de imagens.

\subsubsection{Conceitos Fundamentais}

Diversos recursos computacionais já foram implementados com objetivo de apoiar atividades diversas realizadas anteriormente de forma manual. O Processamento de Imagens contém relevantes e significativas contribuições para o ser humano. Segundo Gonzalez e Woods (2000) o Processamento de Imagens é um vasto conjunto de operações que podem ser aplicadas em uma representação matemática de uma imagem com objetivo de resolver determinado problema.

Atualmente técnicas de processamento de imagens são amplamente utilizadas em áreas como medicina, geografia, arqueologia, física, interação humano computador, eletrônica e outros (GONZALEZ; WOODS, 2000). Na medicina, atividades como interpretação de imagens de raios-X, melhoria na qualidade de imagens de ultrassonografia e apoio a treinamento médico são situações nas quais trabalhos com imagens são aplicados. Na geografia pode-se citar exemplos de utilização em sistemas de reconhecimento de terrenos e simulações e na interação humano computador pode-se apontar a realidade virtual, apoio ao ensino e aprendizagem, reconhecimento facial e apoio a sistemas com recursos de acessibilidade (NUNES, 2011). 
Uma imagem é apresentada por Gonzalez e Woods (2000) como a representação de um objeto físico que pode ser armazenada, manipulada e interpretada de acordo com as necessidades dos interessados. Matematicamente uma imagem pode ser definida como a intensidade de sinal retornada ao sensor. Segundo Nunes $(2006,2011)$ e Gonzalez e Woods (2000) a maioria das imagens são bidimensionais e definidas pelas fórmulas $f=(x, y)$, onde $x$ e $y$ são coordenadas espaciais e $f$ fornece a intensidade da imagem no ponto.

Um caso especial de imagem é constituído por imagens digitais. Nesta abordagem, a imagem é representada por um vetor de valores discretos (NUNES, 2006). Normalmente o vetor trata-se de um conjunto de linhas e colunas e cada índice das mesmas representa um ponto da imagem e os valores armazenados nestes índices identificam o nível de cinza naquele ponto. Os elementos da matriz são chamados de elementos da imagem ou elementos da figura ou pixels, este último é uma abreviação de picture elements (GONZALEZ; WOODS, 2000). Segundo Nunes (2006) os valores assumidos em cada ponto são quantificados por números pertencentes a uma escala de cores diferentes e em geral são representadas por escalas de cinza onde o valor zero representa a cor mais escura (preto) e o valor mais alto $\mathrm{M}$ representa a cor mais clara (branco). A equação retirada do trabalho de Nunes (2006) apresenta uma matriz de imagem digital onde $n$ e $m$ correspondem à quantidade de linhas e colunas respectivamente.

$$
f=(x, y)\left(\begin{array}{cccc}
f 0,0 & f 0,1 & \ldots & f 0, n-1 \\
f 1,0 & f 1,1 & \ldots & f 1, n-1 \\
\cdot & & & \\
\cdot & & & \\
\cdot & & & \\
m,-1,0 & m-1,1 & \ldots & m-1, n-1
\end{array}\right)
$$

Segundo Gonzalez e Woods (2000) a atividade de processamento de imagens abrange uma ampla classe de hardware, software e fundamentos teóricos. Os autores explicam que o objetivo global desta atividade é produzir resultado a partir do domínio de um problema utilizando imagens. Por exemplo, ler o endereço em uma correspondência ou identificar um rosto em uma foto podem ser domínios a serem resolvidos.

Coleta, armazenamento, processamento e exibição são atividades relacionadas ao processamento de imagens. A atividade de processamento merece destaque dentre as demais porque de acordo com Gonzalez e Woods (2000) refere-se aos algoritmos computacionais que realizam a manipulação de uma imagem retornando uma imagem final processada. Gonzalez e Woods (2000) apresentam, de forma técnica, as atividades de proces- 
samento como Aquisição de Imagens, Pré-Processamento, Segmentação, Representação e Descrição, Reconhecimento e Interpretação.

A Aquisição de Imagens é primeira atividade necessária para o processamento de imagens e visa obter uma imagem digital. Pode ser feita utilizando dispositivos de video capaz de coletar e digitalizar o sinal produzido pelo equipamento tais como câmeras digitais, webcam ou um leitor que permita capturar uma linha da imagem.

Após obter a imagem o Pré Processamento deve ser realizado com objetivo de melhorar a imagem aumentando assim as chances de sucesso do processamento em si. Uma forma de melhoria da imagem é a suavização que é utilizada para redução de efeitos da coleta da imagem que comprometem sua qualidade, por exemplo, ruídos. Outra técnica é conhecida por realce que tem o objetivo de destacar detalhes relevantes da imagem e melhorar a visualização de bordas.

Nunes (2011) apresenta dois exemplos de técnicas de suavização (pré processamento) da imagem conhecidos por Média Vizinhança, Mediana Vizinhança e uma técnica de realce chamada Quantização. A Média Vizinhança é uma das técnicas mais clássicas e seu processamento consistem em gerar uma imagem no qual o valor de cada pixel é obtido por meio do cálculo da média dos pixels vizinhos. A Mediana Vizinhança tem processo semelhante a Média Vizinhança, mas diferente da primeira, na segunda técnica cada pixel da imagem final é substituído pelo valor mediano da vizinhança do pixel. O valor mediano de um conjunto de valores $(\mathrm{m})$ é tal que a metade dos valores no conjunto são menores que $m$ e outra metade é formada por valores maiores que $m$. A Figura 3 retirado de Nunes (2011) apresenta exemplos de uma imagem adquirida e de duas imagens finais, uma suavizada pela Média Vizinhança e outra pela Mediana vizinhança nas quais é possível identificar uma melhora na qualidade final da imagem.

Outra técnica de melhoria da imagem apresentada por Nunes (2011) é a quantização. Nesta técnica, percorre-se os pixels da imagem ajustando seus valores para números pré determinados, considerando uma quantidade de cores definidas para tal ação. A Figura 4 também extraída do trabalho de Nunes (2011) mostra um exemplo de realce realizado em uma imagem médica na qual é aplicado um filtro com dez níveis de cinza. A melhoria do contraste é visível na imagem e destacado pela autora como forma de apresentar informações relevantes da figura. A aplicação de realce em atividades que utilizam processamento de imagens é considerada fundamental por destacar estruturas de interesse para seus utilizadores.

A próxima fase é conhecida por Segmentação. Segundo Gonzalez e Woods (2000) esta 


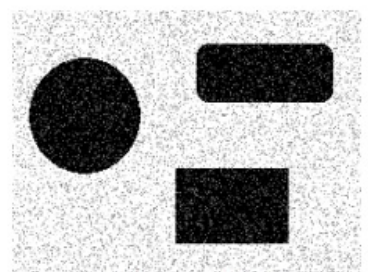

(a) imagem original

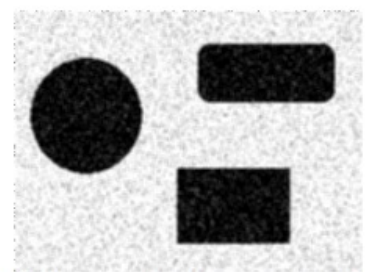

(b) imagem resultante após aplicação do filtro de média da vizinhança

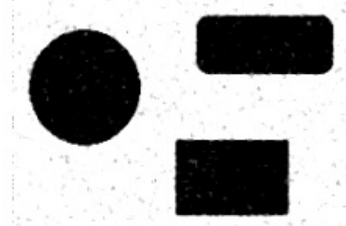

(c) imagem resultante após aplicação do filtro de mediana da vizinhança

Figura 3 - Imagem de aplicação de filtro de suavização com base na vizinhança. Fonte: (NUNES, 2011)

é um dos estágios mais importantes do processamento de imagens. De forma geral, na segmentação a imagem de entrada é dividida em parte ou objetos constituintes para ser processado. A segmentação compreende os algoritmos utilizados para realizar as atividades de processamento. Um bom algoritmo de segmentação pode favorecer a solução do problema e da mesma forma, algoritmos fracos ou erráticos podem comprometer severamente o processo. Um processo de segmentação, por exemplo, poderia extrair caracteres individuais de uma palavra ou selecionar parte de uma imagem que correspondam a imagens faciais. Considerando o objetivo desta pesquisa a segmentação pode realizar a busca de um rosto dentro de uma imagem proposta retornando uma série de pixels que forma a imagem facial.

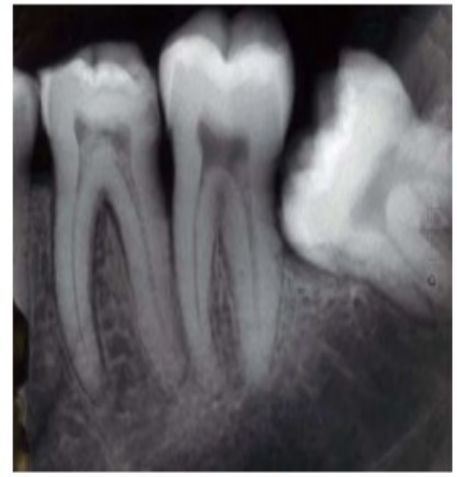

(a) imagem original

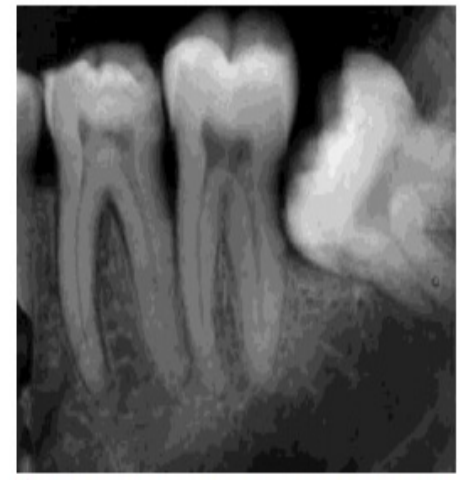

(b) imagem resultante após aplicação do filtro de quantização com 10 níveis de cinza

Figura 4 - Imagem de aplicação de filtro de realce (NUNES, 2011) 
Outra atividade de segmentação aplicável a esta pesquisa é o processo de comparação facial que consiste na entrada de duas imagens faciais, nas quais são aplicados algoritmos de comparação de imagens para detectar se são iguais ou não, ou a taxa de semelhança entre elas.

A fase seguinte é composta pela Representação e Descrição. Representação consiste em determinar se o processamento computacional será realizado com base nas fronteiras ou por região. Na representação por fronteira é adequada quando o interesse se concentra em características como cantos ou pontos de inflexão e a representação por região deve ser aplicada quando o interesse está em propriedades internas como texturas ou forma do esqueleto, podendo ocorrer coexistência das duas representações em algumas aplicações.

A descrição consiste em extrair dados que permitam a identificação de características e resultem em informação quantitativa de interesse para discriminação entre objetos e classes. Em um processo de reconhecimento de letras, descritores, como concavidades, são características que permitem identificar uma letra ou outra. Em um processo de reconhecimento facial, a quantidade de faces identificadas em uma imagem, seu histograma, a média e desvio padrão do histrograma são considerados dados para identificação das imagens (BERGAMASSO, 2010).

O ultimo estágio envolve o Reconhecimento e a Interpretação. Enquanto o Reconhecimento é o processo de atribuir um rótulo a um objeto com base nas informações fornecidas pelo seu descritor, a Interpretação envolve a atribuição de significado a um conjunto de objetos reconhecimentos. Para o exemplo de reconhecimento de caracteres a identificação do caracter $C$ requer associação dos descritores para aquele rótulo. Considerando o reconhecimento ou comparação facial, considerar uma imagem igual ou diferente ou indicar a taxa de similaridade pode ser considerada uma atividade deste estágio.

Segundo Gonzalez e Woods (2000) estas atividades são realizadas com apoio de uma base de conhecimentos previamente desenvolvida com o domínio do problema. O conhecimento codificado pode ser simples como o detalhamento de regiões de uma imagem na qual se sabe a informação de interesse quanto um conhecimento mais detalhado e complexo como uma lista de defeitos em uma análise de material ou as condições que caracterizam as várias emoções expressadas pelas pessoas.

A base de conhecimento direciona a operação de cada fase do processamento de imagens e controla a interação entre as mesmas. A Figura 5 extraída de Gonzalez e Woods (2000) apresenta a dinâmica das tarefas de processamento de imagens. 


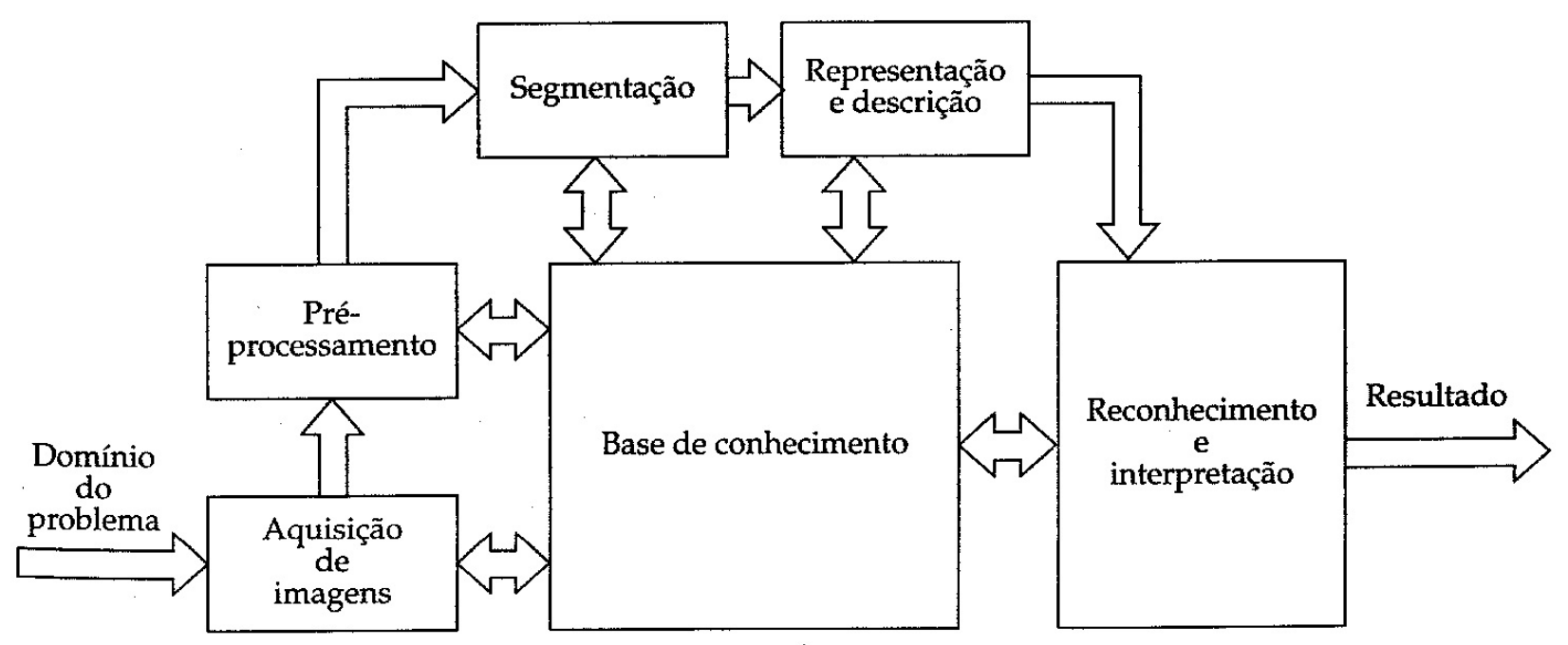

Figura 5 - Atividades do processamento de imagens (GONZALEZ; WOODS, 2000)

\subsubsection{Ferramentas de Apoio ao Processamento de Imagens}

A utilização de Processamento de Imagens levou ao surgimento de ferramentas e aplicativos para apoiar tal atividade reduzindo a necessidade do desenvolvimento de algoritmos complexos. Exemplo dessas ferramentas são a $O p e n C V$ e a ferramenta AForge.

A OpenCV é uma biblioteca open source utilizada para processamento de imagens offline ou em tempo real. Ela pode ser utilizada para atividades como identificação de objetos, reconhecimento de faces, gestos e demais atividades relacionados à computação e imagens (LIMA et al., 2008). A biblioteca foi desenvolvida originalmente na linguagem $\mathrm{C} / \mathrm{C}++$ e permite integração com ambientes de desenvolvimento como Microsoft Visual Studio, Eclipse e C++ Builder.

Algumas distribuições foram criadas com a finalidade de adaptação a um maior número de linguagens e ambientes de programação, exemplo delas é a EMGU OpenCV disponível em (http://www.emgu.com/wiki/index.php/OpenCV). Nesta distribuição foram implementados métodos para utilização junto a linguagem $C \#$ permitindo uma maior integração com o ambiente Microsoft Visual Studio. Outra distribuição conhecida é a $J a$ $v a C V$ e permite a integração da OpenCV com ambientes de desenvolvimento baseados na plataforma Java.

Outra ferramenta, semelhante a OpenCV é a ferramenta AForge. A AForge pode ser adquirida gratuitamente no site http://www.aforgenet.com/ e utilizada em ambientes de desenvolvimento com o Visual Studio e o Visual C\#. A Ferramente contém uma séria de 
algoritmos que permitem acesso e execução de uma série de atividades como reconhecimento facial, manipulação de objetos em terceira dimensão e algoritmos para realização de funções matemáticas sobre números das imagens como Função de Similaridade.

Estas ferramentas foram criadas com objetivo de facilitar a implementação da computação visual, permitindo que seus usuário realizem acesso a recursos de processamento de imagens utilizando códigos pequenos e enxutos, sem a necessidade de implementar complexos códigos fontes. Diversas funcionalidades de computação visual podem ser acessadas por linguagens de programação de alto nível, tais como Java ou C\# de forma simples, através de funções com ou sem parâmetros, dispensando, assim, a implementação de grande variedade de códigos.

Lima et al. (2008) apresentam em seu artigo uma série de funcionalidades aplicadas a biblioteca $O p e n C V$, da mesma forma, no website http://www.aforgenet.com/ é possível ter acesso a toda documentação da respectiva ferramenta e assim, a seus algoritmos e funcionalidades.

Uma das funcionalidadas encontradas na OpenCV é a capacidade de identificação de objetos dentro uma denterminada imagem. Utilizando classificacores treinados conhecidos por Viola Jones, a ferramenta realiza a segmentação de uma imagem identificando e destacando as faces encontradas dentro de uma imagem. Os classificadores são treinados em forma de cascata, ou seja, um algoritmo mais complexo (cascata maior) é formado por diversas cascatas menores (não menos complexos que a maior) nas quais as imagens faciais são identificadas e/ou descartadas. O algoritmo de reconhecimento de objetos pode ser utilizado para identificação de faces e pode ser fácilmente adaptado (treinado) para identificação de outros objetos.

O Processamento de Imagens realiza atividades a fim de resolver problemas para uma série de domínios. Um desses domínios é o Reconhecimento e a Comparação Facial que se tratam de algoritmos utilizada para identificar faces em uma imagem e posteriormente compara-las com outras imagens de face para verificar se são semelhantes. A seguir serão apresentados conceitos sobre Reconhecimento Baseado em Conteúdo.

\subsubsection{Recuperação de Imagens Baseada em Conteúdo}

A recuperação ou reconhecimento de imagens baseada em conteúdo, também conhecido por CBIR é uma técnica que tem por objetivo apresentar aos usuários imagens armazenadas em uma base de dados que sejam relevantes ou mais similares a uma ima- 
gem modelo. As imagens analisadas a fim de verificar sua relevância ou similaridade são conhecidas por imagens candidatas (BERGAMASSO, 2010; NUNES, 2011).

A análise das imagens é feita por meio da extração de características de todas as imagens envolvidas no processamento. As características são dados matemáticas extraídos das imagens por funções conhecidas por extratores (BERGAMASSO, 2010).

\subsubsection{Extratores}

Os extratores são algoritmos que extraem características das imagens em forma de informações matemáticas que representam o conteúdo de uma determinada imagem. Os extratores podem ser globais (característica de uma imagem toda) ou locais (característica de um determinado ponto da imagem). As características são agrupadas em vetores chamados de Vetores de Características nos quais são aplicados funções de similaridades que apontam o quanto uma imagem é semelhante a outra (SOUZA; SANTOS; GULIATO, 2008).

Há três tipos de extratores: Cor, Textura e Forma.

Os extratores de cor são algoritmos voltados a extrair característica por meio da aplicação de cores de uma imagem. É um extrator robusto e independe de tamanho e posicionamento da imagem além de ser fácil de assimilar, o que incentiva seu uso (BERGAMASSO, 2010). A implementação do extrator pode ser realizada utilizando qualquer modelo de cor disponível tais como RGB, CMY, HSV ou HSI. Uma técnica específica para implementação deste tipo de extrator é o Histograma.

O Histograma é um recurso que retorna a frequência de uma determinada cor na imagem, permitindo a comparação e análise estatística delas. Quanto maior a variação do Histograma, maior a variação de cores na imagem. A Figura 6 apresenta o Histograma de uma imagem em níveis de cinza.

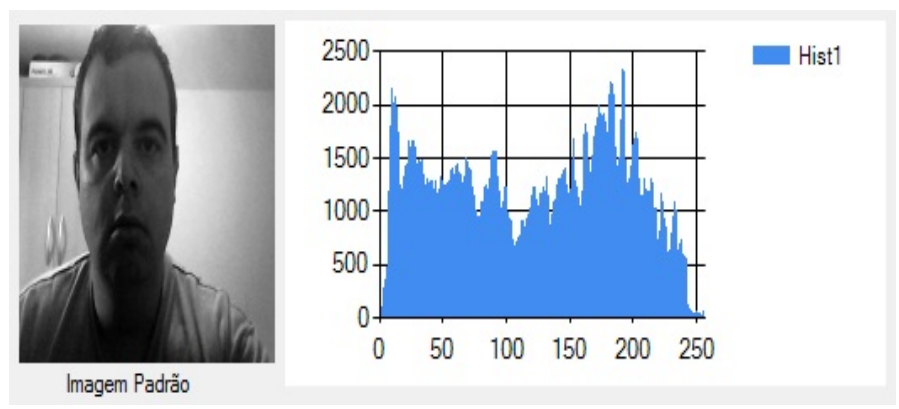

Figura 6 - Histograma de uma imagem em tons de cinza 
O segundo tipo de extratores, conhecidos por extratores de texturas apresentam o arranjo estrutural da imagem medindo propriedades como orientação, regularidade e granularidade. Uma das técnicas utilizadas se chama Matriz de Co-Ocorrência e consiste em demonstrar o relacionamento espacial entre pixels e por meio de fórmulas como a de entropia, contraste e energia, calcular a probabilidade de regiões com texturas e obter o vetor de características (BERGAMASSO, 2010).

Por último, os extratores de forma são considerados os mais difíceis por exigirem um pré processamento da imagem antes de aplicar o extrator, considerando que os objetos de interesse devem estar separados do fundo. Momentos Invariantes de Hu é uma técnica utilizada para analisar propriedades como forma, rotação e escala, por meio de 7 momentos invariantes.

Cada característica extraída é representada matematicamente por seu valor e o conjunto de valores extraídos forma o vetor $V$ composto por $n$ elementos no qual $n$ é a quantidade de características registradas e $V i$ é o valor da Iésima característica da imagem (NUNES, 2011). Por exemplo, em uma situação na qual são extraídas quatro características de uma imagem: Média de Histograma de Cinza, Desvio Padrão de Cinza, Média dos Pixels em Cinza, Desvio Padrão dos Pixels em Cinza, para cada imagem existirá um vetor com quatro posições no qual cada posição representará uma característica da imagem e armazenará seu respectivo valor. A Figura 7 apresenta dois modelos de vetores contendo dados de características de duas imagens para o exemplo citado. Neste exemplo, a primeira tabela apresentada poderia ser associada a uma imagem modelo, enquanto a segundo tabela a uma imagem candidata.

\begin{tabular}{|l|l|l|l|}
\hline $\begin{array}{l}\text { Média do Histograma } \\
\text { em Cinza }\end{array}$ & $\begin{array}{l}\text { Desvio Padrão do } \\
\text { Histograma em } \\
\text { Cinza }\end{array}$ & $\begin{array}{l}\text { Média dos Pixels } \\
\text { em Cinza }\end{array}$ & $\begin{array}{l}\text { Desvio Padrão dos } \\
\text { Pixels em Cinza }\end{array}$ \\
\hline 0,4796 & 0,7611 & 0,4521 & 0,7112 \\
\hline \multicolumn{4}{|l|}{ Imagem 02} \\
\hline $\begin{array}{l}\text { Média do Histograma } \\
\text { em Cinza }\end{array}$ & $\begin{array}{l}\text { Desvio Padrão do } \\
\text { Histograma em } \\
\text { Cinza }\end{array}$ & $\begin{array}{l}\text { Média dos Pixels } \\
\text { em Cinza }\end{array}$ & $\begin{array}{l}\text { Desvio Padrão dos } \\
\text { Pixels em Cinza }\end{array}$ \\
\hline 0,4596 & 0,8951 & 0,4533 & 0,8993 \\
\hline
\end{tabular}

Figura 7 - Vetores de características de uma imagem

Entretanto, segundo Nunes (2011) somente os vetores de características não são suficiente para determinar a similaridade ou relevância de uma imagem candidata, para determinar esses valores é necessário aplicar os valores a uma função de similaridade, conforme será explicado na próxima seção. 


\subsubsection{Funções de Similaridade}

Como mencionado anteriormente o Processamento de Imagens permite a extração de características de imagens e a crição de vetores nos quais cada posição é preenchida com um valor matemático que representa uma característica de uma determinada imagem. Porém, somente esta ação não é suficiente para identificar a similaridade entre duas imagens, para isto é necessário aplicar esses valores a uma função de similaridade.

Uma função de similaridade compara dois vetores e retorna um valor não negativo entre 0 e 1 sendo menor a similaridade quando o valor se aproxima de 0 (zero) e maior quando se aproxima de 1 (um) (NUNES, 2011). Existem várias funções de similaridade, Nunes (2011) apresenta algumas técnicas utilizadas e Bergamasso (2010) apresenta duas como as mais comuns: Distância de Manhattan e Distância Euclidiana.

A distância de Manhattan é o a soma das diferenças absolutas entre suas coordenadas, enquanto a distância Euclidiana é a raiz da diferença absoluta entre suas coordenadas ao quadrado (BERGAMASSO, 2010).

Utilizando como exemplo dois vetores $\mathrm{V} 1=[0.3,0.5,0.8,0.4]$ e V2 $=[0.2,0.6,0.7$, 0.9] e aplicando os vetores a função de distância Euclidiana. Se o valor resultando for 0,993 significa que a imagem candidata tem grande semelhança com a imagem padrão e caso o valor resultante for 0,321 a imagem candidata é consideravelmente diferente da imagem utilizada como base para comparação (NUNES, 2011).

Por fim, o reconhecimento de imagens baseado em conteúdo é uma técnica que utiliza algoritmos extratores para obter valores matemáticos de figuras. Os valores são armazenados em vetores diferentes (uma para cada imagem) e podem ser comparados por meio de funções de similaridade que retornam um valor ajustado entre 0 e 1 que determina o quanto uma imagem é semelhante de outra. Esta técnica pode ser aplicada em diversas áreas como comparação facial, busca de imagens relevantes em base de dados e demais áreas de processamento de imagens.

\subsubsection{Considerações Finais sobre Processamento de Imagens}

Em resumo, o processamento de imagens permite que um determinado problema baseado em imagens seja solucionado por meio da coleta, processamento e saída de um objetivo relacionado à um contexto. Com isso, pesquisas envolvendo área de medicina, IHC, geografia e outras utilizam destas técnicas para obter informações relevantes por meio de 
imagens. O processamento de imagens tem por base algoritmos relativamente complexos contendo a base de conhecimento necessária para trabalhar uma imagem, porém, a grande utilização de processamento de imagens aliado a tecnologia permitiu o surgimento de ferramentas que apóiam atividades de coleta, pré-processamento e sintetização de forma a melhorar as atividades em relação ao tempo, custo e qualidade.

Dentre as técnicas de processamento o $C B I R$ permite realizar atividades nas quais são gerados vetores contendo valores matemáticos que representam características das imagens e através de funções de similaridade efetuar a comparação dos vetores a fim de identificar a similaridade entre elas. Técnicas como esta permitem a comparação de imagens dentro de contextos específicos, por exemplo, comparação de imagens facial.

Na seção seguinte serão apresentados conceitos e trabalhos relacionados ao processamento de fala.

\subsection{Processamento de Fala}

A fala de uma pessoa tem importância comprovada, pois não transmite somente a fala, mas também o gênero da pessoa, sua identidade e suas emoções. Estudos relacionados à área neurológica confirmam a existência de uma área no cérebro especializada em sons vocais (AGUS et al., 2010). Seu importante contexto pessoal/cultural torna a voz uma importante área de estudos e seu processamento computacional é considerado importante e útil para diversas áreas dentre elas a IHC.

O processamento de fala se trata do processo de interpretação da voz humana em um computador. Para tal interpretação é necessária a construção de sistemas para mapeamento de sinais acústicos para palavras escritas (NETO; PATRICK; KLAUTAU, 2010; SHARIAH et al., 2007).

Entretanto, Neto, Patrick e Klautau (2010) não se restringem ao ato de processar um sinal de voz e apresentar em forma de textos e apresenta o processamento de fala de duas formas que atuam em sentidos diferentes: Automatic Speech Recognition (ASR) e Text-To-Speech(TTS).

Na abordagem ASR que em português significa Reconhecimento Automático de Fala a voz é capturada em forma de sinal digital e convertida para texto escritos (NETO; PATRICK; KLAUTAU, 2010; SHARIAH et al., 2007). Na abordagem TST, que traduzindo, significa Texto para Fala, textos escritos em linguagem natural são convertidos para falas 
sintetizadas.

Neto, Patrick e Klautau (2010) explicam também que o processamento de fala tem uma ampla área de pesquisa devido, principalmente, a quantidade e a diferença de idiomas que implica em maiores cuidados no momento da implementação de um aplicativo para tal atividade, além de fatores relacionados à capacidade de IHC de ferramentas computacionais que podem ser melhoradas por meio de processamento de fala.

De acordo com Shariah et al. (2007) há diversas técnicas para processamento de fala dentre elas, Linear Predictive Coding (LPC), Perceptual Linear Prediction (PLP) e MelFrequency Cepstral Coefficient (MFCC) e que o MFCC é o método mais utilizado para processamento de fala.

Estas técnicas de processamento de fala podem variar em relação a atividades específicas com características próprias, ou seja, na quantidade de atividades para realizar o processamento e/ou na complexidade de algoritmos utilizados, porém, todos os processos seguem uma lógica:

- coletar o som (sinal analógico), por meio de uma interface de entrada como microfones;

- processamento do sinal para digital para conversão em texto que pode compreender:

- divisão e normalização do sinal de voz em várias camadas;

- transformação do sinal de voz em palavras e/ou palavras em unidades de reconhecimento (estruturas como árvores lexicas podem ser utilizadas para esta atividade);

- identificação dos termos (palavras) e configurações fonéticas que se adequem às unidades.

- transformação das palavras em textos utilizando como base modelos de linguagem e dicionários fonéticos específicos.

- devolução dos termos devidamente processados em forma de textos por meio de uma interface de saída.

A Figura 8 apresenta uma representação das atividades de processamento de fala citados pelos autores acima com base nas explicações de Neto, Patrick e Klautau (2010) e Shariah et al. (2007). 


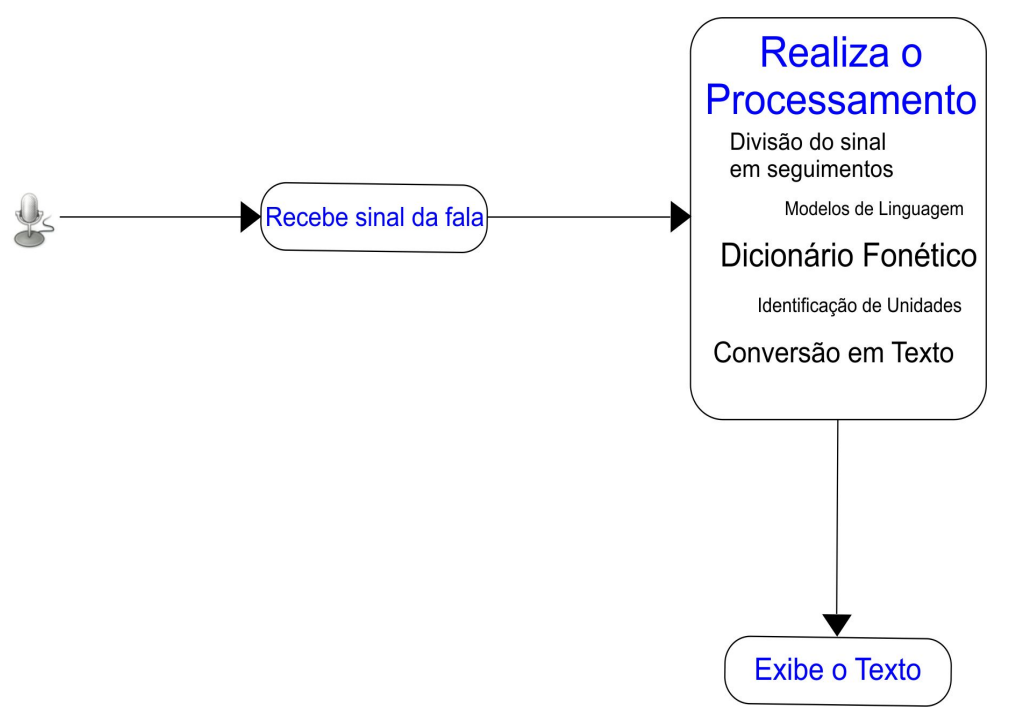

Figura 8 - Atividades de Processamento de Fala

Considerando o TTS as atividade são realizadas de forma "invertida", ou seja: (1) recebe o texto a ser processado, (2)efetua as atividades de processamento, (3) executa o áudio sintetizado resultante do processamento.

\subsubsection{Aplicativos de Processamento de Fala}

Os algoritmos utilizados para processamento de fala se apresentam, na maioria dos casos, de forma complexa, principalmente pela necessidade de treinamento de modelos para realização dos processos de transformação de voz em texto e vice-versa. Visando facilitar a vida de usuários e equipes de desenvolvimento de software, que não tem por objetivo o desenvolvimento e conhecimento de modelos, mas sim de componentes computacionais que permitam a utilização deste recurso para resolução de diversos problemas, surgiram (Application Programming Interfaces) (API’s), ou seja, uma série de funções acessíveis para ambientes de programação (NETO et al., 2010).

Um trabalho desenvolvido no Brasil com resultados relevantes nesta área foi realizado pelo grupo de pesquisa Fala Brasil do Laboratório de Processamento de Sinais (LaPS) da Universidade Federal do Pará (UFPA). A equipe do Fala Brasil, coordenada pelo Prof. Dr. Aldebaro Klautau, desenvolveu uma API na linguagem de programação $C++$ com suporte a Common Language Runtime (CLR) para processamento de fala no idioma Português-Brasileiro. A ferramenta descende da ferramenta Julius, um reconhecedor de fala de alta performance para grandes vocabulários (NETO; PATRICK; KLAUTAU, 2010).

A API recebeu o nome de Coruja e assim como a biblioteca Open $C V$ permite a imple- 
mentação em ambientes de desenvolvimento como Microsoft Visual Studio. Sua principal vantagem está em esconder a plataforma baixa de desenvolvimento, ou seja, algoritmos complexos de treinamento e processamento da fala. Fica a cargo do desenvolvedor que utiliza a API a codificação de métodos de forma prática informando, quando necessário, parâmetros solicitados. Dentre métodos que podem ser acessados estão:

- SREngine: carrega e inicializa o reconhecedor;

- startRecognition: inicia processo de reconhecimento;

- stopRecognition: desliga o reconhecimento;

- OnRecognition: método chamado quando uma sentença é realizada;

- OnSpeechReady: método chamado quando o reconhecedor é ativado.

Uma aplicação completa de exemplo é disponibilizada na página do LaPS, assim como seu código fonte. A aplicação tem por objetivo controlar a apresentação de trabalhos na ferramenta Microsoft Power Point com comandos de voz. Palavras como: Voltar, Próximo, Anterior e Regular são configuradas na aplicação para utilização. Esta aplicação é demonstrada por Neto et al. (2010) o qual apresenta detalhes das configurações e requisitos mínimos de utilização.

O exemplo de Neto et al. (2010) serviu de base para estabelecer a ferramenta de apoio as atividades desta pesquisa. A Figura 9 apresenta cinco linhas de código fonte adaptados do trabalho de Neto et al. (2010) para aplicação no contexto desta pesquisa:

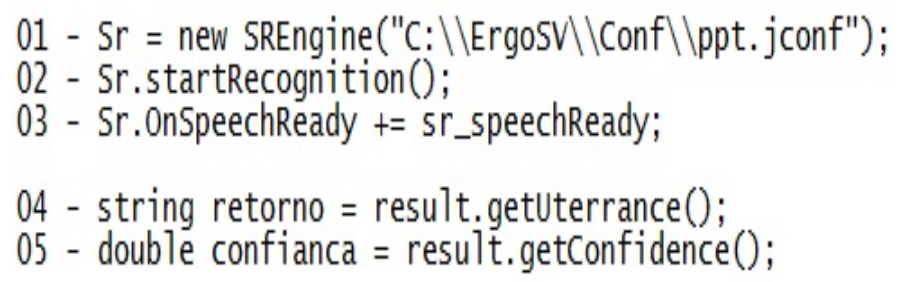

Figura $\mathbf{9}$ - Linhas de código para acesso a funções da ferramenta Coruja

O algoritmo apresentado na Figura 9 realiza, de maneira simples e fácil, o acesso a funções de processamento de fala. As atividades realizadas pelo algoritmo são:

- Linha 01: Indica o arquivo de configuração da ferramenta Julius que contém os modelos acústico e de linguagem; 
- Linha 02: Inicia o motor de reconhecimento de fala;

- Linha 03: Indica a função a ser executada no momento do reconhecimento da fala;

- Linha 04: Grava a palavra reconhecida em uma variável do tipo texto;

- Linha 05: Grava a taxa de confiança (percentual de reconhecimento da ferramenta) em uma variável.

Estes algoritmos foram aplicados na linguagem de programação C\# tanto no trabalho de Neto et al. (2010) quanto no exemplo desta pesquisa.

\subsubsection{Considerações Finais sobre Processamento de Fala}

Em resumo, o processamento de fala, assim como processamento de imagens abrange atividades relevantes que podem apoiar diversas atividades relacionadas à IHC, inclusive a avaliação. Composta por algoritmos complexos e bases de conhecimento que precisam de treinamento são altamente influenciadas por sotaques, gírias e ruídos. Atualmente API's estão surgindo com o intuito de apoiar o processamento de fala e principalmente disponibilizar ferramentas de acesso fácil a métodos de reconhecimento por desenvolvedores.

O processamento de fala é uma importante ferramenta para apoiar atividades de IHC principalmente no aspecto de interação mediada por voz e/ou interfaces multi modais. Seu processamento pode prover recursos de apoio a atividades para pessoas com limitações físicas e permitir uma melhor comunicação entre usuário e máquina. Embora seus algoritmos sejam complexos e requerem um maior tempo de desenvolvimento, ferramentas como o projeto Coruja tem por objetivo facilitar a vida dos desenvolvedores e expandir a utilização de recursos de processamento de fala.

\subsection{Frameworks para Avaliação da Usabilidade}

Está seção apresenta um levantamento bibliográfico realizados para identificar ambientes (frameworks) para apoiar testes de usabilidade que utilizassem processamento de imagens/fala e efetuassem, análise automatizada de dados ou que apresentem contribuições relevantes para a atividade de teste de usabilidade. 


\subsubsection{Revisão Bibliográfica Específica}

Uma pesquisa bibliográfica foi realizada com objetivo de identificar abordagens de avaliação da usabilidade que utilizassem processamento de imagens e reconhecimento de fala ou abordagem que automatizassem o processo de análise e geração de informações.

Esta pesquisa tinha objetivo verificar a existência de trabalhos que se enquadrassem nos seguintes critérios de pesquisa

- Existem ambiente ou frameworks para apoiar a avaliação da usabilidade, mais especificamente teste de usabilidade que utilizam processamento de imagens ou reconhecimento de fala?

- Existem frameworks para apoiar a avaliação da usabilidade, mais especificamente testes de usabilidade que geram informações automatizadas?

A busca destes trabalhos foi realizada em 4 fontes de pesquisas: (1) www.ieee.org na qual foi utilizado o termo "Usability Evaluation Framework and Usability Test"; (2) www.acm.org com o termo "Usability Evaluation Framework"; (3) www.scopus.com utilizando as palavras chave "Usability Evaluation Framework"; (4) www.informaworld.com com os termos "Usability Evaluation Framework".

O total de artigos identificados na primeira revisão são apresentados na Tabela 1. Nesta tabela não foram descartados possíveis artigos repetidos, mas somente uma contagem simples por base de dados a fim de identificar a relevância de cada fonte de pesquisa.

Tabela 1 - Contagem geral de artigos da Revisão Bibliográfica Específica

\begin{tabular}{l|l}
\hline Base de Dados & Quantidade \\
\hline IEEE.org & 49 \\
\hline ACM.org & 29 \\
\hline Scopus.com & 19 \\
\hline InformaWorld.com & 5 \\
\hline
\end{tabular}

Após levantamento inicial, os artigos foram lidos e avaliados por meio de seus abstract. A leitura do abstract tinha por objetivo identificar se o trabalho se encaixava em um dos seguintes critérios de inclusão:

- trabalhos relacionados ao ambientes de avaliação/teste de usabilidade apoiados por processamento de imagens e/ou processamento de fala; 
- trabalhos relacionados ao ambientes de avaliação/teste de usabilidade que geravam informações automatizadas sobre os testes.

Foram descartados trabalhos que tratavam de avaliações de usabilidade de ferramentas e ambientes diversos. Também foram excluídos trabalhos relacionados à geração automatizada de informações, processamento de imagens, reconhecimento de fala e que não estavam relacionados à avaliação/teste de usabilidade. Além da utilização destes critérios de exclusão, foram descartados também artigos relacionados à avaliação da usabilidade para recursos como eletrodomésticos e TV por assinatura e com isso, procurou-se manter o foco em software tradicionais, websites e dispositivos móveis.

A quantidade de artigos selecionados em cada base após leitura do abstract é apresentada na Tabela 2 .

Tabela 2 - Contagem dos artigos incluídos na Revisão Bibliográfica Específica

\begin{tabular}{l|l}
\hline Base de Dados & Quantidade \\
\hline IEEE.org & 7 \\
\hline ACM.org & 2 \\
\hline Scopus.com & 9 \\
\hline InformaWorld.com & 0 \\
\hline
\end{tabular}

Após leitura completa, os artigos foram classificados segundo 3 aspectos:

1. (A1) Artigos que tratavam de Teste de Usabilidade: Resposta: S (Sim), N (Não), NA (Não abordado);

2. (A2) Artigos que abordavam teste de usabilidade apoiados por processamento de imagens e/ou reconhecimento de fala: S (Sim), N (Não), NA (Não abordado);

3. (A3) Artigos que apresentavam abordagens que automatizava a análise e geração dos dados dos testes: S (Sim), N (Não), NA (Não abordado);

A utilização do termo "NA" para o conceito A1 foi aplicada para artigos que não deixaram claro qual a metodologia utilizada (Inspeção ou Teste). Para artigos que deixaram claro a utilização da abordagem da inspeção, os mesmos foram descartados por se enquadrarem em um critérios de exclusão.

Após a leitura completa dos artigos seguida por análise de seus conceitos, abordagens e relevância para esta pesquisa e enquadramento nos critérios de inclusão, foi estabelecida 
uma lista final de artigos sendo ela apresentada na Tabela 3. De todos os artigos analisados, 7 artigos foram considerados adequados aos critérios de inclusão e 11 foram considerados inadequados, sendo o principal fator de descarte tratar ambientes de avaliação da usabilidade utilizando inspeção, ou seja, questionários. Outro fator foi a aplicação de metodologias e técnicas comuns na literatura, sem apresentar nenhuma contribuição, para avaliar a usabilidades de aplicativos específicos.

Os artigos incluídos apresentaram também aplicações, experimentos e resultados de suas respectivas abordagens. Além disto pode-se identificar abordagens para testes com dispositivos móveis, website e aplicativos específicos tais como software para Model Driven Development (MDD). 


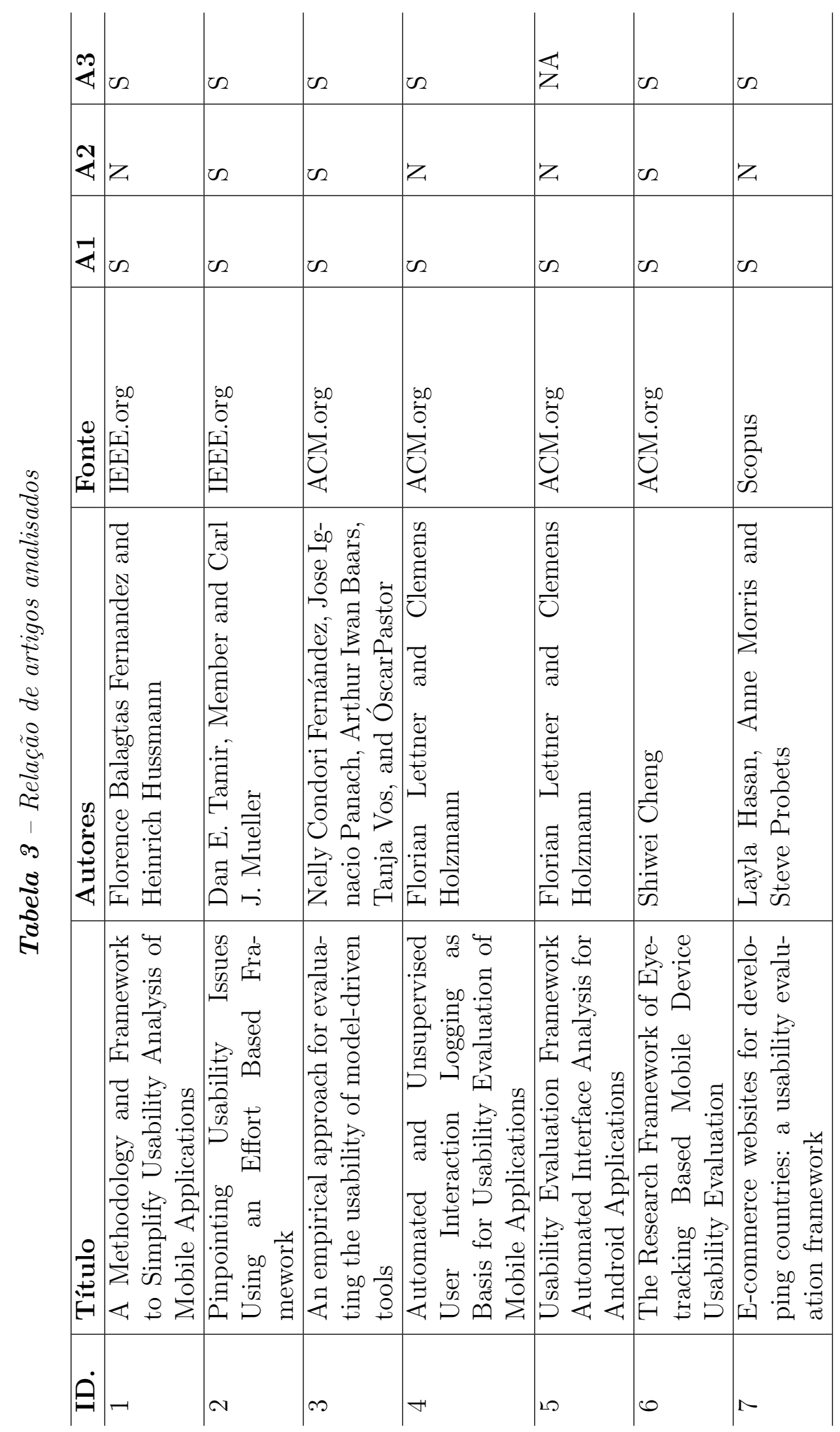


Além dos artigos apresentados na Tabela 3 outros artigos foram incluídos manualmente por apresentarem conteúdos relevantes para esta pesquisa. A lista de artigos incluídos manualmente são mostrados na Tabela 4

Tabela 4 - Relação de artigos incluídos manualmente

\begin{tabular}{l|l}
\hline Título & Autores \\
\hline $\begin{array}{l}\text { A Method for Remote and Semi-Automatic } \\
\begin{array}{l}\text { Usability Evaluation of Web-based Applica- } \\
\text { tions Through Users Behavior Analisys }\end{array}\end{array}$ & $\begin{array}{l}\text { Ariel Vargas, Harold Weffers and Heloísa Vi- } \\
\text { eira da Rocha }\end{array}$ \\
\hline Definition and Prototyping of ErgoMonitor & $\begin{array}{l}\text { Marcelo Morandini and Walter de Abreu Cy- } \\
\text { bis }\end{array}$ \\
\hline $\begin{array}{l}\text { Eye Tracking in Human-Computer Interac- } \\
\text { tion and Usability Research: Ready to Deli- } \\
\text { ver the Promises }\end{array}$ & Robert J.K. Jacob and Keith S. Karn \\
\hline $\begin{array}{l}\text { Eye Tracking in Usability Evaluation: A } \\
\text { Practitioner's Guid }\end{array}$ & Joseph H. Goldberg and Anna M. Wichansky \\
\hline
\end{tabular}

Estes artigos foram incluídos por apresentarem pesquisas com contribuições significativas relacionadas à metodologias ou ferramentas para apoiar a avaliação da usabilidade e o monitoramento do usuário. Dentre as contribuições podemos citar:

- proposta de ambiente para teste de usabilidade remoto;

- aplicativo/ambiente para monitoramento da utilização de website utilizando arquivos de $\log$;

- utilização do dispositivo Eye Tracking (rastreador de olhares) para atividades de IHC, dentre elas, avaliação da usabilidade.

Na próxima sub seção será apresentado um resumo dos resultados da revisão bibliográfica.

\subsubsection{Ambientes de teste de usabilidade}

O desenvolvimento ou melhorias nas abordagens de avaliação de usabilidades relacionadas às técnicas de usabilidade é uma realidade para pesquisadores e desenvolvedores de IHC, principalmente pela adequação a necessidade de conhecer como o usuário interage com o software e como o aplicativo impacta no resultado final da utilização.

Diversas abordagens de avaliação foram desenvolvidas a fim de apoiar e observar as ações dos usuário em um teste de usabilidade e assim identificar características de interação proporcionados pelo software. Dentre as várias melhorias é possível destacar 
ambientes para utilização com IPhones, Tablets e dispositivos móveis em geral, utilização de Eye Tracking (Sistema rastreador de movimentos oculares), filmagem do participante e a consideração das reações emocionais como dados de avaliação. A seguir serão apresentados alguns trabalhos considerados relevantes para esta pesquisa.

\subsubsection{EvaLogger}

Para dispositivos móveis podem ser citados trabalhos como o de Balagtas-Fernandez e Hussmann (2009) que desenvolveram uma técnica de teste de usabilidade baseado em monitoramento por arquivos de logs para dispositivos móveis. Nesta abordagem, um aplicativo de monitoramento chamado EvaLogger é instalado no dispositivo móvel de forma a monitorar todas as ações realizadas por seus usuários. O aplicativo contêm uma classe denominada EvaWriter que processa dos dados coletados e envia os mesmos para um arquivo XML utilizado para geração de dados em gráficos. A classe pode ser estendida para geração de dados em outros formatos desejados, entretanto os autores não detalham os tipos de saída. A Figura 10 apresenta a abordagem de coleta e processamento de dados do sistema EvaLogger.

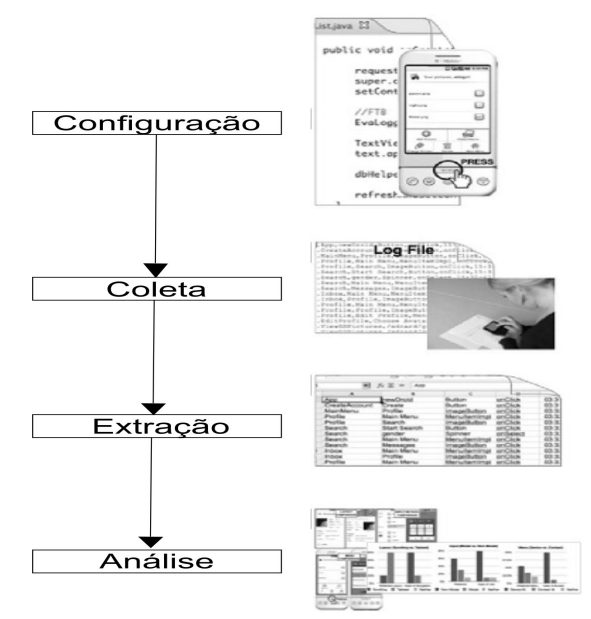

Figura 10 - Abordagem do sistema EvaLogger (BALAGTAS-FERNANDEZ; HUSSMANN, 2009)

Segundo Balagtas-Fernandez e Hussmann (2009), as fases apresentadas na Figura 10 representam as seguintes atividades: A Preparação consiste na configuração do aplicativo para habilitar a coleta de dados necessários para apoiar a avaliação da usabilidade por meio de arquivos log. Nem todos os aplicativo contém recursos para configuração para registros de dados com Log e muitas vezes é necessária uma série de atividades para otimizar esta tarefas, tal como determinar o melhor formato (layout) do arquivo para 
um processo de análise e extração com mais qualidade. A fase de Coleta consiste na realização das tarefas nos dispositivos e em certificar se a aplicação esta registrando todos os dados necessários nos arquivos de log. Já a fase de Extração é uma das mais complicadas, pois se refere a etapa de extração dos dados registrados durante o teste e a transferência para um aplicativo que permita a leitura e análise dos arquivos de Log. Esta fase é considerada delicada, pois pode exigir a manipulação de uma grande quantidade de dados registrados. A última fase, Análise, consiste no estudo dos dados registrados para identificar quais partes do sistema tem problemas de interação.

O processo de análise dos dados no EvaLogger é feita com base em gráficos que apresentam números para gerar métricas diversas. Dentre os dados são apresentadas taxas de acesso a botões, rótulos e demais componentes de interface como forma de avaliar a quantidade de ações e transições de tela. A taxa de aprendizado, eficácia e memorização é tratada utilizando dados de tempo para finalização de tarefas, assim como a simplicidade é medida pelo esforço para realizar as tarefas. As informações dos gráficos são comparadas com a interface atual para verificar se alguma interface não foi utilizada e pode ser removida ou para determinar bons padrões de interface (BALAGTAS-FERNANDEZ; HUSSMANN, 2009).

Outros trabalhos voltados para dispositivos móveis foram realizados por Lettner e Holzmann. Em ambos os trabalhos, (LETTNER; HOLZMANN, 2011, 2012), os autores propõem modelos de monitoramento das atividades dos usuários em dispositivos móveis. Os trabalhos apresentam a utilização de um recurso que pode ser baixado e instalado em aplicativos móveis, com destaque para plataforma Android.

No primeiro trabalho Lettner e Holzmann (2011) apresenta um framework para utilização com Android baseado em injeção de códigos em estruturas bases da codificação Java, tais como entrada e saída de métodos. Esse módulo pode se adaptar de forma relativamente fácil a demais aplicativos da plataforma sem a necessidade de recompilação de grande quantidade de códigos. Além disso, o autor destaca a segurança da aplicação que não tem acesso a dados pessoais do usuário, mas somente a funcionalidades atividades.

No segundo artigo Lettner e Holzmann (2012) destacam o funcionamento da aplicação que é dividida em três estágios: Coleta de dados, módulo instalado no dispositivo móvel que monitora a utilização do participante; Server Backend que contém recursos para recebimento dos dados, análise, processamento e geração de métricas e por último; Web Frontend para visualização e análise por parte de avaliadores.

As métricas geradas pelo aplicativo de Lettner e Holzmann (2012) e disponibilizadas 
para análise foram:

- Contadores: valores simples de contagem de determinadas ações realizadas no dispositivo;

- Relações/Proporções: apresenta a relação de valores coletados dentro de determinados contextos de operação

- Agregação: apresenta valores gerais de utilização e acesso de um software. Está métrica esta relacionada à utilização geral e não com recursos específicos;

- Segmentação: apresentada valores de determinados pontos do sistema em determinado período de tempo pré estabelecido;

- Individual: métricas utilizadas para analisar o comportamento de um usuário em determinado período de tempo

Esses pesquisadores consideraram esta abordagem como eficaz para coleta automatizada de dados e geração de métricas de baixo nível considerando, principalmente, erros de navegação e de comportamento do participante. Como trabalho futuro, os trabalhadores pesquisam para criar uma ferramenta que visa o tratamento e exibição otimizada de informações, assim como a melhora da capacidade de coleta de dados, visando considerar também o comportamento dos participantes.

Os trabalhos apresentados acima apresentaram propostas de frameworks para apoiar testes de usabilidade para dispositivos móveis. O destaque destes modelos é a utilização da abordagem de monitoramento, ou seja, os autores não estão preocupados somente com padrões de qualidade ou guias de padrão de interface, mas também com a capacidade de interação entre usuário e sistema.

A geração de informações pelos sistemas citados pode auxiliar na melhoria de sistemas móveis, algo tão comum na atualidade e que tende a ter sua área de cobertura ampliada.

\subsubsection{Monitoramento por Arquivos de Logs - ErgoMonitor}

O monitoramento de dados não é um recurso exclusivo para dispositivos móveis. Morandini (2002) apresentou uma proposta da utilização de arquivos de log para monitorar o ambiente web e assim gerar métricas para apoiar a avaliação da usabilidade de websites. O autor apresentou a proposta da ferramenta ErgoMonitor que permite a coleta de dados dos servidores no qual são hospedados os websites para posterior análise por ferramentas 
específicas. Cybis, Betion e Faust (2010) e Morandini (2002) apontam a técnica como uma das mais eficiêntes para coleta de dados devido ao baixo nível de intrusividade, pois o usuário não é afetado pelo registro dos dados e muitas vezes não percebe as atividades de monitoramento. Outro fator positivo para este tipo de monitoramento é a capacidade de gerar dados reais, de utilizações verdadeiras em qualquer lugar do planeta. Entretanto, como ponto negativo, os autores apresentam a dificuldade de identificar o comportamento do usuário, considerando que os arquivos de log identificam cliques em botões e rótulos, caminhos de navegação e utilização do website.

\subsubsection{Eye Tracking}

Outro recurso amplamente utilizado para apoiar os testes de usabilidade é o Eye Tracking. Trata-se de um dispositivo computacional que se utiliza de processamento de imagens para identificar e rastrear os movimentos dos olhos. Este dispositivo já era defendido por Jacob (2003) como uma ferramenta para apoiar uma série de atividades em IHC, atividades estas que variam de questões técnicas como avaliação da usabilidade até a utilização para auxiliar na interação de pessoas com deficiência física com computadores. Este recurso também é apresentado por Goldberg e Wichansky (2003) para apoiar a avaliação da usabilidade por permitir identificar exatamente qual o foco de visão do usuário na interface utilizada.

Dois trabalhos com aplicações práticas foram identificados utilizando este recurso. No primeiro trabalho, chamado de Pinpointing, analisado e desenvolvido por Tamir, Member e Mueller (2010) utilizou o Eye Tracking como ferramenta para coleta de dados de um ambiente de avaliação da usabilidade. No segundo trabalho, feito por Cheng (2011) foi utilizado o rastreador de olhar para apoiar avaliação da usabilidade de dispositivos móveis.

Pinpointing: Este ambiente se baseia no esforço do participante para realizar e aprender suas tarefas em um software. Os esforços são classificados pelos autores como esforços mentais e esforços físicos. Enquanto os esforços mentais são apresentados como tempo de fixação do olhar, média do tempo de fixação e número de fixações, os esforços físicos são mostrados como movimentos rápidos dos olhos e movimentos transversais.

A coleta de dados deste ambiente era realizada utilizando três fontes de dados: movimentos do mouse: clicks, rolagem, acionamento de recursos diversos; Ações no Teclado e por último, um Eye Tracking para registrar os dados do movimento dos olhos. Como acréscimo aos dados foram registrados os horários de todas as ações registradas. Segundo Tamir, Member e Mueller (2010) estes dados podem representar os esforços realizados pe- 
los usuários para realizar suas tarefas pois apontam tanto esforços físicos de movimentação dos olhos e acionamento de recursos como esforços mentais de análise de informações.

Como resultado, os autores concluíram que esta abordagem foi eficaz para identificar problemas de usabilidade com base em dados como clicks do mouse, acionamento do teclado e identificação de movimentos oculares. Experimentos realizados mostraram que os dados registrado permitiram a geração de informações que auxiliasse a identificação de problemas de usabilidade, principalmente por permitir a identificação do componente exato que apresentou problemas de usabilidade. Com isto, a abordagem permitiu efetuar comparação entre várias versões de interfaces e entre protótipos e versões completas podendo assim efetuar melhorias. Por fim, a abordagem apresentou dados reais de interação, pois era aplicada a testes de usabilidade realizados por usuários reais em versões de software que seriam utilizados em ambiente de produção(TAMIR; MEMBER; MUELLER, 2010).

Um segundo trabalho utilizando Eye Tracking foi apresentado por Cheng (2011). Neste segundo trabalho o autor utilizou a tecnologia para testar a usabilidade de dispositivos móveis com base em duas abordagens diferentes: utilizando um dispositivo remoto e um dispositivo portátil. Segundo Cheng (2011) o Eye Tracking remoto ou Remote EyeTracking é um dispositivo de rastreamento de olhar posicionado ao lado de um monitor para registrar os movimentos em um posicionamento semelhante a uma webcam. O Eye Tracking portátil ou Portable é um dispositivo que funciona acoplado ao usuário de forma semelhante a um óculos e o mesmo contem os recursos necessários para o rastreamento de olhar.

Dois experimentos foram realizados para avaliar dispositivos móveis, um com cada tipo de dispositivo. Entretanto, o Eye Tracking remoto foi aplicado aos experimentos com emuladores e o dispositivo portátil foi utilizado em um teste com dispositivos móveis reais. Os testes foram realizados focando em tarefas relacionadas à seleção, execução e manutenção de arquivos de músicas.

Foram registrados dados quantitativos para a primeira abordagem (simulador) que permitiu a criação de informações como tempo de fixação em determinadas tarefas, tempo de atenção para cada tarefa e movimentos oculares. Com estes dados, o avaliador também efetuou comparações entre testes de participantes diferentes a fim de verificar o comportamento dos mesmos durante a utilização e as taxas de fixação e realização de tarefas.

Já com o dispositivo portátil, foram coletados dados qualitativos que permitiram a identificação de comportamentos errados do participante, por exemplo. Em determinadas 
tarefas o tempo de fixação foi alto e os dados do Eye Tracking mostraram que o mesmo olhava para uma posição errada da tela e por esse motivo não encontrava o recurso desejado.

Este trabalho é concluído apresentando as vantagens de cada tipo de teste, sendo o teste remoto melhor para identificação de problemas em fase de projeto pois permite que o mesmo seja efetuado em simuladores e permite gerar dados quantitativos para uma analise com mais qualidade. Entretanto, Cheng (2011) aponta o fato de que este tipo de teste é ideal para análise de interfaces de forma isolada ou única. Para testes com alternância entre várias interfaces o mesmo pode apresentar dados difíceis de serem analisados. Já o segundo teste apresentou a vantagem de permitir o monitoramento do comportamento do usuário com o software em dispositivo real e em ambiente real permitindo assim identificar problemas de interação. Como ponto negativo desta forma de teste esta a necessidade de utilizar o dispositivo bem próximo aos olhos para que o Eye Tracking possa atuar de forma efetiva e o incomodo que o uso em excesso do dispositivo pode causar.

Em demais casos, abordagens de teste de usabilidade foram apresentadas com objetivo específico de avaliar determinadas categorias de aplicativos tais como E-commerce ou Model Driven Development.

\subsubsection{Avaliação para E-Commerce}

O trabalho de Hasan, Morris e Probets (2013) teve como objetivo o desenvolvimento de uma nova abordagem de avaliação da usabilidade. Esta nova abordagem foi criada com base em 3 já existentes: Monitoramento por meio do Google Analytics, Teste/Observação por meio de Filmagem e Avaliação Heurística.

Os testes foram realizados utilizando websites de comércio eletrônico de origem do país da pesquisa. As três técnicas citadas anteriormente foram utilizadas considerando que, a princípio, necessitava de uma análise dos resultados de cada uma delas. Segundo os autores os resultados das avaliações em cada abordagem foram:

Monitoramento por Google Analytics (GA): Esta abordagem de avaliação proveu dados importantes que foram considerados potenciais problemas de usabilidade. O aplicativo classificou os dados em 6 áreas distintas: navegação, conteúdo, arquitetura, ferramentas de busca, serviços para cliente e valor de serviços. Duas métricas se destacaram entre os avaliadores: quantidade de visitantes e valores financeiros tratados nos websites. Entretanto, as questões apontadas como possíveis problemas de usabilidade não permitiram 
aos avaliadores se aprofundarem e relacionar tal informação com determinados contextos de operação do usuário (HASAN; MORRIS; PROBETS, 2013).

Testes e Observação X Heuriticas: Segundo Hasan, Morris e Probets (2013) as Heurísticas permitiram a identificação de um número maior de problemas de usabilidade. Porém, os mesmos foram classificados como problemas pequenos e de menor relevância. Os testes permitiram aos avaliadores identificar problemas de maior relevância, por exemplo, quando um usuário efetuava uma tarefa com erro e não tinha condições de abortar a atividade.

Com base nos resultados, Hasan, Morris e Probets (2013) criaram uma abordagem de avaliação que posiciona em, sequência, todas as abordagens comumente utilizadas para avaliar a usabilidade. Os passos da abordagem são apresentados na Figura 11.

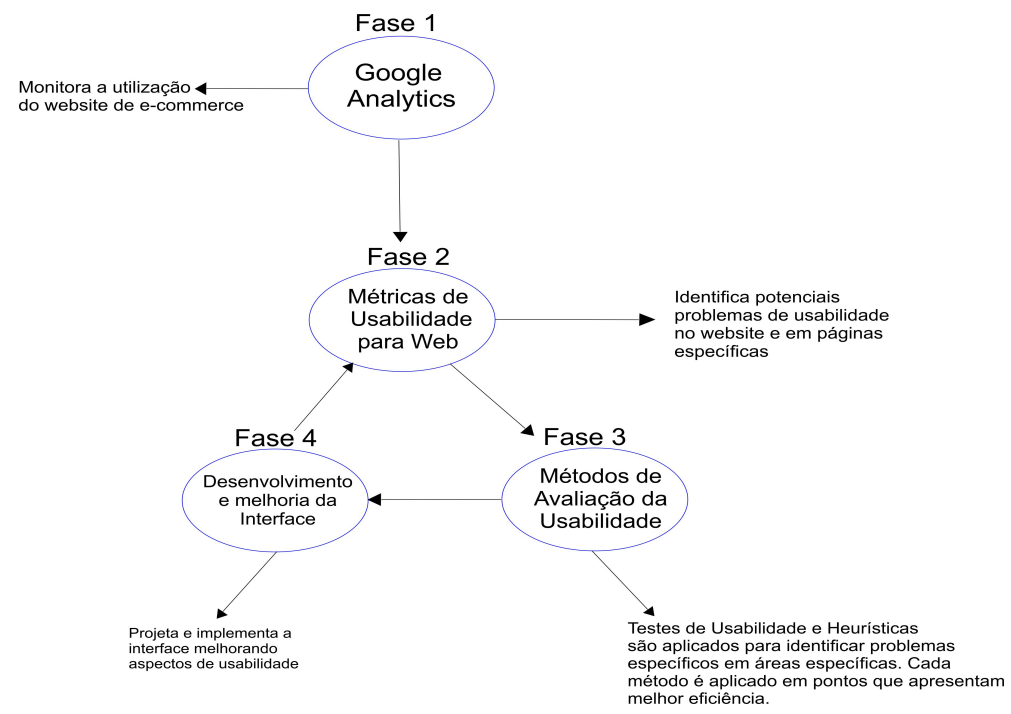

Figura 11 - Abordagem de Avaliação da Usabilidade de Hasan, Morris e Probets (2013)

Os autores apontaram a técnica como satisfatória e detalharam que as técnicas permitiram identificar problemas de usabilidade de pontos de vista diferentes. Para avaliação inicial, o monitoramento realizado pela ferramenta GA permitiu identificar, de forma ágil e rápida, páginas e pontos nos quais o usuário teve problemas de interação. Identificado pontos da interface com possíveis problemas, a aplicação das heurísticas em conjunto com testes de usabilidade permitiram identificar de forma detalhar quais os problemas de usabilidade e assim aplicar correções específicas para cada situação.

\subsubsection{Modelo de Avaliação da Usabilidade para Model Driver Development}

Um outro trabalho, desenvolvido por Fernández et al. (2012), mostrava o uso de uma abordagem empírica para avaliação da usabilidade de sistema para Model Driven Develop- 
ment (MDD), ou, Desenvolvimento Baseado em Modelos (português). Nesta abordagem, os autores realizaram testes de usabilidade em ferramentas de MDD utilizando uma série de participantes com habilidade diferentes que realizaram atividades diferenciadas.

Neste experimentos os participantes foram classificados em 3 níveis: Novatos, Intermediários e Especialistas. As hipóteses dos trabalhos foram: os participantes realizariam suas atividades com eficiência independente do nível de complexidade e; os participantes alcançariam a solução ótima independente do nível do usuário e complexidade.

Os testes deste ambiente foram realizados utilizando a ferramenta Noldus, disponível em (http://www.noldus.com), a fim de registrar imagens do usuário e de suas expressões faciais e identificar se as tarefas foram efetuadas por completo além do tempo para realização destas atividades. Para analisar as expressões faciais foram utilizados 16 emocards, cartões que continham imagens de expressões faciais masculinas e femininas, ou seja, havia 8 imagens de expressões masculinas e 8 de expressões femininas. A Figura 12 apresenta uma adpatação do modelo de cartão de expressões apresentado por Fernández et al. (2012).

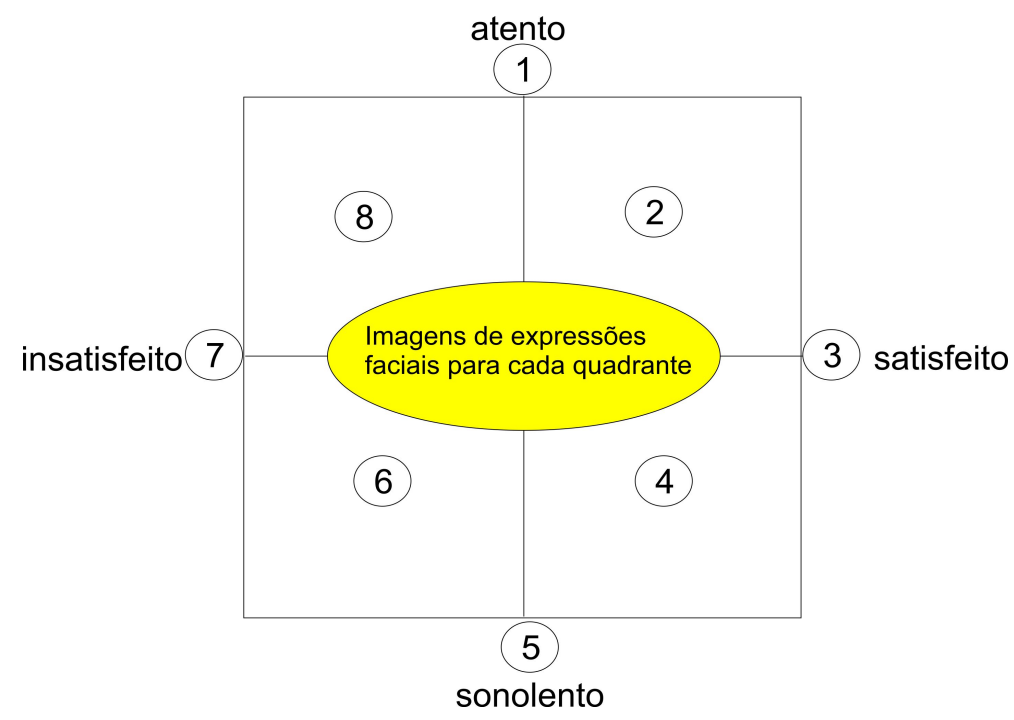

Figura 12 - Modelo de Cartão de emoções de Fernández et al. (2012)

Na Figura 12 é possível perceber que as emoções foram classificadas em quadrantes, sendo os 2 superiores relacionados às emoções nas quais as pessoas se apresentam mais ativas. Nos quadros inferiores, são consideradas as expressões classificadas como "sonolentas" e por fim, as expressões neutras que se posicionam como um divisor dos quadrantes. De forma lateral, as emoções foram classificadas como "Satisfatórias" e "Insatisfatórias". Com base neste conceito e nos números apresentados na Figura 12 as imagens faciais apresentadas nos quadrantes se referiam a: 
1. Atento e Reação Neutra;

2. Atento e Reação Satisfatória;

3. Exitação média e Satisfatória;

4. Sonolência e Satisfatória

5. Sonolência e Reação Neutra;

6. Sonolência e Insatisfação;

7. Exitação Média e Instatisfatória;

8. Atento e Insatisfação.

No cartão eram apresentadas figuras que representavam expressões masculinas e femininas para cada quadrante e tipo de expressão disponibilizada.

Como resultado geral da avaliação da ferramenta, os autores concluíram que o nível de complexidade versus o nível de qualificação do participante afetou significativamente os valores dos resultados. Os usuários mais experientes demoraram mais para realizar as tarefas, porém, realizaram as mesmo com maior completitude, enquanto usuários intermediários e novatos apresentaram taxas inferiores de conclusão das tarefas. Para tarefas simples, a diferença é menor, entretanto, para tarefas complexas, a diferença é muito grande conforme mostram os gráficos da Figura 13.
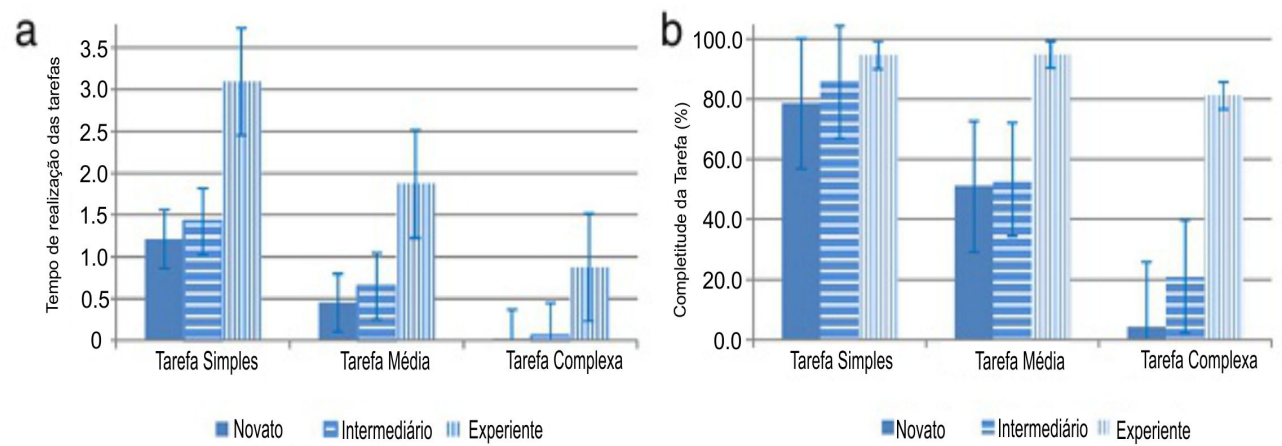

Figura 13 - Resultados dos experimentos de Fernández et al. (2012)

Segundo Fernández et al. (2012), o aplicativo de monitoramento apoiou a coleta de dados que levaram a geração dessas estatísticas. 
Em relação à analise de emoções, além da filmagem, os participantes receberam 1 emocard por tarefa e para cada atividade deveria apontar no emocard qual a reação que melhor se adequava a opinião dele. No final dos experimentos os resultados foram contados e agrupados por tarefa e expressão e gerou os gráficos apresentados na Figura 14.
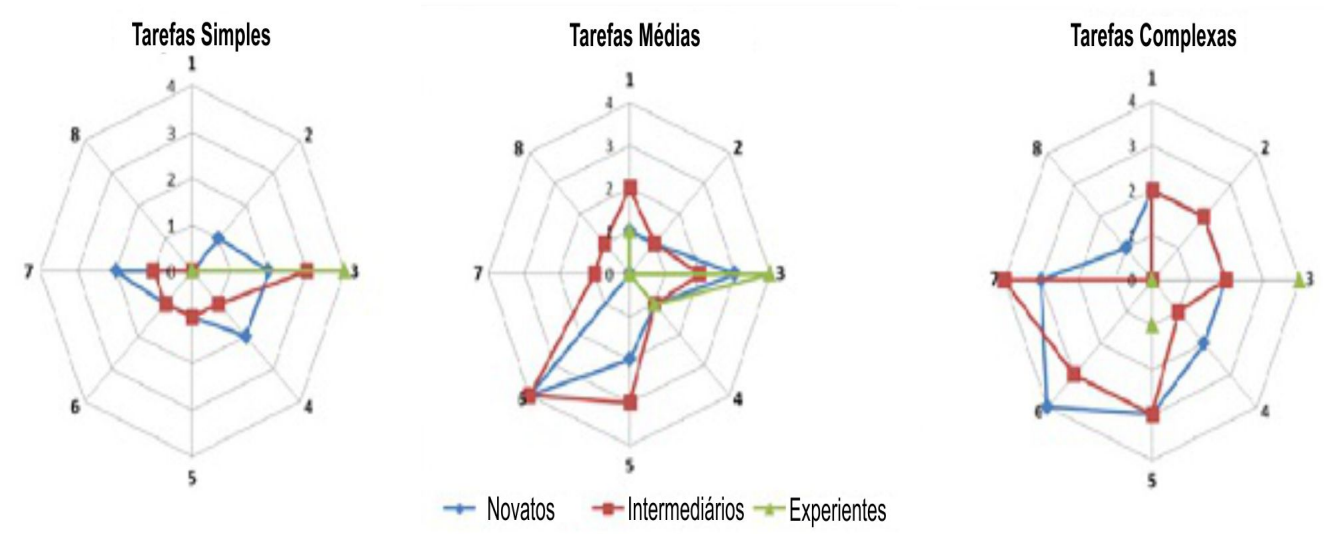

Figura 14 - Resultados da análise de emoções de Fernández et al. (2012)

Como pode ser visualizado na Figura 14 para os três níveis de tarefas (simples, médio e completo) as reações emocionais dos participantes ficaram no quadrante inferior o que indica uma maior índice de tarefas que levaram a situações de sonolência. Entretanto, para tarefas simples os participantes se mostraram relaxados e de certa forma, satisfeitos, situação contrária para tarefas médias e difíceis nas quais os participantes se mostraram calmos, porém insatisfeitos.

A abordagem utilizada permitiu a identificação de problemas de usabilidade nas 18 tarefas executadas. Os problemas foram classificados de acordo com os Critérios Ergonômicos: Condução, Carga de Trabalho, Controle de Usuário, Adaptabilidade, Gerenciamento de Erro, Consistência e Significado de códigos. A Tabela 5 apresentada por Fernández et al. (2012) relaciona os problemas de usabilidade identificados e suas respectivas quantidades classificadas pela complexidades das tarefas nas quais os problemas foram encontrados.

Por fim, os avaliadores compararam os resultados da abordagem com os resultados obtidos separadamente por meio de uma inspeção utilizando os Critérios Ergonômicos. A abordagem permitiu identificar todos os defeitos encontrados pela inspeção com os Critérios Ergonômicos e em maior quantidade. Um percentual pequeno de defeitos foi encontrado somente pelos Critérios Ergonômicos ou somente pela abordagem, conforme mostra a Figura 15 também de Fernández et al. (2012). 


\begin{tabular}{l|l|l|l}
\hline Critério & Simples & Médias & Complexas \\
\hline Condução & 5 & 3 & 2 \\
\hline Carga de Trabalho & 2 & 2 & 0 \\
\hline Controle de Usuário & 0 & 1 & 0 \\
\hline Adaptabilidade & 2 & 1 & 0 \\
\hline Gerenciamento de Erros & 2 & 4 & 1 \\
\hline Consistência & 2 & 2 & 0 \\
\hline Significado de códigos & 2 & 2 & 1 \\
\hline
\end{tabular}

Tabela 5 - Problemas identificados pela abordagem de Fernández et al. (2012)

Como resultado final, além de problemas identificados na ferramenta de MDD, o trabalho apresenta a abordagem como eficiente e rápida para apoiar testes de usabilidade nesta categoria de software. A utilização dos emocards e a forma como os mesmos permitiram classificar as emoções de todos os participantes (Novatos, Intermediários e Experientes) em cada tarefa foi considerado pelos autores como o ponto forte desta técnica de teste de usabilidade.

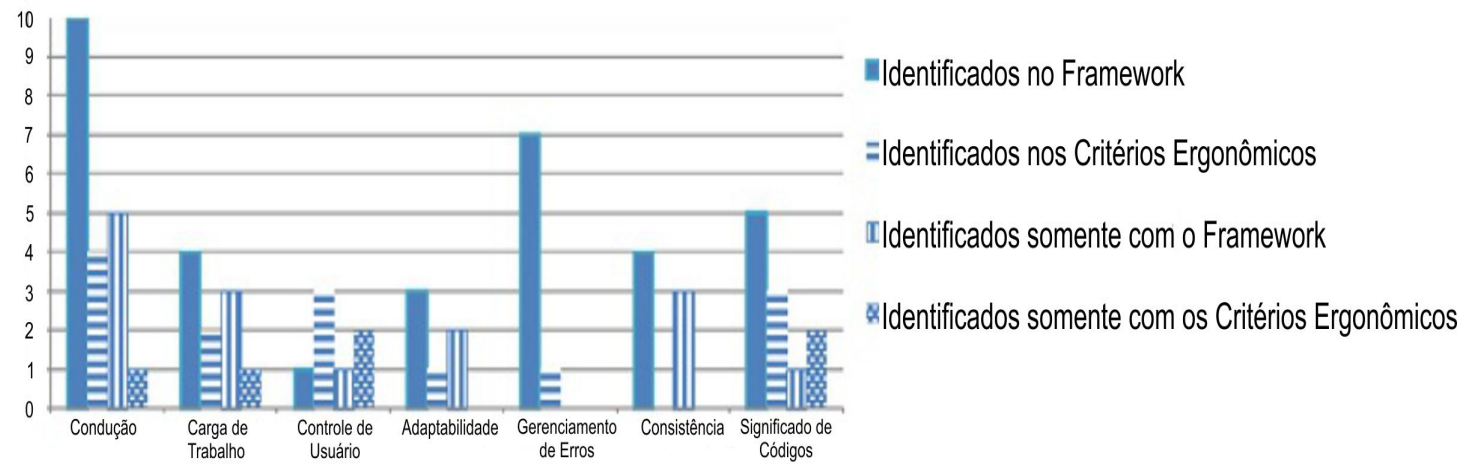

Figura 15 - Comparação dos resultados da abordagem de Fernández et al. (2012) com os Critérios Ergonômicos

\subsubsection{Considerações Finais sobre Ambientes de Avaliação}

Por fim, o uso de abordagens diversas para apoiar testes de usabilidade e monitorar a utilização de um sistema por seu usuário está se destacando dentro de projeto de avaliação da usabilidade. Abordagens e ambientes de teste que utilizam recursos como registro de imagens, Eye Tracking, registro de voz e coleta de dados de utilização por meio de arquivos de logs puderam ser identificados nesta pesquisa.

Entretanto, não foi possível identificar trabalhos que utilizassem, em conjunto, reconhecimento facial e reconhecimento de fala com objetivo de gerar informações que possam reduzir o tempo de identificação de possíveis problemas de usabilidade e assim agilizar o 
processo de análise e tomada de decisões em relação à qualidade da interface.

\subsection{Ferramentas de Avaliação da Usabilidade}

No inicio das atividades da pesquisa foram realizadas buscas por ferramentas que auxiliam a avaliação da usabilidade. As pesquisas bibliográficas com objetivo de realizar levantamento de dados a respeito de IHC, usabilidade e sistemas interativos, automaticamente remeteram a sistemas computacionais utilizados para a avaliação.

Algumas ferramentas foram localizadas e, dentre elas, três foram selecionadas devido a relação com o tema da pesquisa. Estas ferramentas foram desenvolvidas por pesquisadores e/ou empresas com objetivo de apoiarem o monitoramento da avaliação, ou seja, são ferramentas utilizadas em técnicas de observação do usuário. As três ferramentas escolhidas foram:

- Morae: Sistema para observação de interação do usuário com o sistema;

- ErgoManager: Ambiente gerenciador de Interfaces com o usuário, subdividido em:

- ErgoMonitor: Sistema de Monitoramento de Atividades em websites

- ErgoCoin: Sistema de avaliação da Usabilidade por listas de inspeções

\subsubsection{Morae}

O aplicativo Morae é apresentado por Cybis, Betion e Faust (2010) como exemplo de aplicativo para técnicas de avaliação com base na observação do usuário. Este aplicativo está disponível em http://www.techsmith.com/morae-features.html. Sua distribuição não é gratuita, porém, pode ser adquirida uma versão para teste sem custo por um período de 30 dias.

O sistema Morae é composto por três ferramentas distintas que realizam tarefas diferentes, são elas:

Morae Recorder, aplicativo administrativo que permite aos avaliadores estabelecerem as características dos testes, dentre elas, tipo de avaliação, recursos que serão armazenados, tarefas executadas, marcadores diversos, cenários de uso e instruções gerais. O Morae permite armazenar tanto a imagem da webcam quando as palavras pronunciadas e captadas pelo microfone da aplicação. Devido a isso, o administrador pode configurar a melhor 
maneira de trabalhar com estes dois recursos. Para iniciar uma avaliação, o responsável deve criar um arquivo contendo as características configuradas e este arquivo será acessado pelo computador da avaliação. A Figura 16 apresenta duas telas de configuração de atividades no Morae.

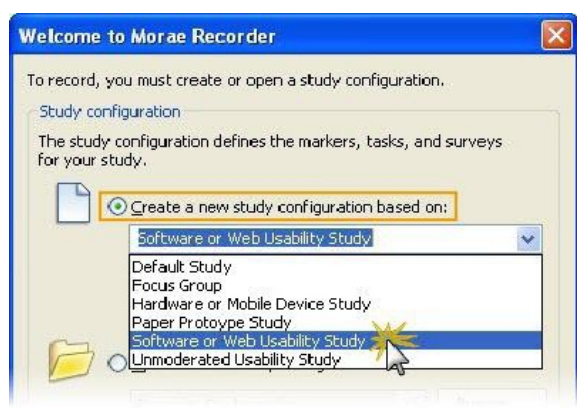

(a) Configuração de Estudo no Morae

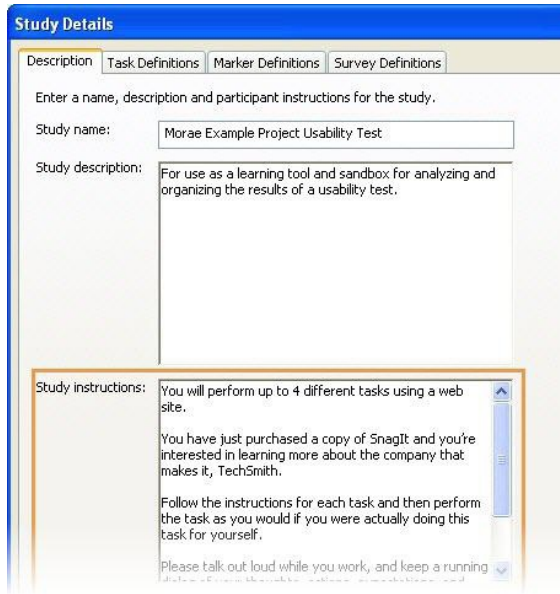

(b) Definição de Cenários no Morae

Figura 16 - Configuração de testes para o aplicativo Morae

Morae Observer é o aplicativo chave para o funcionamento do Morae pois esta ferramenta é instalada no principal computador empregado para a avaliação e por meio de uma rede se conecta ao computador do Morae Recorder. Empregando o Recorder o usuário poderá efetuar marcações, parar e recomeçar a avaliação, criar comentários que são enviados para a equipe de avaliação. Anotações e marcações podem ser inseridas pela equipe de observação quando achar necessário. Estes dados são registrados em arquivos de logs que posteriormente auxiliarão na tomada de decisões sobre a interatividade da aplicação. Os arquivos são enviados para a equipe de observação, porém, o avaliador pode ter uma cópia em sua máquina para conferência imediata. A Figura 17 apresenta a interface do componente Morae Observer.

Morae Manager é o aplicativo para análise e geração de informações com base nos dados coletados pelo Observer. Os arquivos de logs são importados para o Manager sem causar danos aos dados originais, ou seja, os dados são copiados do arquivo do Observer para dentro do sistema Manager. Para efetuar a análise o avaliador deve criar um projeto no qual podem ser trabalhados um ou vários arquivos do observador. Isso ocorre porque um avaliador pode necessitar utilizar várias pessoas para utilizar o software ou avaliar em várias fases diferentes necessitando unir estes dados posteriormente.

O Morae Manager permite a confecção de gráficos com base nos dados da avaliação. 


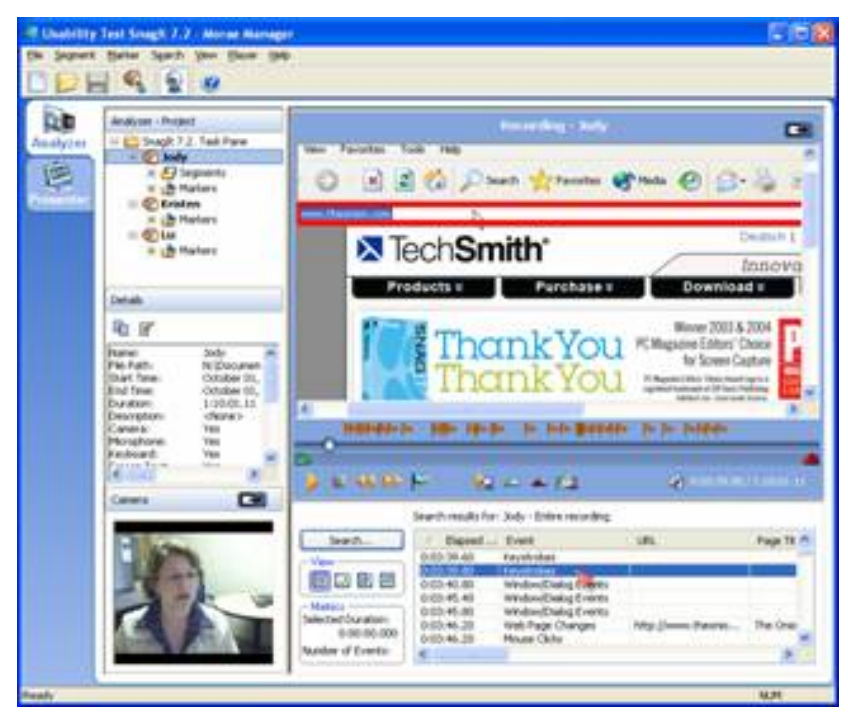

Figura 17 - Tela do aplicativo Morae Observer http://www.techsmith.com

A avaliação permite mensurar informações como:

- tempo de tarefa: apresenta informações quantitativas sobre o tempo médio para realização de uma determinada atividade;

- Mouse Clicks: indica a quantidade de clicks disparados pelo mouse;

Os dados coletados tais como imagens do usuário e da tela e os sons coletados permitem aos observadores mensurarem dados como:

- sucesso na realização das tarefas: apresenta se os usuários alcançaram ou não o sucesso na realização das tarefas, onde ocorreu, se foi realizada com sucesso, fracasso e por que;

- aprendizagem: se a tarefa for realizada mais de uma vez, se a mesma ocorreu em pouco tempo e com poucos erros;

- satisfação: aponta a satisfação do usuário antes, durante e depois da avaliação;

- movimentos do mouse: indica a distância entre movimentos do mouse;

- caminho da tarefa: compara o caminho efetuado por um usuário a um caminho pré-definido.

Em resumo, o sistema Morae é um sistema que apóia a avaliação da usabilidade com base na observação do usuário. O aplicativo disponibiliza recursos de vídeo, sons além 
de registrar dados da avaliação em arquivos de logs. Porém, diferente de sistema de monitoramento por log files o Morae registra dados inseridos pelos usuário da aplicação e não a coleta automática. Um componente gerador de relatórios permite aos avaliadores gerar informações com base nos arquivos de logs além de permitir a geração de gráficos.

Embora o Morae se apresente como uma ferramenta para observação do usuário em si o mesmo ignora a coleta e utilização de imagens faciais e palavras pronunciadas como critério de avaliação, mas utiliza estes recursos coletados de forma natural, ou seja, não é inserida nenhuma técnica de processamento de imagem ou fala.

A seguir serão apresentadas duas ferramentas desenvolvidas por pesquisadores que incluem pesquisadores da Escola de Artes, Ciências e Humanidades da Universidade de São Paulo (EACH-USP): ErgoMonitor e ErgoCoin.

\subsubsection{ErgoMonitor}

O ErgoMonitor é uma ferramenta de avaliação da usabilidade de websites que se utiliza de logfiles ou arquivos de logs. Os arquivos contem dados relacionados à utilização do website por parte do usuário (CYBIS; SCAPIN; MORANDINI, 2005; MORANDINI, 2002).

A coleta de dados é silenciosa, seletiva e muitas vezes imperceptível ao usuário e por isso é considerada uma técnica de baixa interferência no processo de avaliação (MORANDINI, 2002).

Os dados coletados permitem ao avaliador gerar informações sobre os níveis intermediários de usabilidade de uma um website. As informações são consideradas médias porque as medidas podem variar de acordo com o contexto de operação do sistema, potência da Internet, nível de conhecimento de informática e negócio por parte do usuário (CYBIS; SCAPIN; MORANDINI, 2005).

Segundo Cybis, Scapin e Morandini (2005), o principal objetivo do ErgoMonitor é ajudar desenvolvedores e gerentes de websites a enfrentar um grande desafio: assegurar a usabilidade constante das interfaces mesmo com as frequentes mudanças e atualizações de informações e funções de forma simples, objetiva, barata e pouco intrusiva para o usuário.

Morandini (2002), responsável pela proposta desta ferramenta, afirma que o objetivo do ErgoMonitor é a coleta de dados diretamenta das interações em websites e por meio delas produzir taxas e métricas de usabilidade que devem ser comparadas, em sequencia, com taxas relativas a boas e más práticas em websites semelhantes ao avaliado. O Ergo- 
Monitor permite a produção de relatórios quantitativos e apóia uma interação entre estes e relatórios qualitativos. A ferramenta auxilia na confirmação de informações qualitativas elaboradas préviamente ou na geração de novos insumos deste genero.

A Figura 18 apresenta a abordagem da ferramenta ErgoMonitor.

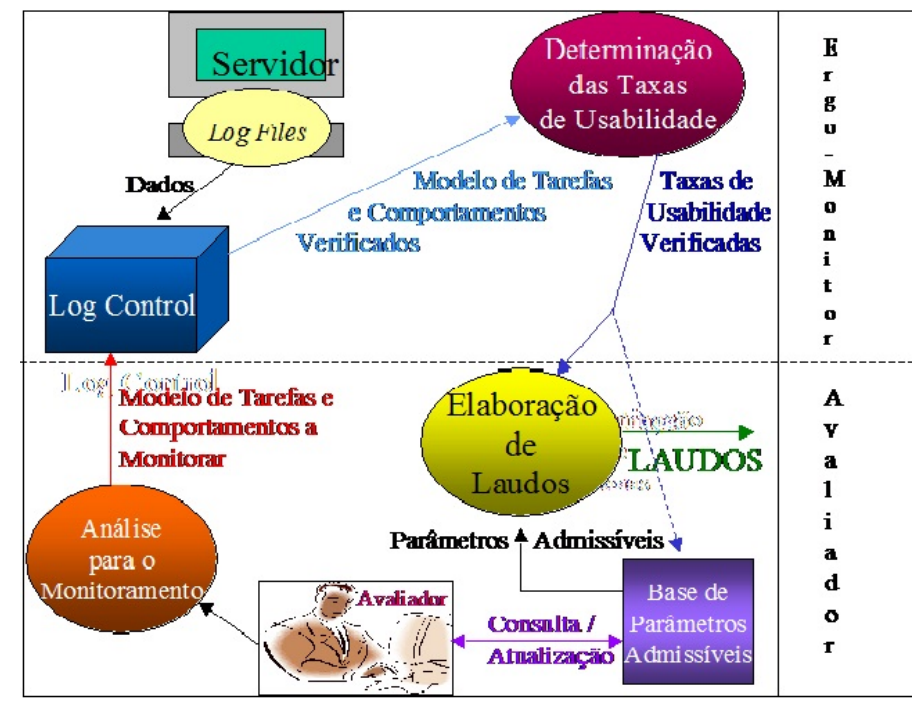

Figura 18 - Abordagem do sistema ErgoMonitor (MORANDINI, 2002)

Portanto, o ErgoMonitor é uma ferramenta desenvolvida com o objetivo de coletar dados sobre a interação do usuário com um website de forma segura e pouco intrusiva permitindo ao avaliador gerar quantitativos apoiando assim relatórios qualitativos. Por ser um ambiente de pouca interferência na interação, o aplicativo tem como ponto forte a capacidade de não interferir nos dados da avaliação, pois o participante não percebe que está sendo monitorado não causando constrangimentos ou interrupções aos participantes. O baixo custo da avaliação é outra característica positiva, pois evita a obrigatoriedade da presença de um participante in loco em laboratórios de avaliação economizando com deslocamento e infraestrutura.

\subsubsection{ErgoCoin}

O ErgoCoin é uma ferramenta desenvolvida para apoiar a elaboração de relatórios qualitativos. Este componente se baseia em uma técnica de avaliação chamada de Inpeção por Lista de Verificação. Este sistema foi desenvolvido atendendo a questões como: o desenvolvimento de website cresce de maneira acelerada levando a um grande número de desenvolvedores muitas vezes, não especialistas em usabilidade e ergonômia de software e o curto período de tempo e custo disponíveis para o desenvolvimento das aplicações 
(MORANDINI et al., 2011).

O sistema foi construído sustentado por uma base de conhecimento composta por questões sobre ergonomia e qualidade de interfaces, questões estas, que devem ser aplicadas a usuários e projetistas por meio de questionários fechados. A aplicação deste questionário deve ser realizada utilizando um website já desenvolvido e em operação com usuários reais. São necessários, também, projetistas com tempo disponível para realização das tarefas. A base de conhecimento foi elaborada com base nos trabalhos de Scapin e Bastien (CYBIS; SCAPIN; MORANDINI, 2005).

A ferramenta implementa as três abordagens determinadas pelos autores como pilares para avaliação utilizando o ErgoCoin. As abordagens se baseiam nas etapas de Análise Contextual que se trata de questionários aplicados a usuários e projetistas a fim de identificar características do contexto do website úteis para as inspeções. A estapa de Inspeção Avaliativa prevê uma comparação entre as informações fornecidas pelos usuários e projetistas com as interfaces avaliadas. Por último a etapa de Documentação refere-se a elaboração de documentos reportando apenas as discordâncias e desconformidades verificadas (CYBIS; SCAPIN; MORANDINI, 2005).

Em resumo, o ErgoCoin se apresenta como uma ferramenta para coleta de dados para avaliação ergonômica de baixo custo e complexidade voltado para a metodologia de inspeção por listas de verificação que podem ser utilizadas por desenvolvedores não especialistas em usabilidade.

O próximo capítulo apresenta as atividades relacionadas ao desenvolvimento da abordagem e da ferramenta proposta nesta pesquisa.

Esta pesquisa foi desenvolvida com objetivo de prover uma abordagem de teste de usabilidade apoiada por técnicas de processamento de imagens e reconhecimento de fala para apoiar as atividades de análise de dados e na geração de informações sobre um teste de usabilidade reduzindo o tempo de estudo e tomada de decisão. Para isso, foi desenvolvida uma ferramenta que continha recursos para execução da abordagem proposta e foi batizada de $\operatorname{ErgoSV}$ e dividia em três módulos: Coleta, Pré-Processamento e Análise.

O processo de desenvolvimento dessa abordagem e da ferramenta foi dividido em quatro etapas: Definição da Estrutura do Sistema, Coleta de dados e Validação/Análise Final dos Dados.

As próximas seções e subseções apresentarão detalhes do desenvolvimento da aplicação e dos experimentos para validação assim como seus resultados. 


\section{Capítulo 3}

\section{Metodologia de Pesquisa}

Esta pesquisa foi desenvolvida com objetivo de prover uma abordagem de teste de usabilidade apoiada por técnicas de processamento de imagens e reconhecimento de fala para apoiar as atividades de análise de dados e na geração de informações sobre um teste de usabilidade reduzindo o tempo de estudo e tomada de decisão. Para isso, foi desenvolvida uma ferramenta que continha recursos para execução da abordagem proposta e foi batizada de $\operatorname{ErgoSV}$ e dividia em três módulos: Coleta, Pré-Processamento e Análise.

O processo de desenvolvimento dessa abordagem e da ferramenta foi dividido em quatro etapas: Definição da Estrutura do Sistema, Coleta de dados e Validação/Análise Final dos Dados.

As próximas seções e subseções apresentarão detalhes do desenvolvimento da aplicação e dos experimentos para validação assim como seus resultados.

\subsection{Definição da Estrutura do Sistema}

O objetivo desta pesquisa foi o desenvolvimento de uma abordagem de teste de usabilidade com técnicas de processamento de imagens e reconhecimento de fala para apoiar atividades de aquisição de dados, identificação de problemas de usabilidade e geração de informações básicas. Esta pesquisa foi possível somente com o uso de um (software) desenvolvido especificamente para este trabalho.

O primeiro desafio do processo de desenvolvimento das aplicações foi o de identificar e selecionar as ferramentas e componentes para serem utilizadas no sistema. Considerando esta necessidade e ciente de que o objetivo da pesquisa não era o desenvolvimento ou melhoria de novos recursos para processamento de imagens e/ou processamento de fala, iniciou-se um trabalho a fim de identificar e testar recursos computacionais (software) que poderiam ser utilizados na implementação e permitissem a execução das atividades da pesquisa sem a necessidade de implementar novos e complexos algoritmos. Além de recursos de imagens e fala, foram analisados também três ambientes de desenvolvimento a fim de escolher qual plataforma e linguagem de programação que seriam empregadas. 
As ferramentas e recursos escolhidos são apresentados nas seções seguintes.

\subsubsection{Componentes para o desenvolvimento da aplicação}

Nesta seção serão apresentadas as atividades realizadas para escolha dos componentes e ferramentas selecionadas para implementação do aplicativo $\operatorname{ErgoSV}$ e os critérios que levaram a escolha das mesmas.

\subsubsection{Ambiente de Desenvolvimento e Linguagem de Programação}

O ambiente de desenvolvimento escolhido foi o Microsoft Visual Studio na sua versão Express e a linguagem de programação foi o C Sharp (C\#). Os recursos apontados são distribuídos pela Microsoft na versão completa utilizando licença paga, porém o ambiente na versão Express é disponibilizado com licença gratuita (CAMACHO, 2008).

A escolha do Microsoft Visual C\# Express se deu devido a três fatores principais: (1) a ampla quantidade de recursos disponibilizados que apoiariam de forma eficiente o desenvolvimento da pesquisa; (2) a integração da ferramenta com componentes selecionados para apoiar o reconhecimento facial e o reconhecimento de fala apresentados nas próximas seções deste capítulo; (3) o bom conhecimento da linguagem de programação que otimizaria o processo de desenvolvimento da aplicação.

A aquisição das ferramentas foi feita por meio de download dos instaladores no site http://www.microsoft.com/visualstudio/ptb/products/visual-studio-express-products na versão 2008.

Na próxima seção serão apresentadas as atividades de teste e seleção da ferramenta Coruja, utilizada para apoiar o reconhecimento de fala.

\subsubsection{Projeto Coruja - Projeto Fala Brasil}

O Projeto Fala Brasil é um trabalho do grupo de pesquisa Fala Brasil do Laboratório de Processamento de Sinais (LaPS) da Universidade Federal do Pará (UFPA) que atua em pesquisas relacionadas ao processamento de sinais. Diversas aplicações foram e estão sendo trabalhadas por essa equipe. Dentre elas projetos relacionados ao framework de processamento de fala no padrão Speech To Text (STT) ou Fala para Texto (TTS) para o português brasileiro.

A equipe do Fala Brasil, coordenada pelo Prof. Dr. Aldebaro Klautau, desenvolveu 
uma ferramenta, chamada de Coruja, na linguagem de programação $\mathrm{C}++$ com suporte a Common Language Runtime (CLR), ou seja, com capacidade de integração com linguagens de programação suportadas pela Microsoft, para processamento de fala no idioma Português-Brasileiro. A ferramenta disponível em http://www.laps.ufpa.br/falabrasil/ descende da ferramenta Julius disponível em(http://julius.sourceforge.jp/en/) que é um reconhecedor de fala de alta performance para grandes vocabulários (NETO; PATRICK; KLAUTAU, 2010). Dentre as vantagens da ferramenta está a implementação dos complexos algoritmos de processamento de fala permitindo assim seu acesso por funções simples e rápidas dentro de uma linguagem de programação, ou seja, fica a cargo do desenvolvedor somente codificar métodos de forma prática informando, quando necessário, parâmetros solicitados.

A gratuidade da ferramenta, a capacidade de integração com outros ambientes de desenvolvimento e o vasto material de apoio disponibilizado pelos seus criadores foram outras vantagens que contribuíram para sua escolha. Entretanto, um critério fundamental foi para escolha do componente: a análise dos resultados dos testes realizados pelo laboratório responsável pelo desenvolvimento da ferramenta e dos testes feitos especificamente para esta pesquisa. O primeiro teste foi realizado por Silva et al. (2010) que comparou esta ferramenta, com base no reconhecedor Julius, com outras duas disponíveis na área. Uma delas tem o nome de HDecoder e outra IBM Via Voice. As duas ferramentas de terceiros apresentaram melhor desempenho que a ferramenta Julius pois reconheceram uma média de 70,5\% das palavras enquanto a ferramenta apresentada pelos pesquisadores reconheceu cerca de $60 \%$, porém, o Coruja foi mais rápido que a outras ferramentas.

Os testes realizados com objetivo específico de verificar a eficiência da ferramenta Coruja para esta pesquisa foram efetuados com apoio de um protótipo de software que continha os recursos necessários para realizar o processamento de fala obtidos por meio do sistema Coruja e os recursos testados no protótipo foram os mesmos utilizados na versão final da ferramenta. Antes de iniciar os testes, o aplicativo Coruja foi adquirido no website da universidade e seus arquivos copiados para o diretório raiz "C:" de uma máquina com Windows versão 7 de 32 bits. Após a aquisição foram disponibilizadas diversas pastas contendo arquivos de controle tais como o reconhecedor Julius, arquivos DLL para integração com as ferramentas de programação e arquivos $X M L$ para controle da ferramenta Coruja.

Alguns arquivos do Coruja requerem atenção especial da equipe de desenvolvimento, pois esses serão responsáveis por realizar a conversão dos sons (sinais) capturados em 
palavras escritas, além de gerenciar o aplicativo para trabalhar no modelo de reconhecimento especificado pelo usuário, visto que o Coruja pode ser configurado para reconhecer qualquer palavra ou somente palavras específicas (NETO; PATRICK; KLAUTAU, 2010). Para esses teste, três arquivos foram modificados a princípio: comandos.dict, comandos.voca e comandos.xml. Foram especificadas nesses arquivos as palavras chave escolhidas para o teste e a respectiva configuração fonética de cada uma delas. A configuração fonética é um conjunto de símbolos que permitem identificar como uma palavra deve ser pronunciada (NETO; PATRICK; KLAUTAU, 2010). Este recurso é fundamental para o bom funcionamento do sistema Coruja, principalmente para o reconhecimento de palavras específicas. As palavras escolhidas para os testes e para utilização no ErgoSV foram: Ótimo, Bom, Ruim, Regular e Péssimo. Estas palavras foram selecionadas por serem pequenas, fáceis de memorizar e por representarem conceitos e/ou opiniões de qualidade em relação à determinados contexto. Portanto, essas palavras foram configuradas nos arquivos do sistema Coruja conforme apresentam as Figuras 19(a) que representa o arquivo comandos.dict e 19(b) que apresenta o arquivo comandos.xml.

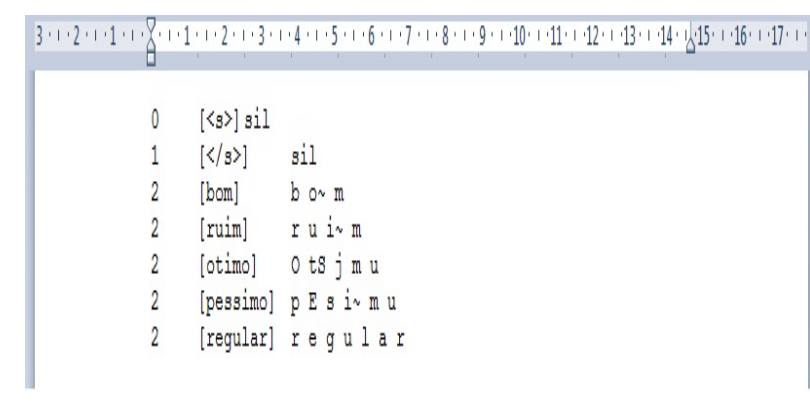

(a) Comandos.dict

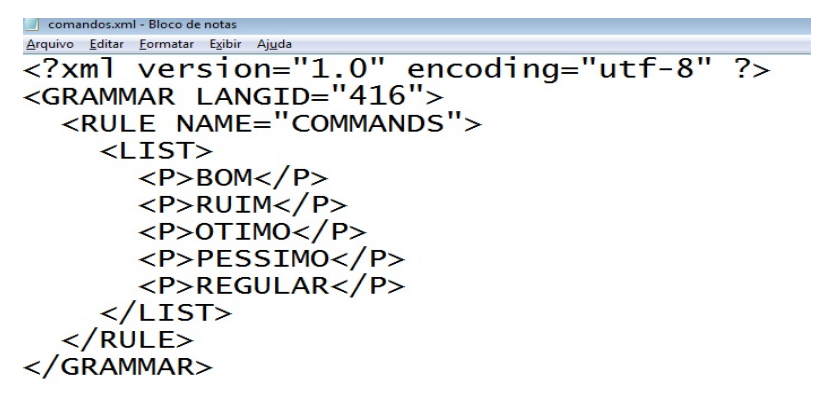

(b) Comandos.xml

Figura 19 - Arquivos de configuração do Coruja

\subsubsection{Testes com a ferramenta Coruja}

Os testes foram efetuados com um pequeno aplicativo criado na linguagem de programação C\# no qual foram integrados os recursos do aplicativo Coruja. Foram selecionadas quinze pessoas do sexo masculino e feminino com idade entre 18 e 50 anos, dentre elas, algumas com maior experiência em desenvolvimento de software e as demais com conhecimentos básicos em informática. Visando verificar a eficiência do sistema em função de apoiar essa pesquisa, o aplicativo de teste foi configurado para reconhecer somente as cinco palavras chave pretendidas para a pesquisa: Ótimo, Bom, Ruim, Regular e Péssimo. A Figura 20 apresenta a interface do protótipo de teste na qual são listadas algumas palavras reconhecidas durante um teste. 


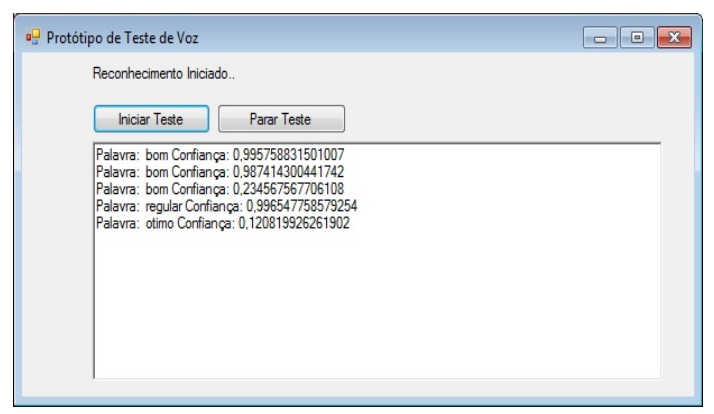

Figura 20 - Interface do protótipo de teste da ferramenta Coruja

Durante os testes com a ferramenta os participantes eram incentivados a pronunciarem as palavras de forma aleatória utilizando um notebook. Não havia critério para pronuncia das palavras, simplesmente foi solicitado aos participantes que pronunciassem pelo menos uma vez cada palavra chave. O computador continha um microfone externo que coletava sons pronunciados no ambiente e também conectores para utilização de headfones ou fones de ouvido com microfone. Dentro da disponibilidade de cada participante foram realizados testes com microfone externo e com fones de ouvidos. Além do recurso tecnológico, o ambiente no qual se instalou o computador (uma sala de aula de uma faculdade) levou a ocorrência de diversas variações de ruídos sendo em determinados momentos um local silencioso e em outros com mais barulhos.

O tipo de microfone utilizado e a variação de sons no ambiente influenciaram significativamente a avaliação da ferramenta levando a cuidados especiais na realização de cada experimento. Os resultados mostraram que a ferramenta se comportava muito bem quando utilizada com um fone de ouvido com resultados ainda melhores em ambientes com pouco barulho. Já o microfone externo apresentou bons resultados em testes feitos em situação de silêncio ou baixíssimo ruído, para ambientes com barulho o percentual de reconhecimento foi baixo.

Os ruídos não foram os únicos fatores a interferir no reconhecimento: o volume, tom da voz e sotaque também interferiram no processamento de algumas palavras. Alguns participantes pronunciaram palavras em volume/tom de voz muito baixo o que dificultou o trabalho da ferramenta Coruja. Ao serem corrigidos e alertados a falarem mais alto e com tom de voz firme o problema de reconhecimento era solucionado. O sotaque foi o terceiro fator que influenciou o processamento da fala, principalmente de palavras com a letra "R" como Regular ou Ruim, com destaque para a primeira palavra. A forma como alguns participantes pronunciaram a letra $\mathrm{R}$ ocasionou a uma dificuldade de interpretação no sistema, porém, não foi possível identificar um padrão para essa divergência. Os resultados dos testes são apresentados na Tabela 6 . 
Tabela 6 - Resultados dos testes da ferramenta Coruja

\begin{tabular}{l|l|l}
\hline Microfone & Ambiente & \% Reconhecimento \\
\hline Headfone & Silencioso & 90 \\
\hline Headfone & Barulho & 65 \\
\hline Externo & Silencioso & 85 \\
\hline Externo & Barulho & 30 \\
\hline
\end{tabular}

A falha nos reconhecimentos ocorreu de duas maneiras: no primeiro a palavra pronunciada não era escrita na tela sinalizando que a aplicação não recebeu o sinal de voz ou não conseguiu efetuar reconhecimento; no segundo caso a palavra escrita na tela era diferente da palavra pronunciada e apresentava uma taxa de confiança (percentual no qual a ferramenta Coruja aponta a qualidade de reconhecimento) muito baixa.

Os resultados apontavam para a necessidade de realização dos testes de usabilidade em ambientes silenciosos, ou com baixo nível de ruídos, independente da utilização do headfone ou de um microfone externo, em outras palavras, o silêncio na sala de testes deveria ser rigorosamente controlado para não afetar os dados e consequentemente o resultado final do teste e/ou afetar o percentual de confiança do reconhecimento das palavras.

Embora tenha apresentado limitações no reconhecimento das palavras, o percentual de sucesso nos testes foi considerado satisfatório para o desenvolvimento do aplicativo ErgoSV e também para os experimentos desta pesquisa, sendo portanto, selecionada para tais atividades.

Na próxima seção serão apresentados os testes efetuados na ferramenta OpenCV a fim de apoiar as atividades de processamento de imagens e reconhecimento facial.

\subsubsection{Biblioteca OpenCV}

O grande número de atividades relacionadas ao processamento de imagens levaram ao surgimento de ferramentas computacionais para apoiar tais atividades. Dentre elas a biblioteca OpenCV que é um frameword Open Source utilizada para processamento de imagens offline ou em tempo real. Ela pode ser utilizada em áreas como IHC, identificação de objetos, segmentação, reconhecimento de faces, gestos e demais atividades relacionadas à computação visual (LIMA et al., 2008). Ela foi desenvolvida originalmente na linguagem $\mathrm{C} / \mathrm{C}++$ e permite integração com ambientes de desenvolvimento como Microsoft Visual Studio, Eclipse e $\mathrm{C}++$ Builder. 
Distribuições (releases paralelas) foram criadas com a finalidade de permitir a adaptação da ferramenta a um maior número de linguagens e ambientes de programação, exemplo delas é a EMGU OpenCV disponível em (http://www.emgu.com/wiki/index.php/OpenCV). Nesta distribuição foram implementados métodos específicos para utilização junto a linguagem $C \#$ melhorando a capacidade de integração com o ambientes como o Microsoft Visual Studio. Outra distribuição conhecida é a JavaCV que permite a integração com a plataforma de desenvolvimento Java.

A distribuição da $O p e n C V$ estudada para esta pesquisa foi a $E M G U$ OpenCV devido ao fato da implementação ser realizada utilizando o $C \#$. A integração é feita por meio de arquivos $D L L$ permitindo que funções que exigiam grande quantidade de linhas de código para implementação fossem acessadas por meio de métodos simples, situação semelhante à apresentada para processamento de fala. Um exemplo da aplicação desta biblioteca é utilização do algoritmo para identificação de faces dentro de uma imagem. A funcionalidade é facilmente acessada pelo comando grayFrame.DetectHaarCascade no qual são atribuídos parâmetros execução do mesmo. Esta função identifica e destaca com um desenho (quadro com bordas pretas) as imagens de rostos encontrados na imagem.

A aplicação desta função no ambiente de desenvolvimento Visual C\# Express em conjunto com um contador de tempo com atualização automática permitiu que a função fosse executada durante todo o tempo de uma filmagem.

Um trabalho desenvolvido por Oliveira e Jaques (2008) foi realizado com auxilio da biblioteca $O p e n C v$ que teve o objetivo de capturar imagens da face do usuário e utilizando uma base de conhecimento complexa contendo informações sobre as características de emoções, o sistema deveria reconhecer qual a emoção expressada pelo usuário. O processo de detecção facial foi efetuado com auxilio da OpenCv.

Isto deve-se ao fato da biblioteca implementar o método Haar-like features, conhecido também por Método de Viola Jones. Para efetuar o processamento a imagem é submetida a biblioteca Open $C V$ que, utilizando o método de Viola Jones, procura por uma face dentro da imagem demarcando a região que contém tal informação (LIMA et al., 2008). A Figura 21 apresenta um exemplo de demarcação da região facial realizado pela biblioteca OpenCV e o método de Viola Jones (OLIVEIRA; JAQUES, 2008). No quadro a esquerda é apresentada a imagem completa obtida por meio de uma câmera; no quadro a direita é exibida a imagem já processada com destaque somente a área da face.

Os experimentos para verificar a eficiência da $O p e n C V$ para esta pesquisa foram realizados de forma similar aos testes com a ferramenta Coruja. Um pequeno aplicativo 

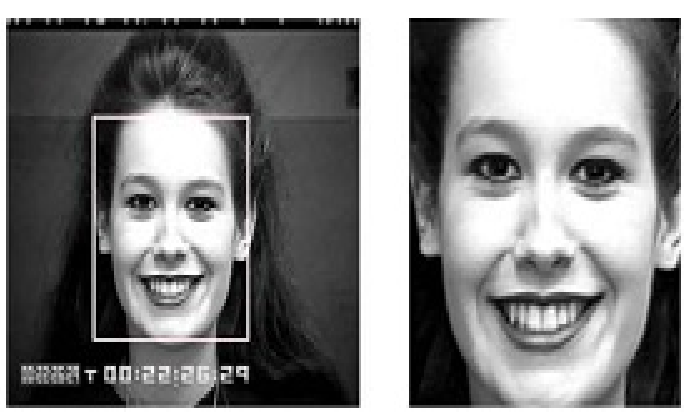

Figura 21 - Reconhecimento facial com OpenCV (OLIVEIRA; JAQUES, 2008)

(protótipo) foi criado com a única função de se conectar com a webcam e efetuar o reconhecimento facial das pessoas que participavam dos testes. Neste software foram inseridos os arquivos $D L L$ que permitem a integração com os algoritmos de reconhecimento facial, além de codificados os algoritmos para execução das funções de reconhecimento e conexão com a câmera. Uma pequena tela contendo um display para exibir a face do participante foi posicionado no centro da tela conforme apresenta a série de imagens que compõe a Figura 22.

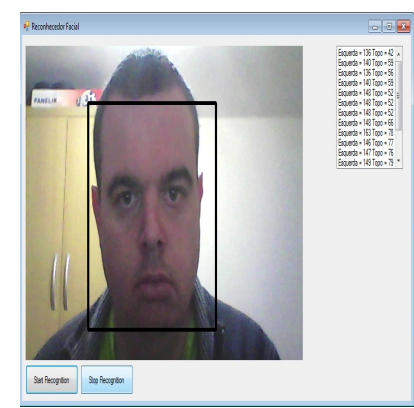

(a) Face 01

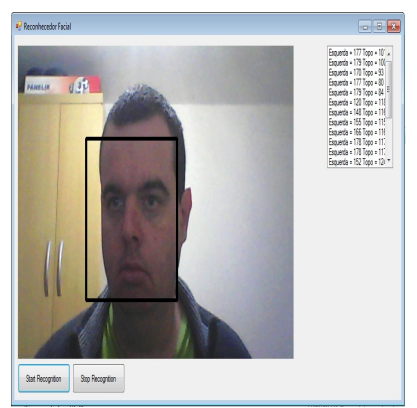

(b) Face 02

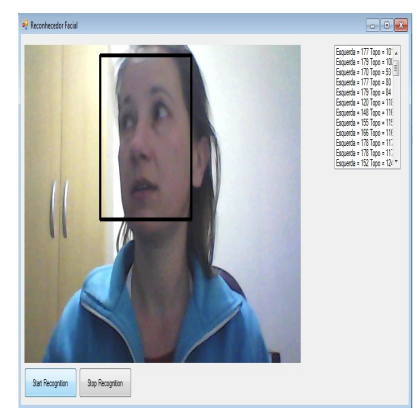

(c) Face 03

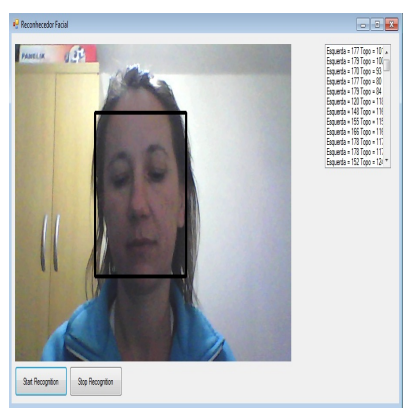

(d) Face 04

Figura 22 - Teste de reconhecimento facial com OpenCV

Os resultados apontaram para uma capacidade de reconhecimento superior a $90 \%$ levando a conclusão de que a ferramenta seria adequada para apoiar a execução dessa pesquisa.

\subsubsection{Considerações Finais sobre a Seleção de Recursos Computacionais}

Os recursos selecionados para apoiar o desenvolvimento desta pesquisa foram escolhidos considerando resultados estabelecidos e publicados em outros trabalhos científicos além dos resultados dos experimentos feitos especificamente para este trabalho. Opiniões técnicas de desenvolvedores de software e especialistas da área de computação, mas não vinculados a área de pesquisa também foram levados em consideração. Os recursos seleci- 
onados foram unidos e utilizados no desenvolvimento da aplicação $\operatorname{ErgoSV}$ e consequentemente nos experimentos deste projeto. No próximo tópico será apresentada a definição das atividades e a modelagem utilizando diagramadas da Unified Modeling Language (UML).

\subsubsection{Definição e Modelagem das Funcionalidades}

Com todos os recursos a serem utilizados no desenvolvimento selecionados iniciou-se a fase de definição das funcionalidades do aplicativo. As funcionalidades foram definidas com base na reflexão da seguinte pergunta: "O que um aplicativo deveria ter para apoiar testes de usabilidade utilizando reconhecimento facial e reconhecimento de fala?" Após estudos sobre o foco da pesquisa e das funcionalidades necessárias, elaboração de rascunhos e análise das funcionalidade e recursos do ponto de vista técnico foi possível definir as funcionalidades da aplicação e consequentemente sua arquitetura.

Em relação a arquitetura da aplicação ficou decidido que: (1) o sistema seria desenvolvido na plataforma desktop ou seja, com padrão de interface convencional para plataforma Windows. Antes desta decisão cogitou-se a possibilidade do desenvolvimento para plataforma web, porém nesta abordagem poderiam ocorrer problemas para gerenciar determinadas funções do aplicativo. Por exemplo, minimizar a aplicação durante o teste e executá-la em segundo plano. Além disso, a plataforma desktop oferecia um maior número de recursos necessários para o bom funcionamento da aplicação e, por último, por não ser o foco desta pesquisa o desenvolvimento de um sistema web, mas de uma plataforma para apoiar a avaliação da usabilidade utilizando técnicas de processamento de sons e imagens; (2)as atividades de processamento deveriam ser organizadas na arquitetura de forma a não comprometer as atividades de coleta e análise dados. Deveriam ser consideradas, também, as características e limitações das ferramentas utilizadas para registrar imagens e áudio de forma a otimizar a utilização de seus recursos. Após aprofundado estudo decidiu-se dividir o software em dois módulos: ErgoSV e ErgoSV Analyzer.

ErgoSV: Esse aplicativo foi desenvolvido contendo uma estrutura focada em recursos para efetuar a coleta de dados. Neste aplicativo foram implementadas as funções do framework Coruja para realizar o processamento das palavras chave pronunciadas e da ferramenta OpenCV para efetuar a comunicação com a webcam o registro da imagem e a execução do processamento que permitiu identificar imagens faciais. Além destas funcionalidades o módulo $\operatorname{ErgoSV}$ apresentava os recursos funcionais demonstrados no Diagrama de Caso de Uso da Figura 23.

O caso de uso Registrar Usuário se refere as atividades de aquisição de dados dos 


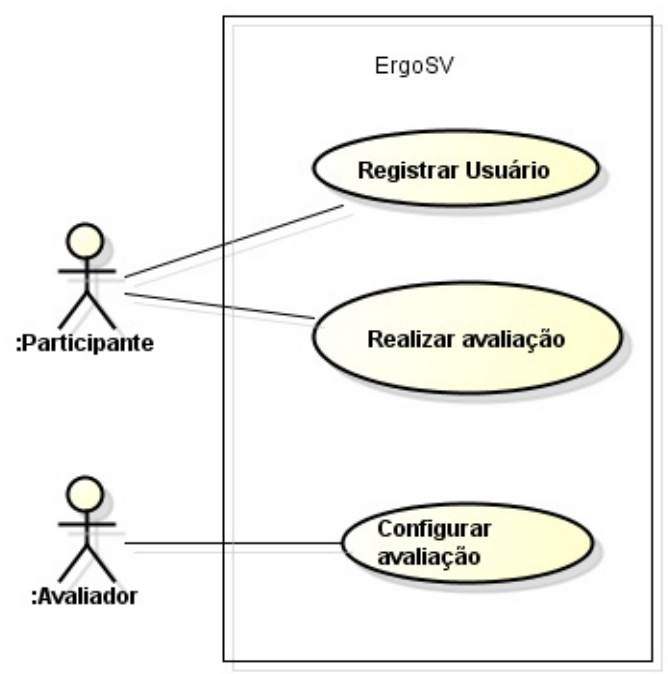

Figura 23 - Diagrama de Caso de Uso do ErgoSV

participantes que realizam os testes. A inserção dos dados no sistema é feita pelo próprio participante que informa dados como nome, endereço, idade e instituição. O caso de uso Configurar Avaliação é uma tarefa destinada ao avaliador que insere dados relativos a características dos testes como: tipo de teste, abordagem utilizada e nome do aplicativo. Por último, o caso de uso Realizar a avaliação consiste na tarefa de execução do teste, iniciada e finalizada pelo participante, que passa a ser monitorado constantemente pelo sistema ErgoSV.

Foi integrado ao ErgoSV um recurso de coleta de snapshots das telas dos aplicativos utilizados no momento de determinada reação a fim de utiliza-las como dados para analisar qual funcionalidade do sistema em teste provocou uma reação positiva ou negativa do participante. As imagens de tela foram registradas em intervalos de tempo em segundos pré determinados. Estes valores podem ser determinados pelo avaliador no momento da execução do teste e influenciará na quantidade de imagens de interfaces disponíveis para análise.

ErgoSV Analyzer: Este módulo do aplicativo foi criado visando realizar atividades de Pré Processamento (enriquecimento) dos dados coletados pelo ErgoSV e a apoiar na geração das informações. O aplicativo acessa a mesma base de dados utilizada pelo primeiro software e foi criado com a intenção de separar a atividade de coleta de dados da análise e geração de informações. O aplicativo ErgoSV Analyzer seria o responsável por gerar as informações além de exibir e permitir o gerenciamento da mesma por parte do avaliador. As funções definidas para esse aplicativo que poderiam ser realizadas pelo avaliador foram: 
- visualizar a lista de avaliações: permite visualizar uma lista com a relação de testes realizados com dados sobre o participante e o teste como data, horário de inicio e fim;

- gerenciar as avaliações: módulo de acesso aos dados completos da avaliação;

- gerenciar dados de fala e imagens: manutenção de dados de imagem e fala como consulta e visualização;

- visualizar interfaces registradas durante os testes: funcionalidade que existe as interfaces que estavam em uso em momentos próximos a um evento específico;

- realizar o processamento offline das imagens: calcular a similaridade das imagens faciais.

A busca e organização dos dados coletados de forma clara e eficiente para análise que compreende o destaque para situações relevantes, criação de gráficos e classificação e imagens e palavras pronunciadas é realizada de forma automatizada pelo ErgoSV. As funções básicas não compreendem o processo de comparação das imagens faciais que foi definida como uma tarefa a ser acionada pelo avaliador. A Figura 24 apresenta o Diagrama de Caso de Uso do ErgoSV Analyzer.

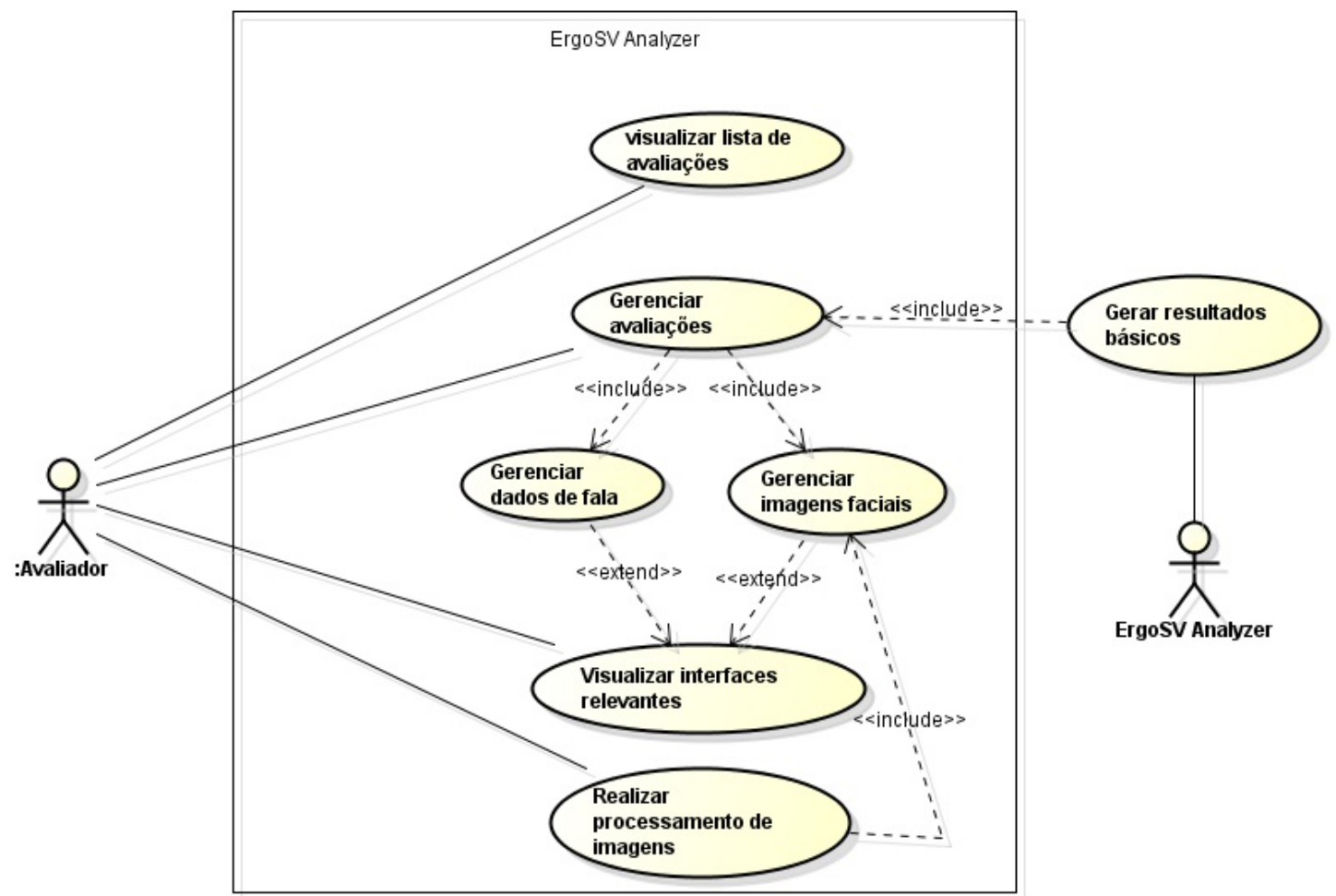

Figura 24 - Diagrama de Caso de Uso do ErgoSV 
As funcionalidades dos aplicativos foram definidas e classificadas de forma que permitissem um melhor aproveitando dos recursos para as atividades de coleta de dados, processamento, geração e visualização de informações além de considerar as atividades do participante e do avaliador. A regra de negócio estabelecida para o $\operatorname{ErgoSV}$ foi modelada utilizando o diagrama de classes conforme apresenta a Figura 25 seguindo o paradigma de desenvolvimento orientado a objetos (GUEDES, 2009).

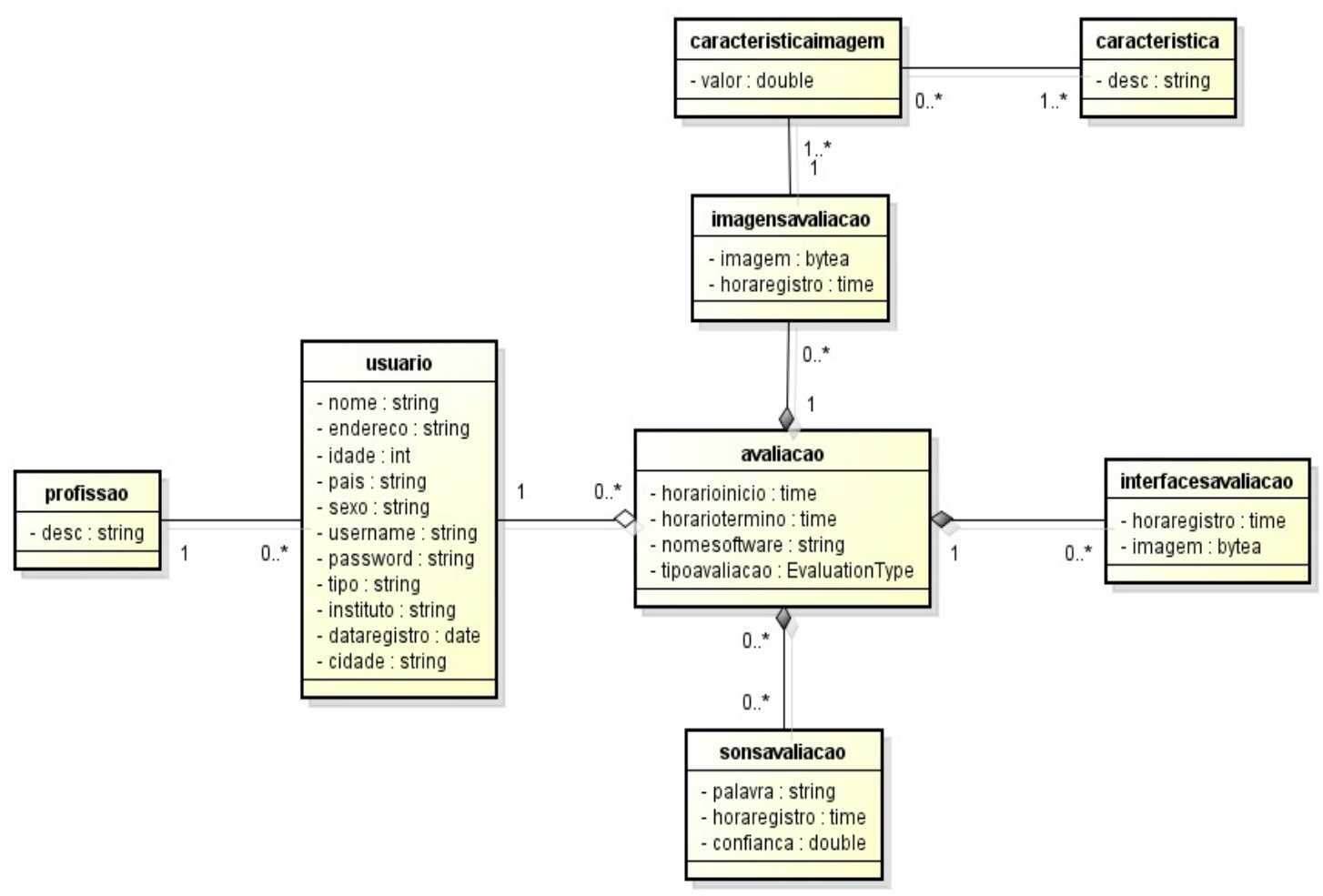

Figura 25 - Diagrama de Classe ErgoSV

O Sistema Gerenciador de Banco de Dados (SGBD) utilizado foi o PostgreSQL. Esse SGBD foi escolhido por ser gratuito, robusto e apresentar todos os recursos necessários para o desenvolvimento da aplicação. Uma base de dados foi modelada e criada para armazenar os dados dos testes realizados. A estrutura de tabela seguiu rigorosamente a estrutura de negócios apresentada no diagrama de classe da Figura 25, ou seja, dentre as tabela criadas pode-se citar tabelas para: registro de dados dos testes, imagens dos testes, palavras pronunciadas, cadastro de participantes, imagens das interfaces dos testes, características das imagens e seus respectivos valores.

$\mathrm{Na}$ próxima seção serão apresentadas as considerações finais sobre a estrutura do software ErgoSV. 


\subsubsection{Considerações finais sobre a Estrutura do Sistema}

O processo de escolha das ferramentas para serem utilizadas no ErgoSV (reconhecimento de voz, reconhecimento facial e plataforma de desenvolvimento) envolveu atividades relacionadas aos testes, validação e estudos de componentes computacionais que permitissem a implementação de um software para apoiar a abordagem proposta nesta pesquisa. Recursos para processamento de fala, processamento de imagens, linguagens de programação e ambientes de desenvolvimento foram testados e escolhidos de acordo com seus resultados, considerando que seriam adequados para implementação.

A estrutura do software referente a regra de negócios e funcionalidades foi estabelecido buscando realizar um enlace entre as ferramentas computacionais e as funções a serem desempenhadas pelo aplicativo. Esta análise levou a conclusão da necessidade do desenvolvimento da ferramenta em dois módulos, um para coleta de dados e outro para análise e geração de informações.

Na próxima seção serão apresentadas as estratégias para o uso dos sistemas ErgoSV e ErgoSV Analyzer.

\subsection{Estratégias de Uso da Abordagem e da Aplicação}

Esta seção apresenta as etapas necessárias para realização dos testes de usabilidade, do processamento dos dados, da análise dos dados e para o acesso as informações geradas. Primeiramente são apresentadas as atividades necessárias para execução do ErgoSV para coleta de dados e após as atividades relacionadas ao aplicativo ErgoSV Analyzer.

Considerando o interesse de possível divulgação e disponbilidade de utilização para testes em laboratórios de usabilidade, os aplicativos ErgoSV e ErgoSV Analyzer tiveram suas interfaces desenvolvidas no idioma Inglês.

\subsubsection{Coleta de Dados}

As atividades de coleta de dados foram realizadas utilizando o aplicativo ErgoSV que continha recursos para aquisição, processamento e registro das palavras chave pronunciadas, das imagens faciais dos participantes e das imagens de telas também registradas durante um teste.

O processamento de fala consiste na verificação da palavra pronunciada pelo parti- 
cipante em uma base de dados em caso de reconhecimento, tal palavra é escrita em um display e posteriormente armazenada em um base de dados para os testes. Essa verificação é feita por algoritmos que inspecionam uma série de arquivos do aplicativo Coruja além de iniciar a execução dos complexos códigos fonte existentes na ferramenta. Já o processamento de imagens e o reconhecimento facial se refere a identificação de uma face em uma determinada imagem executado pela ferramenta $O p e n C V$ e em caso de identificação de face, a mesma é registrada na base de dados dos testes. Esta ferramenta auxilia também no registro e exibição da imagem da webcam em uma interface específica.

O processo de teste de usabilidade se inicia executando-se o sistema $\operatorname{ErgoSV}$ no qual o participante se depara com uma tela de login com campos para informar o nome do usuário e a senha. Caso o participante já tenha efetuado seu cadastro, o mesmo deve informar os dados requisitados, entretanto, se é a primeira vez que do participante em um teste de usabilidade com o ErgoSV o mesmo necessita preencher um formulário conforme apresenta a Figura 26. A tela de login foi criada com objetivo de identificar quais participantes realizaram quais testes para posterior identificação das características dos mesmos.

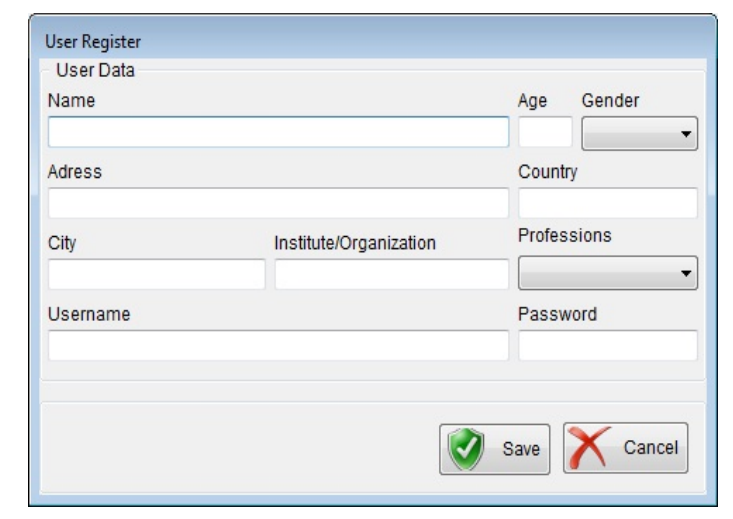

Figura 26 - Interface de registro de participantes do ErgoSV

Efetuado o Login no sistema, é exibido o painel de gerenciamento de testes, dividido em duas partes: a primeira contem um quadro com duas tabulações (abas): na primeira tabulação, chamada Webcam Video, é exibida a imagem da webcam para ajuste, posicionamento e visualizações necessárias; e na segunda, chamada Words Pronounced é apresentada a lista de palavras reconhecidas em um teste. Este painel apresenta também outras duas divisórias nas quais em uma se encontra o formulário para preenchimento dos dados do teste e no outro se encontram os botões que permitem a manutenção do teste.

O formulário de dados do teste deve ser preenchido antes de se iniciar uma avaliação e os dados apresentados são utilizados na análise dos dados e para orientar o aplicativo em relação à seu funcionamento tal como intervalo de tempo para registro de imagens da 
tela do sistema e da face do participante. Este formulário apresenta os campos:

- Application Name: campo para informar o nome da aplicação ou website a ser testado;

- Approach: Filming or Think Aloud: campo no qual deve ser selecionada quais funcionalidades de reconhecimento/processamento serão ativadas para uso um teste de usabilidade;

- Screen Interval: campo para indicação do intervalo de tempo em segundos no qual o aplicativo ErgoSV deve registrar uma imagem da tela;

- Face Interval: campo para indicação do intervalo de tempo em segundos para registro de imagens da face do participante;

- Stage: o avaliador deve indicar o estágio da aplicação testada, nesse caso, Protótipo (Prototype) ou Produto Final (Final Product) para aplicações encerradas.

A Figura 27 apresenta a tela principal do $\operatorname{Ergo} S V$ na se encontra o formulário para realizar a configuração dos testes.

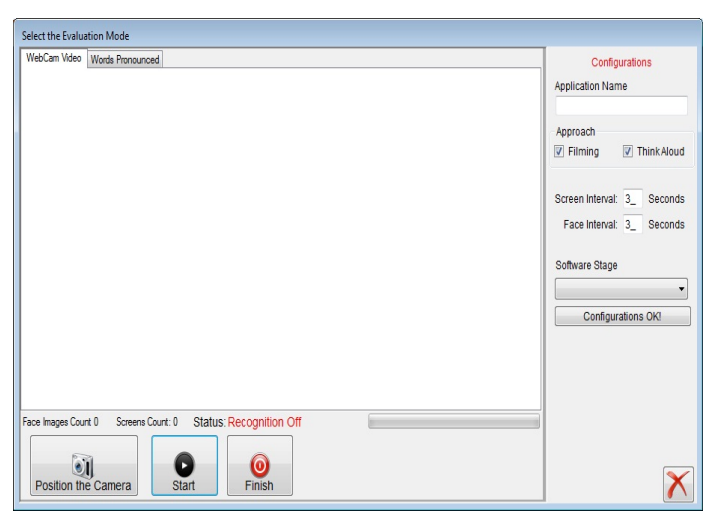

Figura 27 - Tela inicial do sistema ErgoSV

Após o preenchimento dos campos, o botão com o rótulo "Configuration OK" deve ser acionado para ativar as configurações escolhidas.

Informadas as características do teste, o participante pode inicializar o mesmo utilizando o botão Position the Camera. Este botão aciona o recurso da biblioteca OpenCV que conecta o aplicativo a uma webcam do computador e exibe a imagem no painel do ErgoSV para que o participante possa posiciona-la. Após realizar o posicionamento correto, o participante deve acionar o botão Start para dar inicio ao teste. Entretanto, antes 
de começar o teste em si, é necessária a obtenção de uma imagem padrão do participantes, ou seja, uma foto do rosto da pessoa com uma reação neutra (CASTILHO, 2011). Esta imagem será utilizada para comparação com as demais imagens registradas durante o teste. Devido a isso, é exibida uma mensagem solicitando o registro de uma imagem padrão. Após confirmação da foto padrão o teste de usabilidade é inicial assim como o monitoramento das atividades e do usuário. A Figura 28 apresenta o fluxograma com o processo de inicialização de um teste de usabilidade.

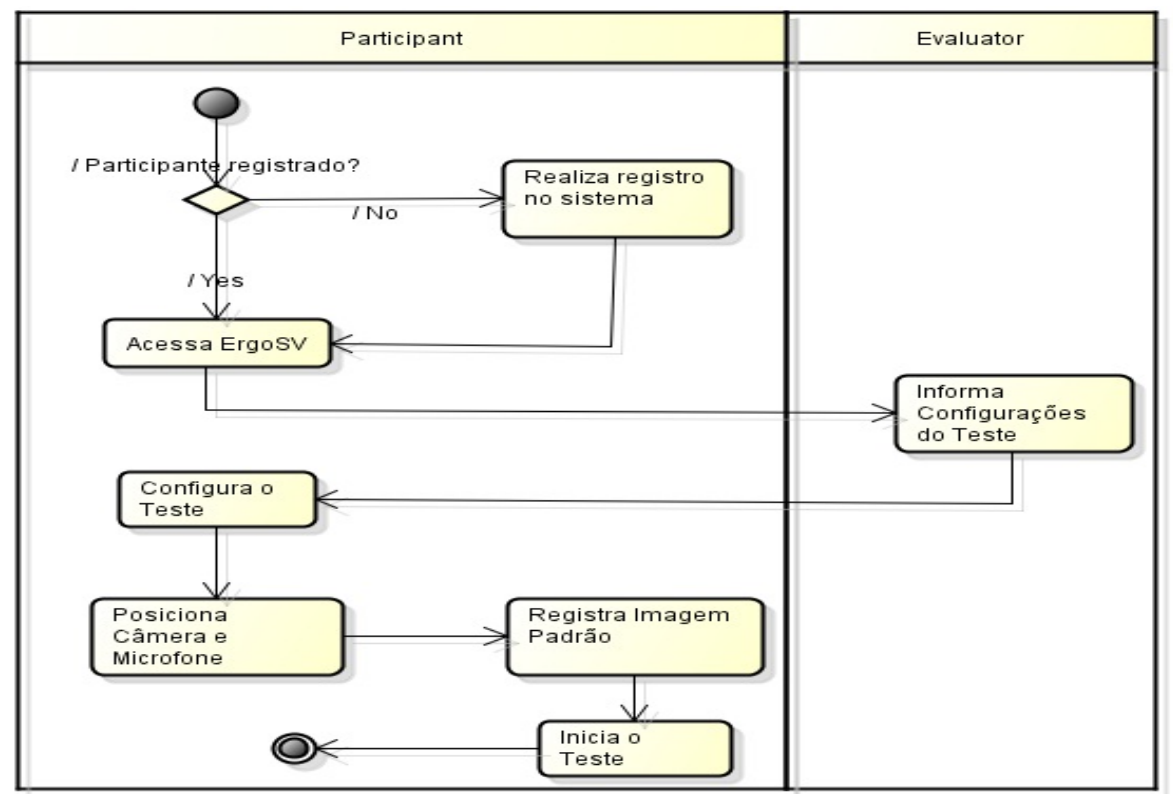

Figura 28 - Fluxograma de inicialização de testes com o ErgoSV

Com a imagem padrão devidamente registrada o aplicativo ErgoSV é minimizado para não interferir na interação entre usuário e sistema. Ao ser iniciado o teste, três recursos de reconhecimento são ativados: reconhecimento de fala, reconhecimento facial e registro de snapshots.

O recurso de reconhecimento de fala fica ativo durante todo o processo de avaliação tentando identificar palavras pronunciadas. Caso o participante pronuncie uma das palavras chave do teste e o aplicativo receba o sinal sonoro, o mesmo efetua o processamento do sinal e analisa se a palavra encontrada estabelecida em seus arquivos de configuração retornando assim uma string (texto escrito) contendo a palavra e o percentual de confiança determinado para o reconhecimento. A Figura 29 apresenta o fluxograma com o processo de reconhecimento de fala.

O sistema de reconhecimento facial tem seu processo de funcionamento diferenciado do reconhecimento de fala pelo fato de que o controle de imagens reconhecidas e registradas é feito dentro do intervalo de tempo estipulado pelo avaliador no início do teste. O sistema 


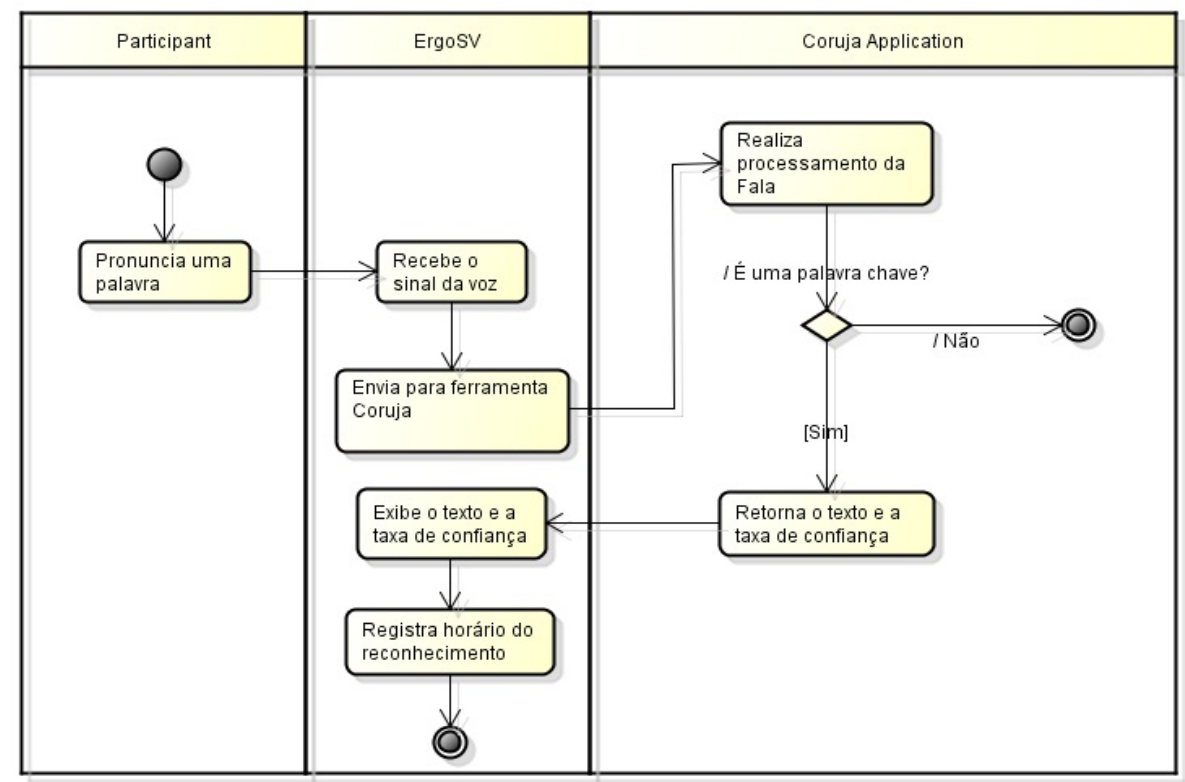

Figura 29 - Fluxograma de reconhecimento de fala

é composto por três contadores de tempo: um contador para conexão com a webcam, um contador para registro de imagens do participante e um contador para registros de imagens da tela. Esses contadores são explicados a seguir:

O contador de tempo para conexão com a câmera tem um intervalo fixo configurado no código fonte da aplicação e executa constantemente a conexão e a exibição das imagens de forma a não comprometer o registro da foto do participante no exato momento em que é executa determinada atividade. No caso das imagens do participante, ao atingir o tempo de intervalo determinado, o aplicativo registra uma imagem de todo o ambiente ao alcance da câmera e logo em seguida executa um algoritmo de reconhecimento facial disponível na biblioteca $O p e n C V$ que permite a detecção de faces dentro da imagem e, em caso positivo (face detectada), separa somente a imagem da face para posterior armazenamento no banco de dados. Em caso negativo, a imagem é separa como uma imagem descartada e assim como uma imagem facial, a imagem descartada também é armazenada na base de dados. O terceiro e último contador efetua uma série de cópias das imagens das telas para posterior registro no banco de dados quando o contador de tempo para este processo atingir o intervalo determinado previamente. Para os três casos é registrado, também, o momento (horário) que cada imagem foi coletada.

Após finalizados os testes, os dados coletados (imagens faciais, imagens descartadas e snapshots) são registrados na base de dados da aplicação para posterior acesso, processamento e consulta no sistema ErgoSV Analyzer. A Figura 30 apresenta o fluxograma com a dinâmica das atividades de reconhecimento facial. 


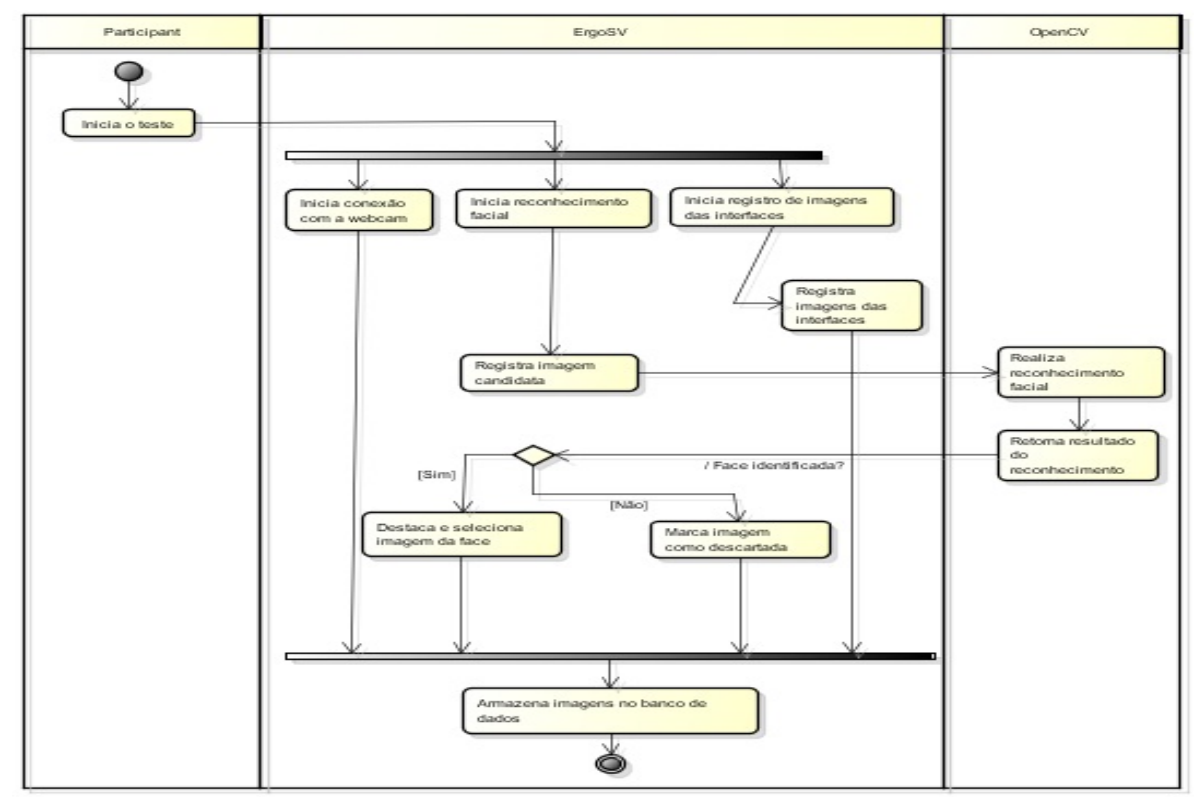

Figura 30 - Fluxograma de reconhecimento de face

Na próxima seção serão apresentados detalhes do aplicativo ErgoSV Analyzer uma parte do sistema ErgoSV desenvolvido para fins específicos de análise, processamento, geração e visualização de informações.

\subsubsection{Análise de Dados e Geração de Informações}

As atividades de visualização e análise de dados, além de algumas atividades de processamento são realizadas no módulo ErgoSV Analyzer desenvolvido especificamente para tais finalidades. Dentre as funcionalidades deste módulo do sistema estão o processamento (comparação) de imagens faciais, apresentação organizada dos dados, geração de informações básicas e assistência na identificação de reações e situações próximas a momento específicos e assim, de possíveis interfaces com problemas de usabilidade. É importante destacar que os dados apresentados neste aplicativo se referem a aqueles coletados no sistema $\operatorname{ErgoSV}$ e que ambos os aplicativos acessam a mesma base de dados.

Ao executar o ErgoSV Analyzer o avaliador tem acesso a uma tela contendo a lista dos testes efetuados com os seguintes campos:

- Participant: nome de cada participante;

- Username: usuário utilizado para acessar o $\operatorname{ErgoSV}$;

- Number: número do teste (identificador);

- Software: nome do aplicativo testado; 
- Type: tipo de teste executado (Video e Voz, Somente Voz ou Somente Video);

- Start: horário de inicio dos testes;

- Finish: horário de término dos testes.

Abaixo da lista de testes, o software apresenta seis botões nos quais seus nomes e funcionalidades são:

- Data Processing: permite acesso a funcionalidade de processamento e comparação de imagens faciais;

- Complete Information: opção de acesso a tela de informações completas (voz + imagens da face) dos testes;

- Only Words Information: opção de acesso a tela de informações geradas somente com dados de voz;

- Only Face Information: opção de acesso a tela de informações geradas somente com dados de imagens faciais;

- Feature Charts: permite acesso a tela para análise dos gráficos gerados com dados de características das imagens da faciais do teste.

A Figura 31 apresenta a interface inicial do $\operatorname{ErgoSV}$ Analyzer na qual é possível identificar a lista de testes realizados, encontrada na parte superior da tela e o painel de botões que dão acesso as funcionalidades.

\begin{tabular}{|c|c|c|c|c|c|c|c|c|}
\hline \multicolumn{9}{|l|}{ ErgoSV Evaluator } \\
\hline \multicolumn{9}{|l|}{ Evaluations Performed } \\
\hline Participant & \multicolumn{2}{|l|}{ Username } & Number & \multicolumn{2}{|c|}{ Software } & Type & Start & Finish \\
\hline Thiago Adriano Coleti & \multicolumn{2}{|c|}{ thiagocoleti@hotmail.com } & 001 & \multicolumn{2}{|c|}{ Lepostiche } & VideoSound & 11:42:42 & 11:43:57 \\
\hline Thiago Adriano Coleti & \multicolumn{2}{|c|}{ thiagocoleti@hotmail.com } & 002 & \multicolumn{2}{|c|}{ Virtual Reality } & VideoSound & 11:58:01 & 11:59:15 \\
\hline Thiago Adriano Coleti & \multicolumn{2}{|c|}{ thiagocoleti@hotmail.com } & 003 & \multicolumn{2}{|c|}{ Lepostiche } & VideoSound & 02:21:13 & 02:22:33 \\
\hline Julian Tessaro Lopes & \multicolumn{2}{|c|}{ julian } & 005 & \multicolumn{2}{|c|}{ Lepostiche } & VideoSound & 02:41:37 & 02:46:17 \\
\hline Julian Tessaro Lopes & \multicolumn{2}{|l|}{ julian } & 006 & \multicolumn{2}{|c|}{ Lepostiche } & VideoSound & 02:54:58 & 03:00:23 \\
\hline Julian Tessaro Lopes & \multicolumn{2}{|l|}{ julian } & 007 & \multicolumn{2}{|c|}{ Lepostiche } & VideoSound & 03:02:31 & 03:04:50 \\
\hline Andrei & \multicolumn{2}{|l|}{ andreiCG } & 008 & \multicolumn{2}{|c|}{ Lepostiche } & VideoSound & 03:12:44 & 03:15:35 \\
\hline Andrei & \multicolumn{2}{|l|}{ andreiCG } & 009 & \multicolumn{2}{|c|}{ Lepostiche } & VideoSound & 03:17:58 & 03:22:27 \\
\hline Andrei & \multicolumn{2}{|l|}{ andreiCG } & 010 & \multicolumn{2}{|c|}{ Lepostiche } & VideoSound & 03:23:45 & 03:25:55 \\
\hline Cassiano de Moura Bueno & \multicolumn{2}{|l|}{ Cassiano } & 011 & \multicolumn{2}{|c|}{ Lepostiche } & VideoSound & 03:31:17 & 03:35:03 \\
\hline Cassiano de Moura Bueno & Cassiano & & 012 & Lepost & iche & VideoSound & 03:36:03 & 03:40:26 \\
\hline Cassiano de Moura Bu & Cassiano & & 013 & Lepost & iche & VideoSound & 03:41:16 & 03:43:32 \\
\hline Thiago Adriano Coleti & thiagocoleti@hotm & ail.com & 017 & SITE PF & PGSI & VideoSound & 03:14:15 & 03:21:12 \\
\hline (7) Data Processing & (2) Complete Informations & 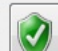 & Vords Inform & nations & $\nabla$ & Face Informations & ( $)$ Feature Charts & \\
\hline
\end{tabular}

Figura 31 - Tela inicial do sistema ErgoSV Analyzer 


\subsubsection{Processamento/Comparação Facial}

Para ter acesso as informações corretas o avaliador deve realizar, primeiramente, a segunda parte do processamento das imagens faciais que consiste na execução de uma série de passos necessários para comparar as imagens candidatas (registradas durante o teste) com a imagem padrão a fim de determinar sua similaridade. O processo de comparação facial consiste nas seguintes atividades: Extração de Características e Cálculo da Similaridade.

O sistema ErgoSV foi desenvolvido contendo como recurso de comparação facial o $C B I R$ que em português significa Reconhecimento de Imagens Baseada em Conteúdo. O CBIR utiliza vetores com características das imagens expressadas em valores matemáticos para comparar imagens candidatas com uma imagem padrão e determinar o percentual de similaridade entre as imagens. Para isto, utiliza-se funções de similaridade que efetuam cálculos matemáticos nos vetores de características de cada imagem (BERGAMASSO, 2010).

Portanto, o primeiro passo para este processamento é criar os vetores de características de cada imagem. Uma funcionalidade foi inserida no aplicativo ErgoSV Analyzer que permite tal atividade. A Figura 32 apresenta a interface do sistema ErgoSV Analyzer que executa tais funções e o processamento das imagens (extração de características) deve ser iniciado por meio da função Start Faces Processing.

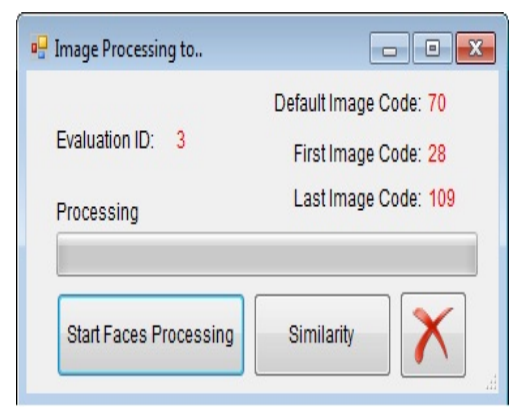

Figura 32 - Tela para funcionalidade de processamento de imagens faciais

A Extração de Características é criação do vetor de características para a imagem padrão e para todas as imagens registradas no teste que tiveram uma face reconhecida, aqui chamadas de imagens candidatas. O vetor é criado por meio de extratores, ou seja, algoritmos que extraem valores matemáticos que representam as características das imagens que, após transformação em números, podem representar o conteúdo da imagem (BERGAMASSO, 2010). Os algoritmos utilizados neste trabalho, com exceção de ajustes efetuados para se adequar ao ErgoSV, foram os mesmos utilizados por Bergamasso (2010) em seu trabalho. 
Para este projeto (ErgoSV) os algoritmos geram um vetor para cada imagem contendo as características apresentas a Tabela 7. As descrições de cada característica são apresentadas no capítulo 2.5.3

Tabela 7 - Características das imagens extraídas pelo ErgoSV Analyzer

\begin{tabular}{l|l}
\hline Tipo & Nome \\
\hline$C$ or & Média do histograma em nível de cinza \\
\hline$C$ or & Desvio padrão do histograma em nível de cinza \\
\hline$C$ or & Média dos pixels em nível de cinza \\
\hline$C$ or & Desvio padrão dos pixels em nível de cinza \\
\hline$C$ or & Média do histograma em RGB \\
\hline$C$ or & Desvio padrão dos histograma em RGB \\
\hline$C$ or & Média dos pixels em RGB \\
\hline$C$ or & Desvio padrão dos pixels em RGB \\
\hline$F$ orma & Escala \\
\hline$F$ orma & Rotação \\
\hline$F$ orma & Translação \\
\hline
\end{tabular}

Para as características que utilizam padrões de cores RGB existia um extrator para cada cor do padrão (Vermelhor - R, Verde - G, Azul - B), totalizando 19 características por imagem.

Embora Bergamasso (2010) apresente outras características passíveis de extração tais como obliquidade, contraste e entropia, as mesmas não foram utilizadas nesta pesquisa. A Obliquidade foi retirada seguindo resultados apresentados pela autora que apontavam para problemas quando tratava imagens em ambientes controladas, como imagens faciais, e que essa característica seria melhor aplicada a imagens em ambientes mais amplos como paisagens. O Contraste e a Entropia foram descartados devido ao grande processamento computacional necessário, considerando que uma imagem demorava aproximadamente de 10 a 15 minutos para ter sua característica extraída e que um teste de 1 minuto pode ter 60 imagens, essa característica comprometeria seriamente a qualidade do processamento.

As características das imagens são representadas por valores matemáticos, entretanto para identificar a taxa de similaridade é necessário realizar o Cálculo da Similaridade que utiliza de funções de similaridade. As funções de similaridade são responsáveis por calcular matematicamente quanto uma imagem é similar a outra aplicando uma série de cálculos nos vetores de características (BERGAMASSO, 2010). Para isso, é necessária a escolha de uma função específica que no caso desta pesquisa foi utilizada distância Euclidiana que, segundo Bergamasso (2010) é a raiz das diferenças absolutas entre cada características ao quadrado. 
O cálculo de similaridade para todas as imagens do teste pode ser realizado no ErgoSV Analyzer acionando a função Similarity apresentada na Figura 32, entretanto é obrigatória a extração de características antes de realizar esta tarefa. O resultado será um valor real aplicado para cada imagem do teste entre 0 e 1 no qual, quanto mais próximo a zero, menos similar e quanto mais próximo a 1 mais similar. Por exemplo, para uma imagem candidata com similaridade 0.98551125221 significa que ela é $98,55 \%$ similiar a imagem padrão e uma outra imagem candidata com similaridade 0.541252215 significa que a imagem é $54,12 \%$ similar a imagem padrão.

Após esta fase de processamento os dados e com os dados enriquecidos, as imagens são disponibilizadas para análise nos módulos explicados a seguir. Na próxima seção serão apresentados os procedimentos para visualização dos dados e informações.

\subsubsection{Vizualização de Dados e Informações}

Com a atividade de processamento das imagens realizada, as informações são disponibilizadas para análise por meio de umas das três funcionalidades disponíveis na tela inicial: Complete Information, Only Words Informations e Only Face Informations.

As três funcionalidades apresentam as mesmas informações, porém nas duas últimas são restringidas informações das palavras pronunciadas ou imagens da face, de acordo com a escolha do avaliador. Com isso, a explicação será feita com base na função Complete Information apresentando as restrições de cada função nos momentos adequados.

A função Complete Information exibe a interface apresentada na Figura 33 na qual são disponibilizadas as seguintes informações: (1) na parte superior é exibido um painel com a imagem padrão registrada e sua lista de características com seus respectivos valores matemáticos. Logo abaixo são exibidas quatro abas: (a) Words, (b) Face Images, (c) Charts, (e) Discarted Images. As próximas seções apresentarão detalhes do funcionamento de cada aba.

\subsubsection{Aba Words}

A aba Words esta disponível nas funcões Complete Information e Only Words Informations e exibe a lista de palavras registradas durante um teste com os seguinte dados:

- Words Pronounced: apresenta a palavra pronunciada pelo participante;

- Time Moment: apresenta o horário que o participante pronunciou a palavra; 


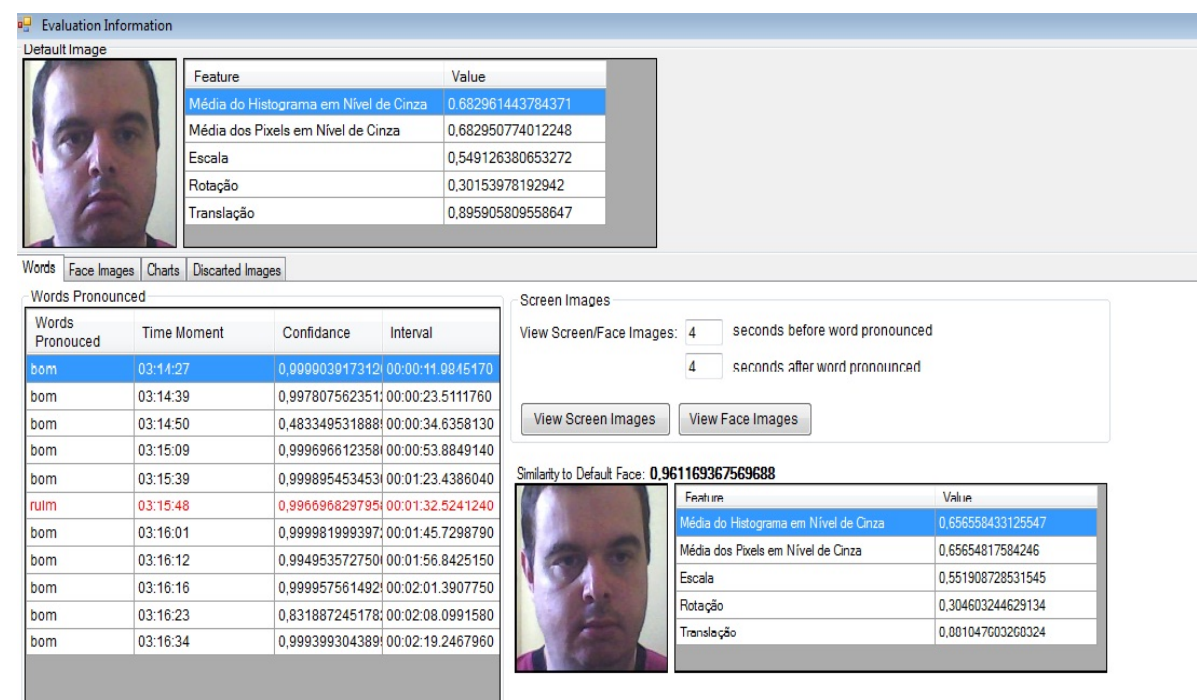

Figura 33 - Tela para análise de dados de fala - módulo Complete Informations

- Confidence: apresenta a taxa de confiança do reconhecimento, ou seja, o percentual de garantia de reconhecimento correto disponibilizado pelo aplicativo de reconhecimento de fala;

- Interval: intervalo de tempo entre a pronuncia da palavra e o início do teste.

A lista destaca as palavras pronunciadas que representam baixa satisfação do participante como, Regular, Ruim e Péssimo. Esse recurso foi disponibilizado para "chamar a atenção" do avaliador para momentos em que o participante teve uma reação insatisfatória. Selecionando um registro da lista o aplicativo verifica na base de dados se existe alguma imagem com uma face reconhecida no momento do registro da palavra, caso positivo a imagem é exibida ao lado direito da lista de palavras juntamente com suas características e a taxa de similaridade. A imagem na lateral e suas características é exibida somente na função Complete Informations sendo ocultada na abordagens de análise que utiliza somente com dados de fala. A Figura 33 apresenta a interface explicada e a aba Words Pronounced.

Ao lado direito da lista encontra-se também uma opção com o rótulo Screen Images Images e dentro deste painél duas opções: View Screen/Faces "X" seconds before/after word pronunciation. Esta funcionalidade reflete o principal desafio no desenvolvimento da abordagem e do aplicativo propostos nesta pesquisa que se trata da facilidade e agilidade na identificação de possíveis problemas de usabilidade utilizando informações sobre a palavra pronunciada e/ou a características da imagem da face registrada. Selecionando uma determinada palavra, identificando um intervalo de tempo antes e após a palavra pronunciada, o software exibe uma lista de imagens da tela do sistema testado utilizadas 
pelo participante no momento da reação e em momentos próximos ao registro da palavra e a partir desta lista também é possível, caso o participante faça uma análise completa, acessar a lista de imagens faciais. A quantidade de imagens selecionadas está vinculado ao intervalo proposto para busca e no intervalo determinada para o registro de imagens estabelecido no primeiro aplicativo. O momento próximo é determinado pelo intervalo estabelecido nas caixas de texto "Visualizar imagens da tela/face X segundos antes/depois da palavra pronunciada". Para o sistema ErgoSV Analyzer foi determinado um valor default de quatro segundo antes e depois da palavra pronunciada, mas este valor pode ser alterado de acordo com a necessidade do avaliador. Maiores detalhes desta opção serão destacado posteriormente em uma seção chamada Acesso a imagens de tela/face.

\subsubsection{Aba Face Images}

A aba Face Images foi criada para listar todas as imagens de face registradas em um teste de usabilidade. Esta função está disponível na análise completa dos dados e na análise dos dados somente com dados de imagem

Assim como na aba Words, a Face Images apresenta uma lista contendo o registro de todas a imagens de rostos registradas. A carga dessa lista é feita ainda na coleta de dados quando o sistema ErgoSV identifica imagens que contenham um rosto e separa para serem exibidas nesta lista. A lista contem os seguintes campos:

- Image ID: código identificador da imagem;

- Time Moment: horário no qual a imagem foi registrada;

- Interval: intervalo entre o início do teste e o momento do registro da imagem;

- Similarity: taxa de similaridade em relação à imagem padrão. Esta informação é utilizada para identificar quanto (\%) uma imagem registrada é semelhante a imagem padrão.

Esta lista permite a navegação do avaliador pelos registros e de acordo com esta atividade a foto registrada é exibida na lateral direita da lista juntamente com a lista de características e seus respectivos valores. Na parte direita da aba há, também, o recurso de acesso a imagens de tela/face, semelhante ao encontrado no recurso Words e que será explicado posteriormente. A Figura 34 apresenta imagem da aba Face Images. 


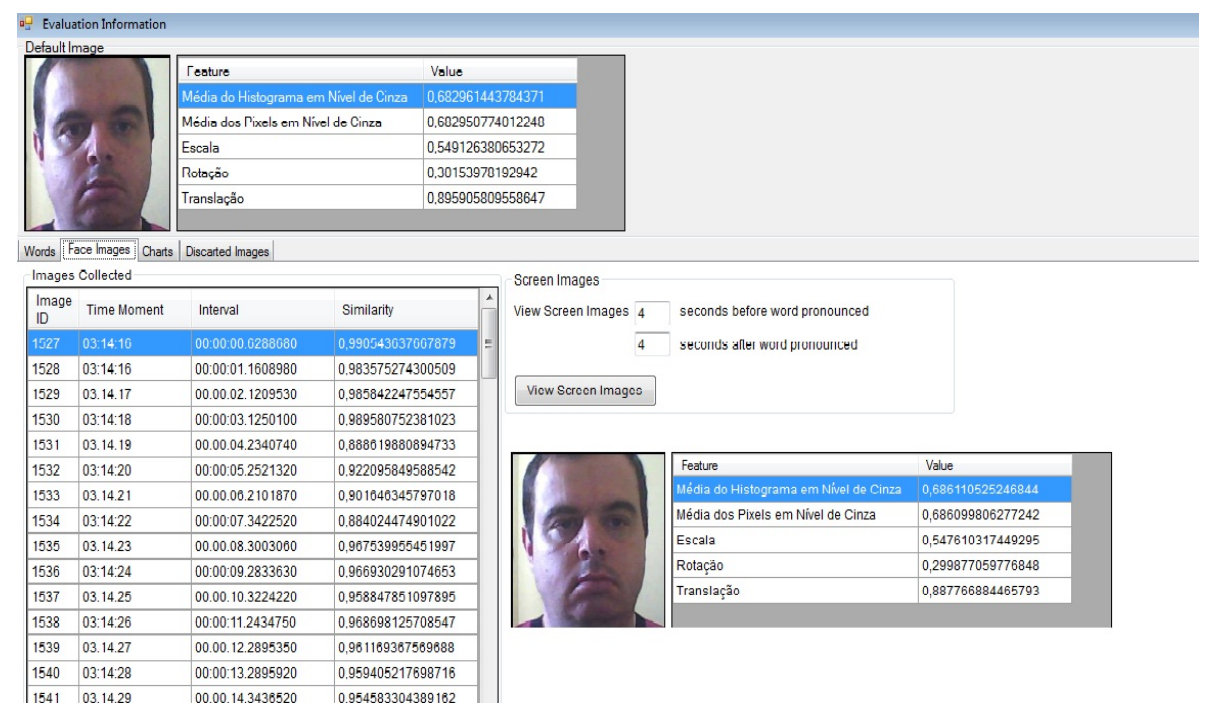

Figura 34 - Tela para funcionalidade de processamento de imagens faciais

\subsubsection{Aba Charts}

A aba Charts apresenta dois gráficos básicos no formato "pizza" contendo o percentual de palavras reconhecidas agrupadas por descrição e a taxa de imagens reconhecidas e não reconhecidas. Este recurso está disponível na avaliação completa, caso o avaliador utilize uma avaliação limitada, os gráficos são exibidos de acordo com o tipo de avaliação escolhida, por exemplo, a análise utilizando somente dados de sons exibe somente o gráfico de palavras, da mesma forma que a análise somente com dados de imagem exibe somente o gráfico de imagens faciais reconhecidas ou não.

O primeiro gráfico apresenta a taxa de imagens registradas nas quais foi possível identificar a face do participante versus a quantidade de imagens descartadas (imagens sem nenhuma face reconhecida). Esse gráfico proporciona uma visão geral em relação à capacidade que o $\operatorname{ErgoSV}$ teve de reconhecer as faces nas imagens do teste. Em um teste com $100 \%$ das faces reconhecidas o avaliador terá disponível dados íntegros das imagens faciais indicando que o mesmo estava com o rosto voltado para tela durante todo o teste, porém em uma teste com percentual de reconhecimento menor, o avaliador deverá analisar o porquê do não reconhecimento, no qual poderiam se enquadrar situações como distração, mal posicionamento da câmera, proximidade do participante com o dispositivo de vídeo e até mesmo problemas com o algoritmo de reconhecimento.

O segundo gráfico apresenta um agrupamento das palavras pronunciadas no teste exibindo a descrição e a quantidade total de cada uma. O gráfico de palavras, em particular, pode ser utilizado pelo avaliador com objetivo de ter uma análise rápida da satisfação do participante com o sistema testado utilizando a quantidade de palavras pronunciada para 
cada conceito. Por exemplo, um teste no qual foram pronunciadas 100 palavras das quais 70 vezes a palavra "Bom", 20 vezes a palavra "Regular" e 10 vezes a palavra "Ruim", o avaliador teria um cenário no qual o software pode ter agradado seu participante, mas há certos pontos que requerem atenção. Entretanto, em uma segunda hipótese na qual de 100 palavras 80 foram a palavra "Ruim", o avaliador tem um cenário extremamente preocupante podendo concluir a priori que toda a aplicação merece uma revisão de interface. Por fim, o segundo gráfico permite ao responsável pela avaliação uma visão mais ampla do resultado do teste e não somente a identificação de palavra por palavra.

A Figura 35(a) e 35(b) apresentam imagens da tela de gráficos.

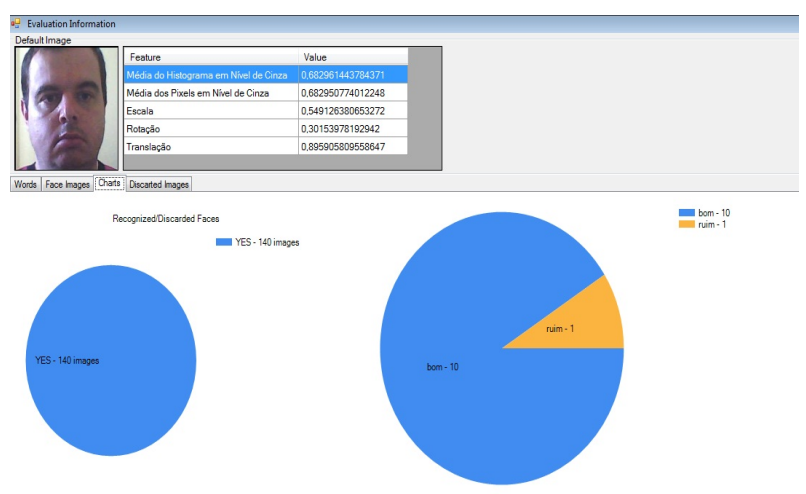

(a) Aba Gráficos 1

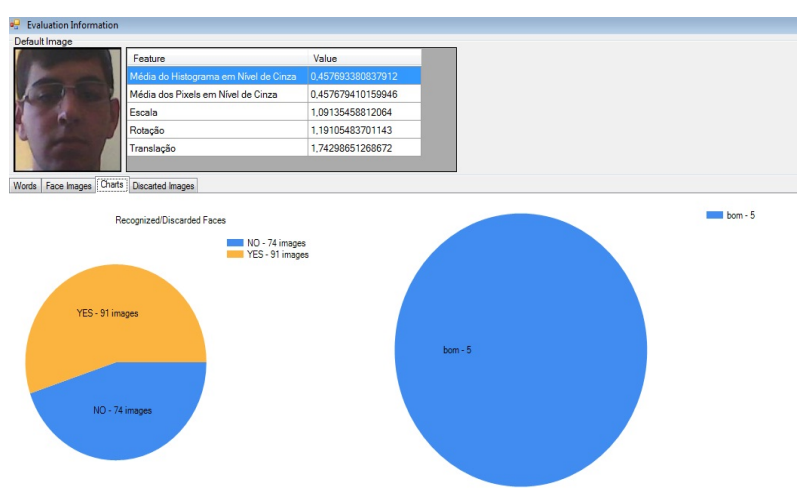

(b) Aba Gráficos 2

Figura 35 - Imagens da tela de apresentação de gráficos

A seguir será apresentada a funcionalidade de visualização de imagens das telas e imagens faciais do participante.

\subsubsection{Aba Discarted Images}

Esta aba apresenta uma lista de imagens nas quais o aplicativo ErgoSV não conseguiu identificar uma face. A lista apresenta os mesmo campos da lista de imagens com face reconhecida (ID, Time Moment, Interval), exceto pelo campo Similarity devido ao fato que o objetivo do aplicativo é comparar imagens faciais com a imagem facial padrão e, assim não é realizada comparação com imagens sem faces identificadas.

Inicialmente foi decidido que imagens sem face reconhecida seriam descartadas, porém testes mostraram que os "descartes" poderiam ser dados relevantes para avaliação porque algo comprometeu a identificação da face e algumas hipóteses poderiam ser analisadas tais com desvio de posicionamento da câmera ou do participante, luminosidade ou mesmo problemas com o aplicativo. A identificação desse problema levaria o avaliador a tomar 
decisões sobre o motivo que levou a esse problema ou mesmo corrigir problemas externos, relativos ao ambiente de teste que também poderiam ter comprometido o reconhecimento. A Figura 36 apresenta a tela de imagens descartadas.

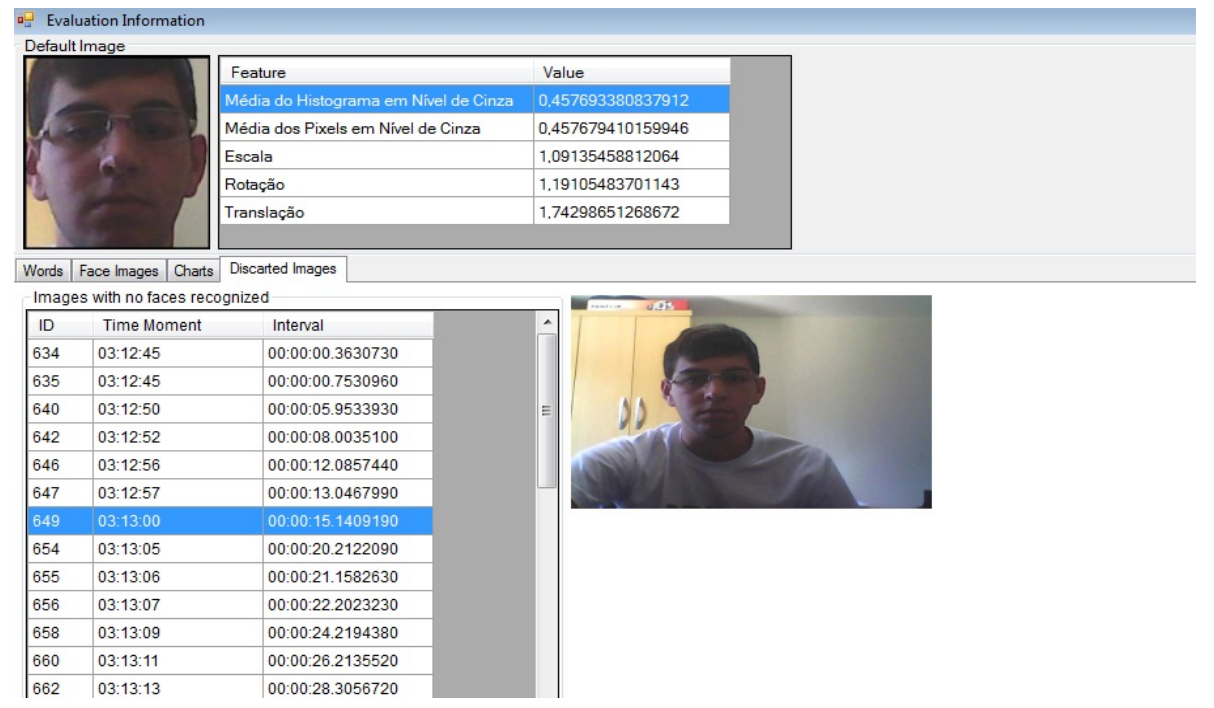

Figura 36 - Tela com a relação de imagens descartadas

\subsubsection{Visualização de Imagens das Telas/Face}

O recurso de visualização de imagens de telas e face é um dos componentes mais importantes desta aplicação. Este recurso permite acesso ao avaliador a imagens da interface que estavam em uso no momento da pronuncia de uma palavra ou de uma reação facial além de permitir o acesso a imagens em momentos próximos a determinado acontecimento. Momentos próximos referem-se a atividades realizadas segundos antes ou segundos após uma reação do participante e o intervalo de tempo utilizado para seleção das imagens em momentos próximos pode ser determinado pelo avaliador, mas inicialmente foi selecionado o valor de 4 segundos antes e depois da reação.

As possíveis reações do participante consideradas para execução desta atividade serão: uma palavra pronunciada; um registro de imagem com reconhecimento de face. As informações disponibilizadas neste módulo foram classificadas de acordo com o tipo de avaliação (análise) realizada e foram estabelecidas como:

(1) Caso o avaliador utilize o recurso de análise somente com dados de fala ou somente com dados de imagens da face, o ErgoSV Analyzer disponibilizará uma interface para visualização somente de imagens da tela do aplicativo testado a partir do momento da palavra pronunciada; Em um segundo caso, (análise completa) o módulo de visualização permitirá acesso as seguintes informações: a primeira são as imagens da tela do aplicativo 
registradas a partir do momento da reação (fala ou imagem) permitindo a navegação nas demais interfaces capturadas dentro do tempo estipulado como "momento próximo". A partir das imagens das telas o avaliador também terá acesso as imagens das faces registradas a partir do momento do registro da imagem da tela. O avaliador pode acessar diretamente as imagens faciais a partir do momento da ação (fala ou imagem) caso utilize o análise completa e a partir da aba Words.

O acesso as informações é feito por meio do fragmento de interface localizado nas abas Words, Face Images e Discarted Images. Esta parte de tela exibe dois campos de texto sendo o primeiro para informar o intervalo de tempo para busca de imagens antes do momento selecionado e a outra para inserção do tempo de busca das imagens após o momento selecionado. A Figura 37 apresenta a tela correspondente quando acessada na aba Words na análise completa, nas demais situações não é apresentada a função View Face Images.

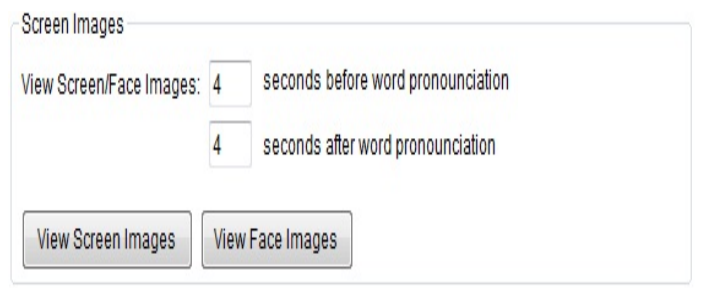

Figura 37 - Interface de seleção de intervalos de tempo

Considerando o preenchimento dos valores dos intervalos, o avaliador deve selecionar qual o momento específico que deseja visualizar as imagens. A seleção deve ser feita em uma das listas disponibilizadas pelo $\operatorname{Ergo} S V$ por meio de sua interface visual.

Não há limites para os valores informados nos intervalos, mas o avaliador é orientado a saber que quanto quanto maior o valor, maior o tempo de espera para carregar as imagens caso escolha uma intervalo grande. Esta situação ocorre devido as características de consulta e carga de imagens de um banco de dados.

Após informar os tempos e selecionar a função View Screen Images uma nova interface é exibida apresentando a imagem da tela utilizada no exato momento da reação selecionada. A Figura 38 apresenta o recurso citado na qual é exibida uma interface registrada em um teste.

A interface de visualização apresenta um painel central dominante no qual é exibida a imagem da tela no momento selecionado e na parte inferior é disponibilizado outro painel que permite a navegação entre as imagens, visualização de dados e acesso a imagens faciais 


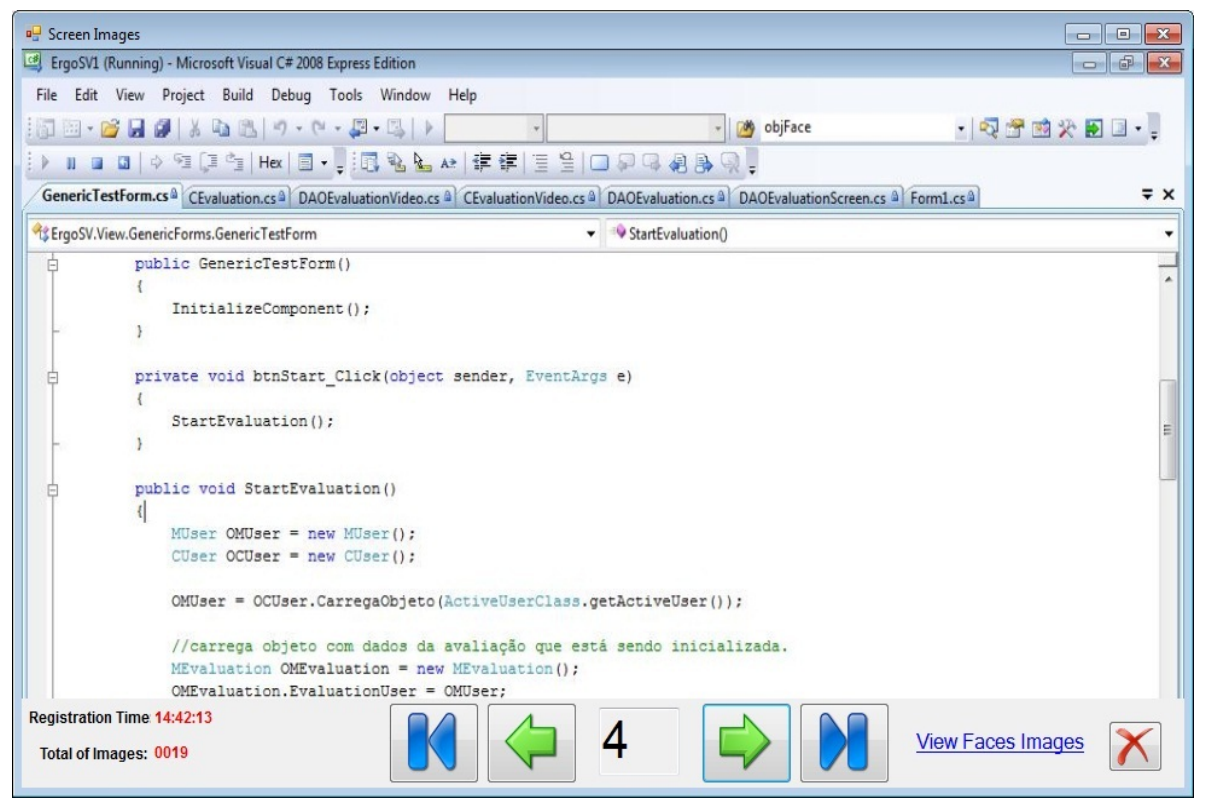

Figura 38 - Interface de visualização de imagens de interface

(quando permitido).

O painel inferior exibe, no centro da tela, um rótulo com um número, apresentado no exemplo da Figura 38 como número 6. Este número se refere ao número da interface exibida no momento, no caso do exemplo é a sexta imagem da lista. O total de imagens recuperadas na busca pode ser visualizado no canto inferior esquerdo no rótulo Total of Images, ou seja, a imagem exibida no exemplo é a sexta imagem de dez que foram recuperadas na lista. Acima do totalizador de imagens é exibido outro rótulo com o título de Registration Time que se refere ao horário que foi registrada essa imagem de tela.

Os botões de navegação possuem as seguintes funcionalidades: Primeiro, Anterior, Próximo e Último. Cada botão permite a navegação pelas imagens exibidas na lista proporcionando ao avaliador uma idéia real de qual o caminho percorrido pelo participante do teste antes, durante e após a reação selecionada. Uma imagem com o símbolo de um raio é exibida ao lado do botão de navegação indicando que a imagem exibida é a aquela registrada no exato momento da reação selecionada pelo avaliador.

Um link é exibido no canto inferior direito com o título View Faces Images e direciona para uma nova interface na qual são exibidas imagens da face do participante no momento em que utilizava a tela exibida, momentos antes e momentos após. O tempo de busca das imagens da face do participante é o mesmo utilizado para a busca de snapshots do teste diferenciando pelo fato que o momento chave é o momento do registro da imagem da tela e não da reação selecionada na interface anterior. As imagens exibidas podem ter uma face reconhecida ou podem ser imagens descartadas. Em ambos os casos são apresentados os 
dados básicos como horários de registro e identificador. Caso seja identificada uma imagem com face reconhecida, são exibidos os dados sobre suas características e também a taxa de similaridade em relação à imagem padrão. Em caso de uma imagem descartada, os dados sobre características e similaridade são ocultados. A Figura 39 apresenta a interface de visualização de imagens faciais.

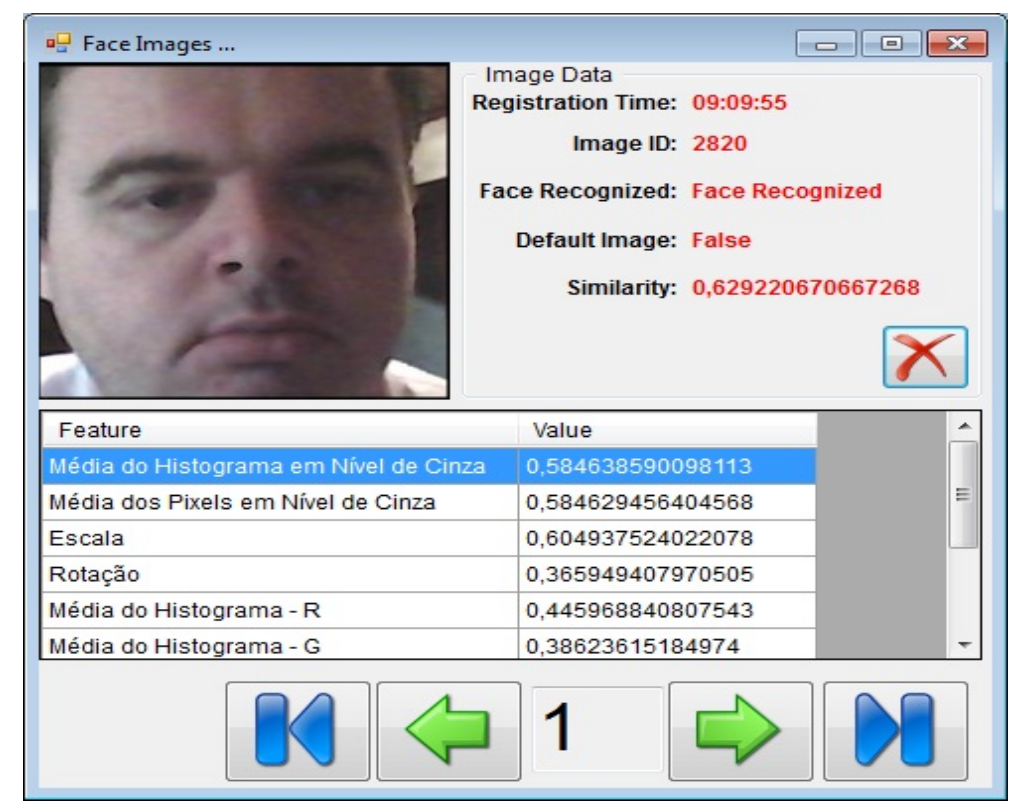

Figura 39 - Interface de visualização de imagens faciais

As regras para utilização dos botões de navegação e recurso da imagem do "raio"são as mesmas apresentadas para a visualização de imagens da tela.

\subsubsection{Função Features Charts}

A função Features Charts apresenta um recurso para visualização de gráficos referentes a valores de similaridade calculados para as imagens de um teste em relação à uma imagem padrão. Segundo Bergamasso (2010), a variação de valores pode influenciar seriamente a taxa de similaridade de uma imagem e essa afirmação pode ser constatada durante os testes para esta pesquisa. Em uma característica com pouca variação de valores entre as imagens a tendência é de um resultado de similaridade maior em relação à uma característica no qual os valores variam severamente. Em outras palavras, a utilização de características com grande variação de valores reduz a taxa de similaridade de uma imagem. Uma melhor análise pode ser feita estudando a Figura 40(a) que apresenta um gráfico com uma característica com menos variação e a Figura 40(b) apresenta um gráfico com uma característica com maior variação. 


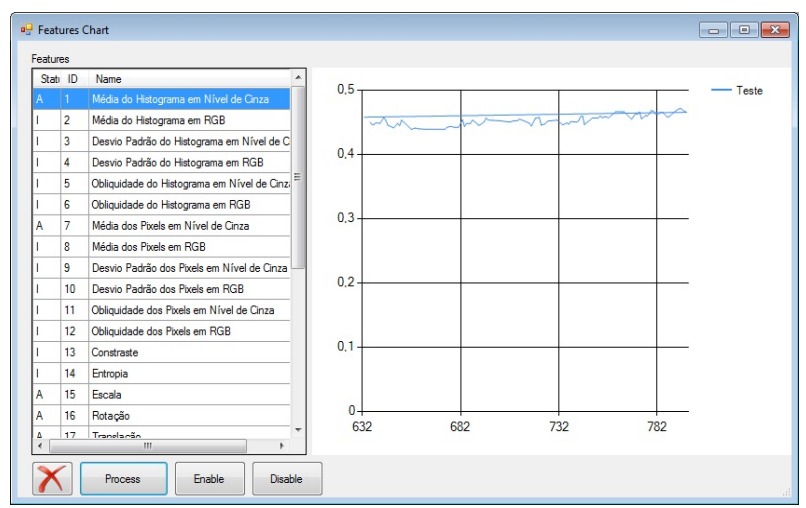

(a) Característica 1

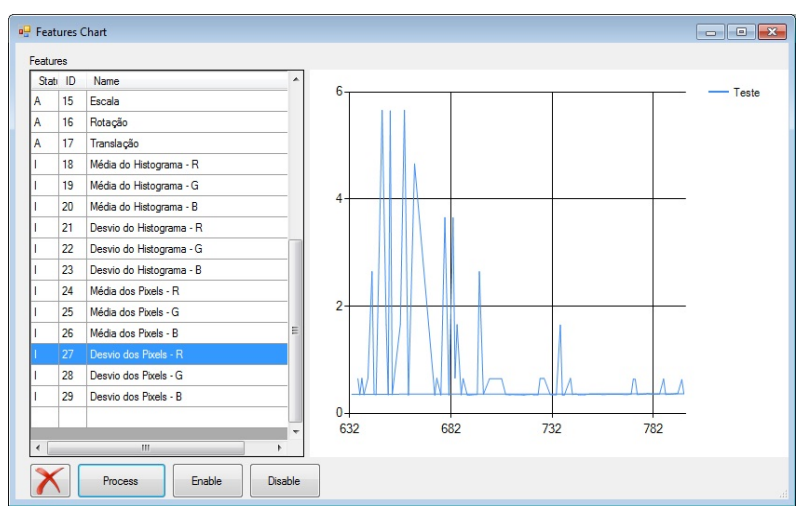

(b) Característica 2

Figura 40 - Gráficos de valores das características

O gráfico apresentado na Figura 40(a) apresenta a variação dos valores da característica "Média do Histograma em Nível de Cinza" e como pode ser observado tem variação pequena e a sua aplicação, de forma isolada, implicaria em um valor maior de similaridade. Entretanto no gráfico 40(b) é possível notar uma maior variação do valores e sua utilização, de forma isolada ou em conjunto com outras características influenciam o valor da similaridade reduzindo o mesmo.

Este módulo do aplicativo ErgoSV Analyzer permite ao avaliador ativar e desativar as características que são incluídas no cálculo de similaridade. Esse recurso foi disponibilizado para auxiliar nos experimentos permitindo a avaliação da função de similaridade combinando várias características. A ativação e a desativação são feitas pelas funções Enable e Disable localizadas na parte inferior da tela. É importante destacar que, ativando ou inativando uma característica a mesma não deixa de ser utilizada com extrator de característica, mas não participa do cálculo da função de similaridade para as imagens.

\subsubsection{Considerações Finais sobre a Estratégia de Uso da Aplicação}

A estratégia de uso dos sistemas $\operatorname{ErgoSV}$ e $\operatorname{ErgoSV}$ Analyzer foi desenvolvida de forma a otimizar as atividades de teste de usabilidade apoiado por técnicas de processamento de imagens e reconhecimento de fala. A divisão em dois módulos, um para coleta de dados e outra para análise de informações foi realizada com objetivo de otimizar a utilização os recursos disponíveis e não sobrecarregar um único sistema oferecendo riscos a qualidade dos dados e informações. Com o correto uso por parte de avaliadores e participantes dos testes pretende-se levar a insumos relevantes como palavras pronunciadas pelo participante, valores de similaridade de imagens, lista de imagens descartadas e imagens 
das telas utilizadas pelo participante, que permitam uma rápida e correta identificação de possíveis problemas de usabilidade assim como características positivas do sistema reduzindo o tempo de análise dos dados a um tempo próximo ao tempo total do teste.

\subsection{Validação da Abordagem}

Esta seção apresenta os experimentos realizados para validar a eficácia da abordagem proposta. Esta fase foi realizada utilizando experimentos, ou seja, testes de usabilidade que eram monitorados pela ferramenta $\operatorname{ErgoSV}$. Os experimentos foram realizados em 3 aplicativos prontos, sendo 2 websites e 1 aplicativo na plataforma desktop por 12 participantes escolhidos entre estudantes de cursos de computação com conhecimento avançados na área e usuários tradicionais.

\subsubsection{Aplicativos Selecionados}

Mesmo considerando que o objetivo deste trabalho foi avaliar a eficiência da ferramenta $\operatorname{ErgoSV}$ e sua abordagem e não a qualidade dos websites e aplicativos testados decidiu-se não divulgação do nome dos sistemas testados. Para este trabalho os mesmos serão chamados de:

- WCE: refere-se a um website de comércio eletrônico;

- WPG: refere-se a um website de um curso de Pós Gradução;

- PEM: refere-se a um software de edição de imagens.

Além destes, dois experimentos foram realizados sem utilizar um aplicativo específico, mas com diversas funções de aplicativos diferentes. Embora não contabilizados nas próximas seções, os mesmos proporcionaram informações que contribuíram para a melhoria da abordagem e do software de forma isolada.

\subsubsection{Experimentos no WEC}

O WEC selecionado é uma ferramenta de comércio eletrônico de uma organização que tem como atuação a comercialização de bolsas, mochilas e acessórios diversos para o público masculino e fiminino das mais variadas faixas etárias. O website permite realizar tarefas relacionadas ao processo de aquisição de produtos da empresa tais como busca 
de produtos, visualização de mercadorias e seus detalhes, processo de compra, processos financeiros, consulta de pedidos, dentre outras atividades.

As atividades selecionadas para os testes consideravam situações reais de uso. Entretanto, os participantes não estavam restritos as estas atividades e estavam autorizadas a navegar e/ou utilizar outros recursos do website desde que todas as tarefas previamente especificadas fossem realizadas. As tarefas indicadas para os participantes foram:

Consulta e Pesquisa: Estas tarefas compreendiam a busca de dados e informações diversas no website tais como buscar uma mercadoria específica, consultar preços, navegar por menus que permitiam a visualização de mercadorias, visualização de detalhes do produto, consulta de informações sobre pedidos, regras de compras, consulta de produtos por marca, modelo, departamento e demais classificações e consulta de informações como franquia e descontos.

Compra: Cada participante foi incentivado a realizar no mínimo um procedimento de compra de mercadorias que envolvia tarefas como escolher um produto, consulta frete, adicionar ao carrinho de compra, lançar cupom de desconto, remover item do carrinho de compra, alterar quantidades, criar e atualizar cadastro pessoal.

Pagamento e Fechamento do Pedido: Nesta fase cada participante realizou atividades tais como: escolha da forma de pagamento, preenchimento de dados de cartão de crédito e/ou conta bancária, parcelamento e adequação de valores. Esclarecendo que foram fornecidos dados fictícios para pagamento e a atividade de teste era finalizada antes da confirmação da compra e que em nenhum momento foi efetivada uma compra e/ou gerado custo aos participantes.

\subsubsection{Experimentos no WPG}

O website WPG utilizado se refere à página de um programa de pós graduação na área de computação. Este foi disponibilizado no ano de 2013 em uma nova versão e apresenta uma série de informações do curso em questão. O mesmo disponibiliza informações como lista de professores, alunos, egressos, diretrizes do programa, calendários de atividades, lista e horários de disciplinas. O usuário pode também efetuar a aquisição gratuita de modelos de documentos do programa que são utilizados para atividades como matrículas, transferências e modelos de trabalhos. Neste website não são disponibilizados recursos de manipulação de dados tais como cadastros, alterações, compra e venda o que faz o objetivo do website puramente informativo. 
As atividades selecionadas para o teste do $W P G$ foram:

Consultar informações do curso: Conhecer detalhes do curso tais como diretrizes, informações para ingresso, linhas de pesquisa e requisitos para finalizar o curso.

Pessoas envolvidas com o curso: Visualizar dados dos professores, suas linhas de trabalho, lista de alunos, ter acesso a lista completa de egressos, acessar currículos de todos os envolvidos, trabalhos disponíveis de professores e alunos.

Informações Gerais: Ter acesso a quaisquer informações que o participante considerasse necessária e caso não a encontrasse, ter acesso a um ambiente de contato com pessoas ou setores que podem sanar tal dúvida.

\subsubsection{Experimentos no PEM}

O terceiro aplicativo testado foi um software desenvolvido na plataforma desktop para edição de imagens. Este aplicativo é gratuito e bem conhecido por diversos usuários e realiza atividades de edição de imagens tais como alterar nitidez, renomear fotos, fazer montagens com diversas imagens, mudar padrão de cores, salvar novas imagens, imprimir imagens alteradas dentre outros recursos.

As atividades selecionadas para o teste com o PEM são:

Seleção e Manipulação de Foto: Selecionar uma foto no aplicativo e aplicar comandos de modificação para ajuste de características como contraste, nitidez, brilho, inserção de molduras e salvar uma foto alterada.

Editor de Lotes: Fazer a manipulação (alteração) de diversas imagens ao mesmo tempo, aplicando as modificações em lote.

Páginas e Combinação: Criar uma página utilizando vários layouts disponibilizados pelo aplicativo para criar uma foto utilizando a combinação de várias fotos disponíveis no computador.

GIF: Criar um arquivo .gif com fotos disponíveis no computador.

Impressão: Selecionar um layout de impressão de fotos, adicionar fotos a impressão e efetuar configurações diversas de impressão.

Ajuda: Acessar módulo de ajuda do aplicativo. 


\subsubsection{Considerações finais sobre a escolha dos aplicativos}

Para os testes com websites, os participantes não eram avisados previamente qual era o endereço a ser testado. Esta decisão foi tomada considerando que um aplicativo na plataforma web pode ser acessado a qualquer momento e por qualquer pessoa e deve prover condições de uso e realização de todas as tarefas sem a necessidade de um treinamento prévio. Para o aplicativo PEM os participantes foram avisados com 5 dias de antecedência e receberam informações de como adquirir e instalar o aplicativo. Por ser um aplicativo na plataforma desktop decidiu-se que seria melhor o participante ter um contato prévio com a aplicação, entretanto não foi monitorado ou confirmado se a pessoa realizou tal tarefa.

Além destes aplicativos, dois participantes realizaram um teste cada que foram classificados como Testes Gerais pois os mesmos utilizaram diversas funções do sistema operacional e de demais software sem obedecer uma regra sistemática. Embora realizados em curto período de tempo os testes foram incluídos na lista de experimentos por conter dados que poderiam ser relevantes para validação da ferramenta.

Na próxima seção será apresentada a seleção de participantes.

\subsubsection{Seleção de Participantes}

Para a validação foram selecionados 12 participantes que realizaram os experimentos com base nas tarefas e nos aplicativos citados anteriormente. A quantidade de participantes foi fundamentada na afirmação de Nielsen (1993) no qual aponta que uma avaliação de usabilidade apresenta resultados bastante satisfatórios quando realizada pelo número mínimo de 4 ou 5 pessoas e que devem realizar suas tarefas separadas uma das outras para não influenciar a opinião e análise de determinadas interfaces. Os participantes foram selecionados considerando uma faixa etária variada assim como os conhecimentos sobre tecnologia da informação e mais especificamente, IHC. Mesmo que alguns participantes tivessem conhecimento de informática básica e outros, como alunos ou profissionais de computação, um conhecimento maior, todos os participantes estava familiarizados com a utilização de website e aplicativos e assim não apresentaram dificuldades na utilização dos aplicativos escolhidos

A Tabela 8 apresenta as características do participantes dos testes.

Esses participantes realizaram seus testes separados um dos outros e acompanhados 
Tabela 8 - Características dos participantes dos experimentos

\begin{tabular}{l|l}
\hline Característica & Informações \\
\hline Idade & 18 a 45 anos \\
\hline Média de Idade & 21 anos \\
\hline Moda (Idade) & 18 anos \\
\hline Desvio Padrão da Idade & 8,04 \\
\hline Sexo Masculino & 11 participantes \\
\hline Sexo Feminino Inoçado & 1 participante \\
\hline $\begin{array}{l}\text { Conhecimento Avarticipantes } \\
\text { em Tecnologia da In- } \\
\text { formação }\end{array}$ & 8 participantes \\
\hline $\begin{array}{l}\text { Conhecimento Inediário em Tecnologia da } \\
\text { Informação }\end{array}$ & \\
\hline $\begin{array}{l}\text { Conhecimento Básico em } \\
\text { Tecnologia da Informação }\end{array}$ & 1 participante \\
\hline $\begin{array}{l}\text { Utiliza E-commerce com } \\
\text { frequência }\end{array}$ & Todos os participantes: SIM \\
\hline $\begin{array}{l}\text { Conhecimentos sobre } \\
\text { técnicas de avaliação de } \\
\text { usabilidade }\end{array}$ & 3 Participantes \\
\hline
\end{tabular}

somente pelo pesquisador que estava presente para resolver possíveis problemas que ocorressem além de tirar dúvidas sobre o $\operatorname{ErgoSV}$, website / software testado ou qualquer situação de não conformidade identificada.

Antes do inicio de cada experimento, o participante era informado do objetivo do teste e que seriam registradas imagens faciais e as palavras chave pronunciadas pelo mesmo. Em virtude de questionamento de alguns participantes que temiam que sua capacidade de utilizar um computador se tornasse foco da avaliação, o participante recebia o esclarecimento que o foco era a validação da abordagem de teste de usabilidade e a ferramenta ErgoSV e que em momento algum seria objetivo de análise ou avaliação.

A seguir serão explicadas as estratégias utilizadas nos experimentos.

\subsubsection{Estratégias de Validação da Abordagem}

A validação da abordagem de teste de usabilidade apoiado por técnicas de processamento de imagens e processamento de fala foi realizada utilizando o aplicativo ErgoSV desenvolvido especificamente para as atividades desta pesquisa. O aplicativo apresenta funções para coleta de dados tais como imagens faciais, palavras pronunciadas e imagens da tela. 
Para correta validação os participantes receberam orientações a respeito do aplicativo, do funcionamento da abordagem e como o software auxiliaria a validação do ambiente.

O primeiro passo para realização do teste era uma apresentação verbal e visual sobre conceitos de IHC, avaliação de usabilidade na qual os participantes foram posicionados sobre o objetivo principal do teste e o posicionamento do teste de usabilidade frente a necessidade do desenvolvimento de sistema interativos. Embora cada participante tenha realizado seu teste de forma isolada em todos os experimentos, os mesmos se reuniram em um horário e local combinado para as instruções iniciais principalmente na primeira vez que participaram do experimento.

Após receber orientações sobre a abordagem e o aplicativo, os participantes eram conduzidos até um computador notebook com uma webcam instalada e um microfone. $\mathrm{O}$ computador estava devidamente localizado em uma sala com o mínimo de ruído possível para não afetar o reconhecimento de fala e/ou distrair o participante na realização de suas tarefas.

Os participantes receberam uma folha contendo as palavras chave que poderiam ser utilizadas no teste e seus respectivos significados além de serem orientados a pronunciarem uma palavra para cada ação que realizassem no aplicativo tais como mudança de interface, acionamento ou interrupção de uma função ou a visualização de uma mensagem. Os usuários foram lembrados que era permitida a pronuncia somente das palavras chave especificadas. Os significados de cada palavra foram apresentados e os mesmos avisados que os conceitos escolhidos se aplicavam única e especificamente aos experimentos desta pesquisa e que cada termo não refletia demais realidades.

Foram escolhidas cinco palavras chave que são consideradas adjetivos. As palavras escolhidas eram pequenas, fáceis de memorizar e cada uma representava um conceito de qualidade. As mesmas eram apresentadas aos participantes da maior (melhor conceito) para a menor (pior conceito). As palavras e significados determinados para os testes foram:

- Ótimo: a interface é agradável, utilizável, intuitiva e permitiu que a realização de suas atividades com eficácias, eficiência e satisfação sem apresentar qualquer problema;

- Bom: foi possível realizar as tarefas pois o sistema é simples, intuitivo, porém apresenta pequenas questões que atrapalharam o perfeito andamento da tarefa;

- Regular: a interface tem problemas de design que comprometem o bom andamento 
das tarefas impedido/atrasando o usuário na realização das tarefas do propostas;

- Ruim: a baixa qualidade da interface compromete significativamente a realização das atividades e a utilização dos recursos do sistema testado, poucas tarefas puderam ser realizadas;

- Péssimo: não foi possível realizar nenhuma tarefa na interface apresentada.

Para finalizar as orientações a respeito do reconhecimento de fala, o participante era avisado que deveria pronunciar as palavras em tom de voz normal e forte evitando falar baixo. Essas orientações eram passadas seguindo os resultados dos testes efetuados na ferramenta Coruja que mostraram uma boa taxa de reconhecimento de palavras quando a mesma era pronunciada de forma clara.

No próximo passo, o participante era informado sobre a necessidade de registrar uma imagem padrão antes de iniciar o teste. Uma imagem padrão foi definida como uma foto da face do participante com reação neutra (CASTILHO, 2011). A Figura 41(a) apresenta um exemplo de imagem padrão registrada nos teste enquanto as Figuras 41(b) e 41(c) apresenta um exemplo de imagem que não eram consideradas padrão. Caso uma imagem não padrão, que é uma foto na qual o participante expressa alguma reação ou uma face não é reconhecida, fosse registrada no momento do registro da foto padrão, a mesma era descartada para realização de novo registro.

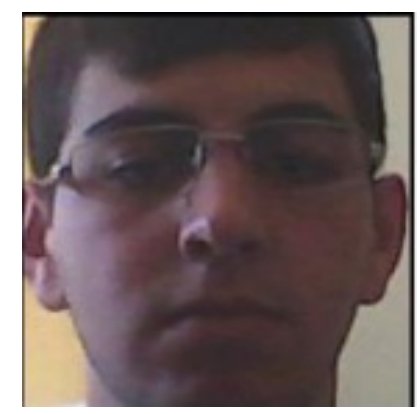

(a) Imagem Padrão

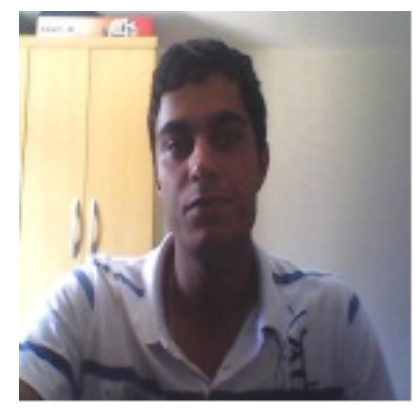

(b) Imagem Não Padrão

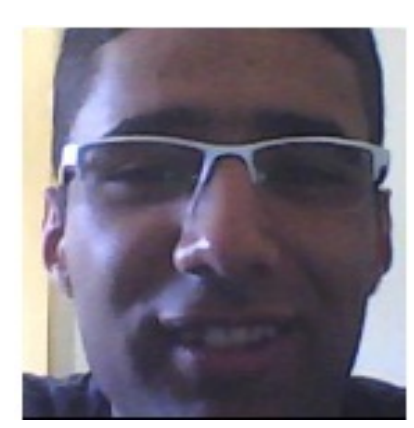

(c) Imagem Não Padrão

Figura 41 - Imagem padrão X Não padrão

Ciente dos procedimentos e registros de dados, o participante era informado a respeito da lista de tarefas. Uma lista contendo as atividades descritas na seção anterior foi disponibilizada aos usuários acompanhada de suas explicações.

Após a foto padrão, participante era liberado para efetuar o teste utilizando o computador de teste no qual continha acesso a Internet para avaliações de websites ou o devido 
aplicativo desktop instalado. Por último, os participantes receberam a informação de que a imagem da tela utilizada seria registrada dentro de um intervalo de tempo específico e a imagem seria utilizada para identificar qual componente da aplicação foi avaliado no momento de uma determinada reação. Finalizadas todas as instruções e a preparação do participante, o teste era iniciado.

Alguns testes foram realizados por completo dentro de um único registro do ErgoSV, ou seja, não ocorreram interrupções entre o início e o término da avaliação. Entretanto, fatores externos tais como a falta de Internet para acessar os website, problemas com o sistema $\operatorname{ErgoSV}$ ou com o computador, interrupções de outras pessoas (embora cuidados tenham sido tomados para não ocorrer) forçaram a pausa de algumas avaliações. Estas pausas ocorreram nos três primeiros experimentos e não influenciaram a análise dos dados sendo que a única interferência significativa foi um maior intervalo entre o registro de uma imagem e/ou palavra pronunciada em relação ao intervalo definido no início do teste.

\subsubsection{Experimentos}

Esta seção apresenta o experimentos realizados para validação do ambiente de avaliação de usabilidade proposto, assim como a utilização das ferramentas ErgoSV e ErgoSV Analyzer para apoiar os testes. São apresentados e discutidos os resultados obtidos nos experimentos.

\subsubsection{Coleta de Dados}

Para validação da ferramenta ErgoSV foram realizados 16 testes em 3 aplicativos diferentes utilizados por 12 participantes os quais 5 deles realizaram mais de um teste. A quantidade de testes efetuados em cada aplicativo é apresentada na Tabela 9.

Tabela 9 - Quantidade de testes por aplicativo

\begin{tabular}{l|l}
\hline Aplicativo & Qtde. \\
\hline WCE & 5 \\
\hline WPG & 3 \\
\hline PEM & 6 \\
\hline Testes Gerais & 2 \\
\hline Total & 16 \\
\hline
\end{tabular}

De todos os testes realizados, 2 deles não utilizaram os recursos de imagens e fala em conjunto (teste completo) sendo 1 teste realizado somente com dados de fala devido a problema com o funcionamento de uma webcam e outro teste somente faciais com imagens 
devido a restrições de barulho no local realizado. Entretanto, ambos os testes utilizaram o recurso de registro de snapshots para apoia na identificação de possíveis interfaces com problemas. Os identificadores dos testes nesta pesquisa são: o teste número 1 para o teste somente com dados de fala e o teste número 11 para o teste somente com dados de imagem.

O tempo médio de cada teste foi de 12 minutos e ocorreram com certa facilidade já que os participantes não apresentaram dificuldades em utilizar os aplicativos. Acredita-se que o fato de todos os participantes terem o conhecimento básico em computação e serem usuários comuns da Internet e de aplicativos diversos contribuiu para tal facilidade. A Tabela 10 apresenta a lista de testes realizados.

Tabela 10 - Lista de experimentos da abordagem

\begin{tabular}{|c|c|c|c|c|}
\hline $\mathbf{N}$ & Aplicativo & Duração & Intervalo Face & $\begin{array}{l}\text { Intervalo Te- } \\
\text { las }\end{array}$ \\
\hline 1 & WCE & $25 \min$. & 1 segundo & 1 segundo \\
\hline 2 & WCE & 13 min. & 1 segundo & 1 segundo \\
\hline 3 & WCE & 13 min. & 1 segundo & 1 segundo \\
\hline 4 & WCE & 10 min. & 1 segundo & 1 segundos \\
\hline 5 & WCE & $10 \mathrm{~min}$. & 2 segundos & 2 segundos \\
\hline 6 & WPG & 8 min. & 1 segundo & 1 segundo \\
\hline 7 & WPG & 8 min. & 1 segundo & 1 segundo \\
\hline 8 & WPG & 9 min. & 1 segundo & 1 segundo \\
\hline 9 & PEM & $7 \mathrm{~min}$. & 2 segundos & 2 segundoss \\
\hline 10 & Testes Gerais & 2 min. & 1 segundo & 1 segundo \\
\hline 11 & Testes Gerais & $3 \mathrm{~min}$. & 1 segundo & 1 segundo \\
\hline 12 & PEM & 13 min. & 1 segundo & 1 segundo \\
\hline 13 & PEM & 10 min. & 1 segundo & 1 segundos \\
\hline 14 & PEM & 8 min. & 1 segundo & 1 segundos \\
\hline 15 & PEM & 11 min. & 2 segundos & 2 segundos \\
\hline 16 & PEM & 8 min. & 2 segundos & 2 segundos \\
\hline
\end{tabular}

Conforme apresentado na Tabela 10 os dados estatísticos referentes aos testes podem ser visualizados na Tabela 11.

Tabela 11 - Estatísticas dos teste

\begin{tabular}{l|l}
\hline Estatística & Valor \\
\hline Teste mais curto & 2 minutos \\
\hline Teste mais longo & 25 minutos \\
\hline Tempo médio dos testes & 10 minutos \\
\hline Tempo com maior ocorrência & 8 minutos (4 ocorrências) \\
\hline Desvio Padrão & 5,94 \\
\hline
\end{tabular}


O tempo total de monitoramento foi de 2 horas e 37 minutos os quais foram contabilizadas 201 palavras chave pronunciadas e devidamente reconhecidas, 3323 imagens faciais e o total de imagens de tela foi de 3526. Quando citado o termo imagens candidatas, o mesmo se refere a imagens sem o processamento facial, ou seja, contabiliza-se tanto imagens com face reconhecida quanto imagens descartadas.

As quantidades de palavras, imagens faciais reconhecidas, imagens descartas e imagens de tela de todos os testes são apresentadas na Tabela 12

Tabela 12 - Quantidade de dados registrados

\begin{tabular}{l|l|l|l|l}
\hline $\mathbf{N}$ & Aplicativo & Palavras & Imagens & Snapshot \\
\hline 1 & WCE & 29 & 522 & 527 \\
\hline 2 & WCE & 12 & 459 & 455 \\
\hline 3 & WCE & 26 & 429 & 426 \\
\hline 4 & WCE & 00 & 31 & 18 \\
\hline 5 & WCE & 08 & 150 & 158 \\
\hline 6 & WPG & 15 & 324 & 284 \\
\hline 7 & WPG & 04 & 312 & 281 \\
\hline 8 & WPG & 07 & 129 & 115 \\
\hline 9 & PEM & 30 & 147 & 130 \\
\hline 10 & Testes Gerais & 10 & 48 & 47 \\
\hline 11 & Testes Gerais & 00 & 44 & 32 \\
\hline 12 & PEM & 24. & 523 & 433 \\
\hline 13 & PEM & 00 & 27 & 17 \\
\hline 14 & PEM & 00 & 309 & 258 \\
\hline 15 & PEM & 23 & 217 & 197 \\
\hline 16 & PEM & 13 & 174 & 158 \\
\hline
\end{tabular}

Divergências entre o tempo aproximado dos testes, a quantidade de imagens registradas (face e tela) e o intervalo de registro de imagens estipulado ocorreram devido a interrupções ocasionadas nos experimentos por motivos diversos tais como queda de energia, interrupção do serviço de Internet ou problemas com o aplicativo testado e o $\operatorname{ErgoSV}$.

A quantidade de palavras registradas, processo que dependia da ação humana de pronunciar a palavra, teve grande variação em relação à quantidade devido ao fato que alguns participantes pronunciaram um número maior de palavras por ação e outros se mostraram mais tímidos. A princípio, o participante foi cobrado para pronunciar mais palavras, porém foi possível perceber que alguns se mostraram tensos ou retraídos com a cobrança. Embora instruídos a respeito da necessidade de pronunciar uma palavra em tom de voz alto e firme a cada ação realizada no software tal como um clique em um botão, uma consulta ou uma simples ação de mudar a interface movendo a barra de rolagem ou 
no máximo a cada 15 segundos em certos casos o participante demorou para falar.

O total de palavras registradas em cada teste é a soma dos conceitos pronunciados que pode ser uma das palavras selecionadas para o teste: Ótimo, Bom, Regular, Ruim e Péssimo. A Tabela 13 apresenta os totais de palavras pronunciadas por conceito.

Tabela 13 - Quantidade de palavras registradas

\begin{tabular}{l|l|l|l|l|l}
\hline & Ótimo & Bom & Regular & Ruim & Péssimo \\
\hline WCE & 1 & 59 & 14 & 1 & 2 \\
\hline WPG & 1 & 16 & 6 & 1 & 0 \\
\hline PEM & 3 & 27 & 10 & 1 & 0 \\
\hline Total & 5 & 102 & 30 & 3 & 3 \\
\hline
\end{tabular}

As imagens dos participantes registradas nos testes passava, ainda na fase de coleta de dados, pelo processamento da ferramenta $O p e n C V$ no qual procurava uma imagem facial na foto. Em caso positivo a mesma era classificada como "Relevante" e ao contrário como "Descarte".

A princípio, as imagens descartadas não seriam utilizadas na fase de análise, porém decidiu-se mantê-las porque poderiam fornecer dados relevantes para verificação do motivo da não identificação facial. Reforçando que a deteç̧ão de imagem facial era realizada por um framework conhecido por OpenCV que foi integrado ao ErgoSV para permitir a utilização de seus recursos na totalidade sem a necessidade de alterar o código fonte responsável pelo reconhecimento. A Tabela 14 apresenta os totais referentes ao registro, reconhecimento de face e descarte das imagens dos testes.

Tabela 14 - Quantidade de imagens registradas versus imagens descartadas

\begin{tabular}{l|l}
\hline Aplicativo & Imagens \\
\hline WCE & 364 \\
\hline WPG & 614 \\
\hline PEM & 800 \\
\hline
\end{tabular}

Após a coleta, as imagens faciais passaram por uma fase de pré processamento a fim de enriquecer seus dados para apoiar de forma mais efetiva a análise do teste. A fase de Pré Processamento é explicada a seguir.

\subsubsection{Pré Processamento dos Dados}

Embora a maioria dos dados tivessem sido coletados e processados já na primeira fase do teste empregando-se o aplicativo $\operatorname{ErgoSV}$, alguns processamentos necessitaram ser 
deixados para realização em uma fase posterior devido ao alto custo computacional que poderia comprometer o desempenho do aplicativo na fase de coleta de dados. O principal processamento realizado foi a extração de características e o cálculo de similaridade de todas as imagens faciais registradas.

A princípio, um dos objetivos desta pesquisa era identificar se uma imagem facial registrada durante o teste era igual ou diferente a imagem padrão e esta verificação foi aplicada nos três primeiros experimentos. A técnica utilizada foi uma simples comparação dos pixels das imagens no qual o valor de um pixel na posição X da imagem padrão era comparado com o valor do pixel na posição X da imagem candidata. Esta comparação retornou $100 \%$ das imagens candidatas diferentes das imagens padrão.

Esta situação ocorreu em imagens visivelmente diferentes e com imagens que a "olho nu"se mostravam iguais. Por serem imagens recolhidas em um ambiente real no qual os participantes estavam sujeitos a movimentações diversas e sem controle que levaram a alterações dos valores dos pixels nas posições analisadas e consequentemente a divergência da imagem. Considerando que o algoritmo comparava pixel a pixel, qualquer diferença mínima para mais ou para menos o retorno do código era, sempre, a diferença das imagens.

Após analisadas as imagens e realizados testes informais (foras dos experimentos) concluiu-se que não seria possível utilizar esse algoritmo para comparação das imagens e que a utilização de um classificador do gênero: $A$ imagem é diferente da padrão: $S I M / N \tilde{A} O$ seria algo inviável. Portanto, decidiu-se verificar outras técnicas para comparação das imagens que levou a conclusão da necessidade da utilização da Recuperação de Imagens Baseado em Conteúdo (CBIR) (BERGAMASSO, 2010; NUNES, 2011).

Com a técnica CBIR foram extraídas uma série de características faciais (padrão e candidatas) utilizando algoritmos de extração de características de (BERGAMASSO, 2010) e comparadas por meio de uma função de similaridade disponibilizada na ferramenta AForge (www.aforgenet.com).

Os extratores utilizados nesta pesquisa foram de cores e de formas e, após extraídos, os extratores retornaram valores matemáticos que representavam as características das imagens. Para cada imagem do teste foram extraídas as seguintes características:

- Desvio Padrão do Histograma em Cinza;

- Média do Histograma em Cinza;

- Desvio Padrão do Histograma em RGB; 
- Média do Histograma em RGB;

- Desvio Padrão dos Pixels em Cinza

- Média dos Pixels em Cinza;

- Desvio Padrão dos Pixels em RGB;

- Média dos Pixels em RGB;

- Escala;

- Rotação;

- Translação

Após execução dos algoritmos de extração, todas as imagens passaram a ter um vetor de características, permitindo assim, a execução do algoritmo de cálculo de similaridade. A similaridade euclidiana retorna um valor ajustado entre 0 e 1 no qual quanto mais próximo de zero menor a similaridade e quanto mais próximo de 1 maior a similaridade.

A princípio, o cálculo de similaridade foi feito considerando todas as características extraídas das imagens, porém, percebeu-se que o valor da similaridade apresentado foi extremamente baixo, por exemplo, 0,005\% de similaridade em uma imagem relativamente semelhante a imagem padrão, quando analisada a "olho nu". Visando resolver esse problema e seguindo uma linha de raciocínio apresentada por (BERGAMASSO, 2010) foi iniciada uma análise dos valores extraídos das características de cada imagem.

Como resultado, foi possível identificar algumas características com grande variação de valores em relação ao valor da imagem padrão. Por exemplo, se considerarmos o valor da imagem padrão e efetuarmos o levantamento dos valores das imagens candidatas para a característica A a variação dos valores era visivelmente menor que a característica B. As Figuras 42(a) e 42(b) apresentam os valores obtidos em duas características diferentes.

Como pode ser analisada nas figuras, a característica A (Média do Histograma em Nível de Cinza) tem uma variação de valores menor em relação ao valor obtido na característica da imagem padrão em relação à característica B (Desvio Padrão do Pixel B). A utilização característica B reduz de forma significativa a taxa de similaridade da imagem e a mesma situação ocorrem com demais características que apresentem maior variação.

Considerando as duas imagens faciais apresentadas na Figura 43 com suas respectivas características, sendo a imagem superior a imagem padrão e a imagem inferior a imagem 


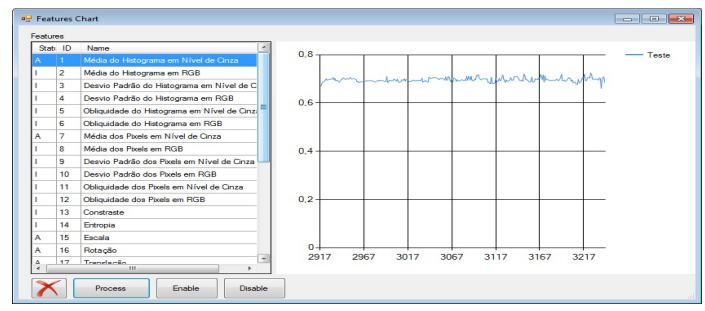

(a) Variação Característica A

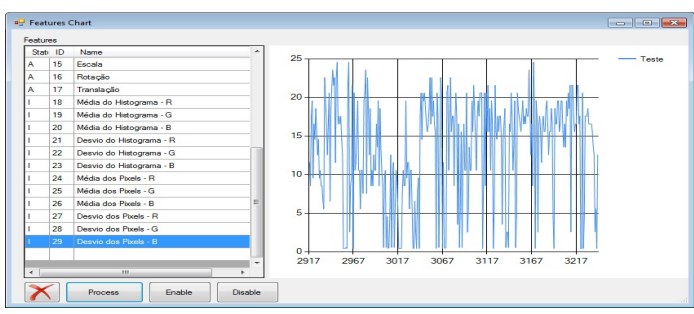

(b) Variação Característica B

Figura 42 - Variação dos valores das características

candidata, em testes no qual não foi utilizada a característica B (Desvio Padrão do Pixel B), a taxa de similaridade foi de 0,91970 e quando a característica B foi aplicada a valor da similaridade reduziu para 0,111 .

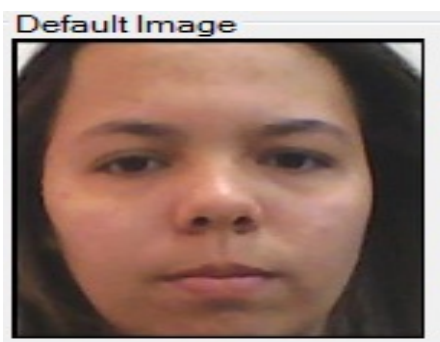

\begin{tabular}{|l|l|}
\hline Feature & Value \\
\hline Média do Histograma em Nivel de Cinza & 0.569852782104534 \\
\hline Média dos Pixels em Nivel de Cinza & 0.569840454299621 \\
\hline Escala & 0.67106166890997 \\
\hline Rotação & 0.45032376348058 \\
\hline Translação & 0.935777087384923 \\
\hline
\end{tabular}

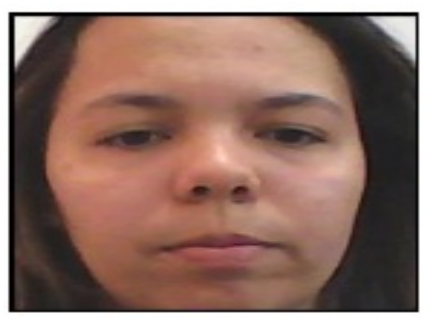

\begin{tabular}{|l|l|}
\hline Feature & Value \\
\hline Média do Histograma em Nivel de Cinza & 0.573253305207752 \\
\hline Média dos Pixels em Nivel de Cinza & 0.573241461131198 \\
\hline Escala & 0.683149015299602 \\
\hline Rotação & 0.466692577104845 \\
\hline Translação & 1.02054465896454 \\
\hline
\end{tabular}

Figura 43 - Imagem padrão X Imagem candidata e suas respectivas características

Ainda foi realizada uma análise de quais características sofreram menor variação, ou seja, tiveram comportamento semelhante ao gráfico da característica de Média do Histograma em Nível de Cinza.

As características selecionadas para comparação em todos os testes foram:

- Média do Histograma em Nível de Cinza;

- Média dos Pixels em Nível de Cinza;

- Escala;

- Rotação;

- Translação; 
Embora algumas características tenham apresentado maior variação em alguns testes e maior linearidade em outros buscou-se analisar quais características mantiveram um padrão de valores os quais eram apresentados por gráficos mais lineares.

Após o processamento das imagens para identificar o valor matemático e a similaridade das imagens de todos os testes, os dados foram considerados adequados e assim disponibilizados por completo para análise. O processo de análise será explicado na próxima seção.

\subsubsection{Análise dos Dados}

Após a coleta dos dados e a realização de todos os processamento necessários, os dados foram disponibilizados para os processos de análise.

O principal objetivo da análise era verificar se abordagem permitiria realmente reduzir o tempo gasto para identificar interfaces com problemas de usabilidade em relação à teoria de Nielsen (1993) que afirma que o tempo para análise dos dados de um teste é de 2 a 3 vezes o tempo do teste. Para isso, os dados foram agrupados de acordo com o software testado e o tempo de teste foi somado chegando a um tempo total de teste final. O tempo ideal estipulado para análise utilizando esta abordagem deveria ser menor que o tempo do teste ou, no máximo, 1,5 vezes maior. Este parâmetro foi escolhido considerando que o objetivo da abordagem seria claramente atingido caso reduzisse o tempo de análise em relação ao máximo estipulado por Nielsen (1993). Com o agrupamento dos resultados foi possível definir qual o tempo limite para análise dos dados conforme apresentado na Tabela 15.

Tabela 15 - Tempos utilizados para parâmetros para análise

\begin{tabular}{l|l|l}
\hline Software & Tempo de Teste(Min.) & $\begin{array}{l}\text { Tempo Máximo de } \\
\text { Análise Esperado (Min) }\end{array}$ \\
\hline WCE & 71 & 107 \\
\hline WPG & 25 & 38 \\
\hline PEM & 57 & 86 \\
\hline
\end{tabular}

As atividades de análise dos dados foram realizadas de três formas diferentes e na seguinte ordem: (1) utilizando somente dados de voz: nesta abordagem foram disponibilizadas todas as palavras pronunciadas, reconhecidas e seus dados além das imagens das telas utilizadas pelo participantes no momento da pronuncia e instantes antes e após; (2) utilizando somente dados de imagens: para estas avaliações, foram utilizadas somente imagens com faces reconhecidas, imagens descartadas e imagens das telas nos 
momentos próximos ao registro da reação; (3) na terceira e última forma, a análise foi realizada utilizando uma combinação de palavras pronunciadas e imagens registradas.

As análises foram feitas restringindo ou liberando dados em determinados momentos de acordo com os recursos disponibilizados na ferramenta ErgoSV Analyzer. Porém, em todas as abordagens utilizadas foram disponibilizadas as imagens da tela no momento de uma determinada reação. A Figura 44 apresenta a estrutura de análise realizada no ErgoSV Analyzer.

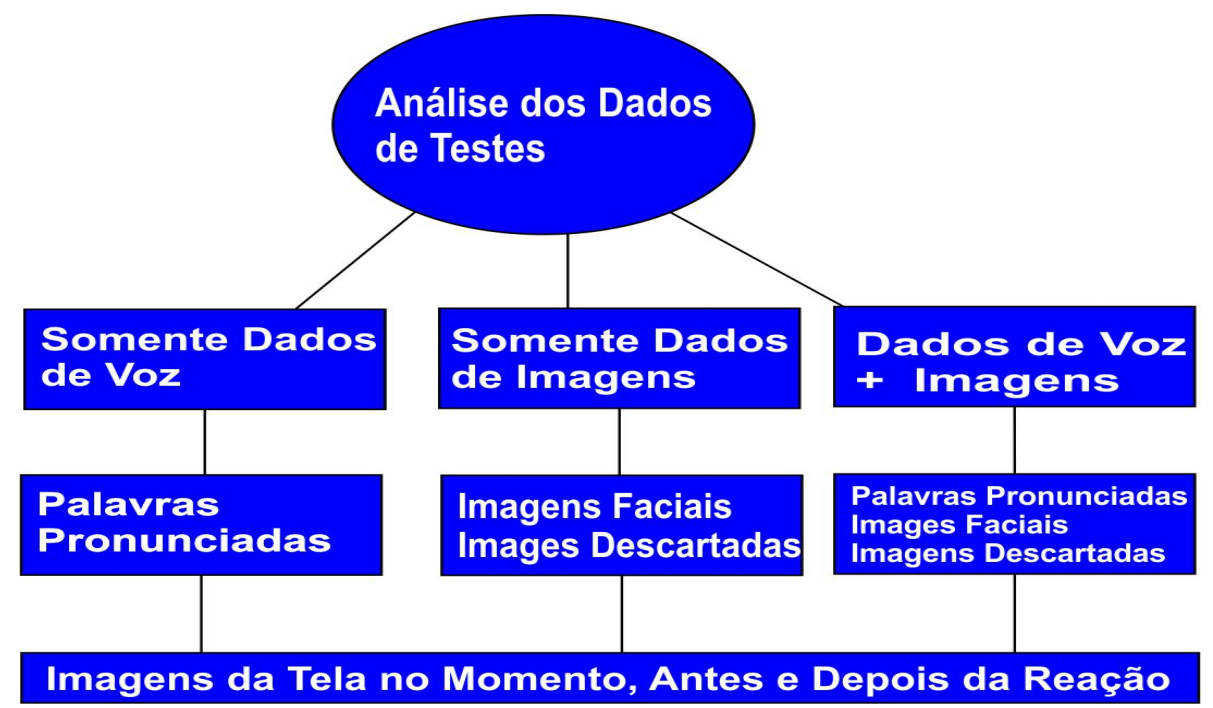

Figura 44 - Estrutura de análise dos dados

Nas próximas subseções serão detalhadas as atividades de análise com as três abordagens propostas assim como os resultados obtidos em cada uma.

\subsubsection{Análise Somente com Dados de Voz}

A primeira abordagem foi realizada utilizando somente dados de fala, ou seja, dados relativos a palavras pronunciadas pelo participante. Nesta análise, foram disponibilizados os 15 experimentos realizados com a utilização de palavras pronunciadas e o recurso de "análise somente com dados de voz" do aplicativo ErgoSV Analyzer que disponibilizava a lista de palavras pronunciadas e seus respectivos momentos, além do gráfico que apresentava o total de palavras pronunciadas agrupadas por conceitos.

A primeira etapa desta abordagem foi realizada utilizando o gráfico de palavras a fim de obter uma ideia geral da satisfação do participante com o sistema. Como as palavras pronunciadas refletiam conceitos de qualidade representando maior ou menor satisfação. O gráfico de pizza apresentava uma "fatia" para cada palavra pronunciada e se mostrou 
eficiente como recurso para se obter uma visão inicial da opinião do participante sobre o sistema.

A Figura 45 apresenta um comparativo entre dois gráficos que representam as palavras pronunciadas em dois testes. É possível observar nesses gráficos que a opinião dos participantes foi, em mais de 50\%, satisfatória para os dois casos.
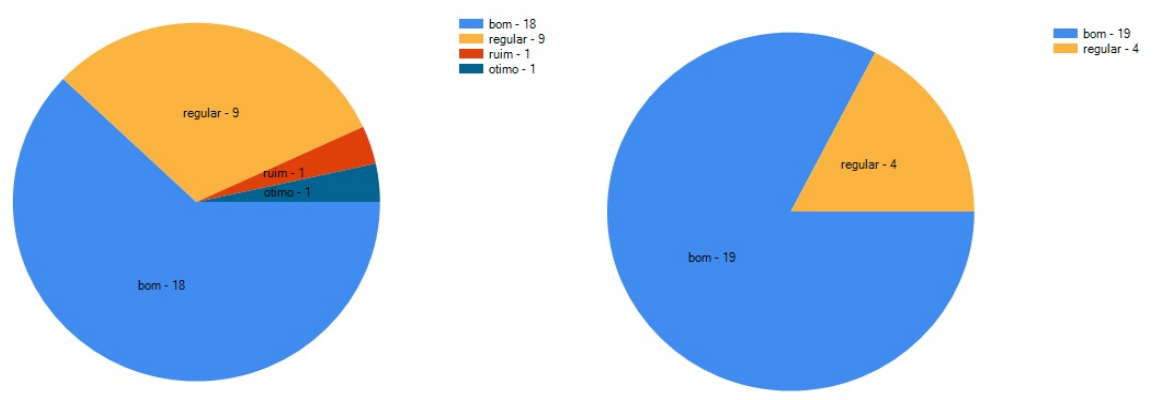

Figura $4 \mathbf{5}$ - Gráficos de palavras pronunciadas para análise

No primeiro gráfico ocorreram duas situações particulares consideradas relevantes: uma opinião "Ótimo" e uma opinião "Ruim". A primeira situação refere-se ao extremo positivo do teste, ou seja, alguma interface que permitiu seu usuário realizar suas tarefas por completo sem oferecer problemas ou riscos algum, sendo assim, fácil de utilizar, com altos níveis de usabilidade e satisfazendo assim seu usuário. Os recursos contidos nesta interface poderiam ser aplicados a demais pontos do sistema que se adequassem tal contexto. A segunda refere-se à segunda pior avaliação, ou seja: segundo extremo negativo do teste o que indica claramente problemas na interface que devem ser tratados pela equipe de designer com atenção.

O segundo gráfico apresentou a não ocorrências de opiniões extremamente positivas ou negativas. A não ocorrência de opiniões insatisfatórias ("Ruim"e "Péssimo") proveu informações de que o aplicativo não dispõe de recursos de baixa interatividade de acordo com a opinião do usuário participante. Esses resultados apresentam somente as pronuncias das palavras Bom e Regular e a segunda palavra em baixa quantidade em relação à primeira, visto que se trata somente de $18 \%$ do total de palavras. Para este caso, foi possível avaliar que o aplicativo esta adequado para o participante e que melhorias precisam ser realizadas, porém em baixa quantidade.

A avaliação por meio de gráficos foi considerada satisfatória por apresentar uma informação em alto nível da opinião dos participantes em relação à qualidade da interação do software permitindo ao avaliador ter uma classificação imediata de satisfação ou insatisfação para direcionar ações de correção, melhorias ou expansão. Entretanto, ao serem 
identificados pontos relevantes específicos tais como opiniões extremamente negativas ou opiniões extremamente positivas "ótimo" era necessário haver uma detalhamento do ocorrido a fim de realizar um estudo para identificar o que poderia ter gerado tal reação e qual procedimento poderia ser tomado em relação ao mesmo.

Tais detalhes foram obtidos por meio de uma lista contendo as palavras pronunciadas pelo participante, seu horário, intervalo em relação ao início do teste e taxa de confiança. Além da palavras, foi disponibilizado acesso as imagens das telas utilizadas pelos participantes no momento da pronuncia, segundos antes e segundos após, sendo o valor dos segundos, indicado pelo avaliador. Para isso, uma palavra registrada em determinado momento $(\mathrm{X})$ deveria ser selecionada e após, o intervalo em segundos $(\mathrm{N})$ indicado, conforme apresentado na Figura 46. Por fim, o aplicativo ErgoSV Analyzer efetuou uma busca de imagens de tela no momento X (selecionado pelo avaliador) e nos momentos $(\mathrm{X}-\mathrm{N})$ até $(\mathrm{X}+\mathrm{N})$ como mostrado no exemplo da Figura 47.

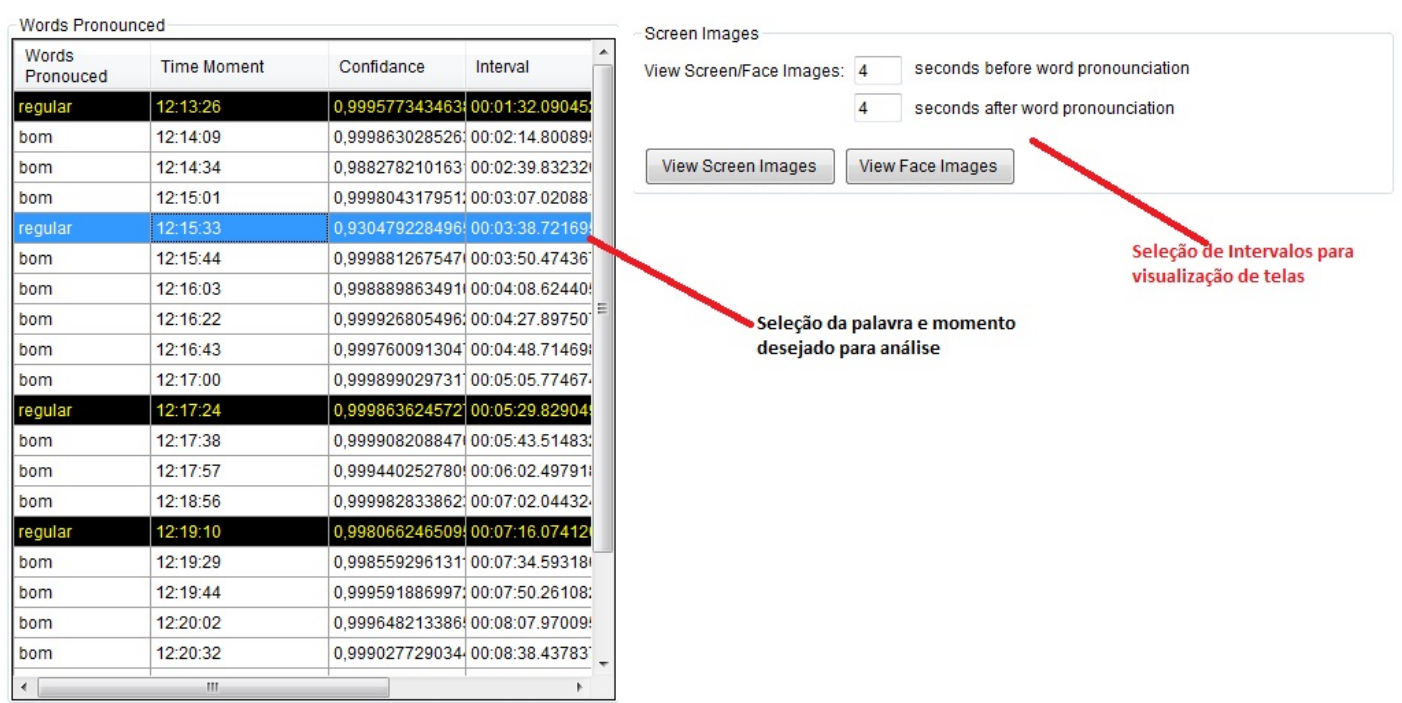

Figura $\mathbf{4 6}$ - Seleção de palavra e intervalo

O estudo da lista de palavras foi feito seguindo as seguintes regras: (1) buscaram-se palavras que representem insatisfação total do participante ("Ruim"e "Péssimo"e "Regular"); (2) foi realizada uma busca para verificar se existiam opiniões totalmente satisfatórias como a palavras "Ótimo". (3) analisou-se as palavras "Bom", considerado-a um termo satisfatório e comum, ou seja, algo que agradou o participante, porém sem ter algo de especial, logo, sua avaliação detalhada foi realizada somente para casos considerados relevantes, tais como uma lista com 6 palavras regulares e no centro desta lista 1 palavra "Bom", ou seja, a palavra Bom foi analisada, a princípio, quando seu contexto divergia de palavras pronunciadas logo antes ou depois. 


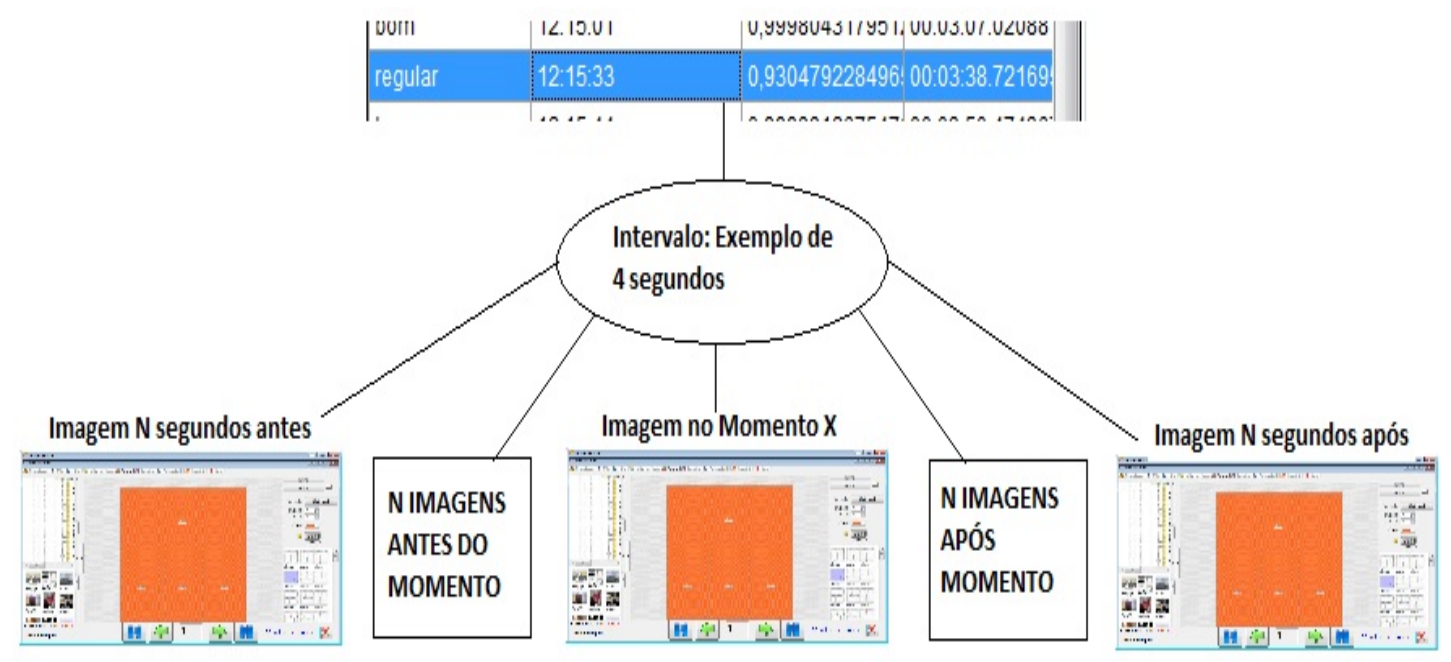

Figura 47 - Estrutura de seleção de imagens de tela por palavra

A análise dos dados do WEC durou 25 minutos, tempo abaixo do total dos testes. Neste período foram analisadas todas as questões consideradas "Regulares", "Ruins"e "Péssimas" assim como as questões "Ótimas" e situações interessantes com a palavra "Bom". Esta análise permitiu identificar um padrão na opinião dos participantes, pois as telas classificadas como Regulares e Ruins (o termo péssimo não foi utilizado pelos participantes) eram praticamente as mesmas.

As interfaces utilizadas e reprovadas foram identificas de forma relativamente fácil graças à palavras que representavam uma classificação negativa. A repetição de classificações, em pelo menos dois testes, para mesma interface, indicava que existia a necessidade de uma análise rigorosa da interface, pois vários participantes consideraram a mesma ruim. Um exemplo de interface reprovada por mais de um participante é exibida na Figura 48 na qual é exibida um texto de mensagem de erro na procura de um produto.

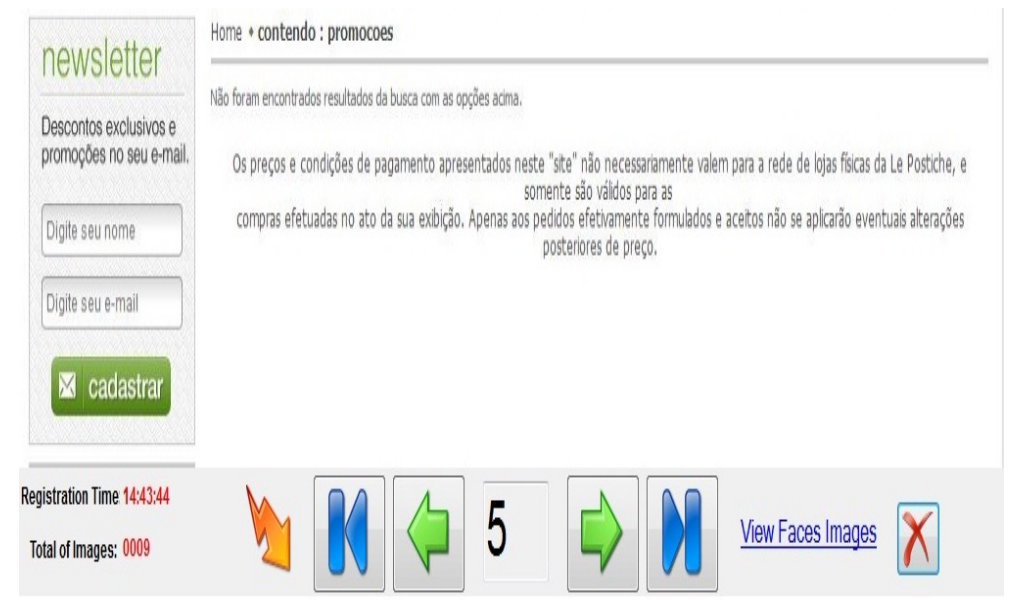

Figura $\mathbf{4 8}$ - Interface reprovada por diversos participantes 
Além da interface apresentada, outros recursos com classificação negativa puderam ser identificados na análise tais como a tela de visualização de produtos, classificada duas vezes como "Regular", o Formulário de Cadastro, também reprovado duas vezes e a tela de finalização do "Carrinho de Compras".

A segunda análise foi realizada no WPG que seguiu as mesmas diretrizes da analise do WEC. O WPG contêm funcionalidades simples e foi criado com objetivo de prover informações sobre o programa de Pós Graduação não apresentando processamentos complexos de dados e/ou funções de inclusão, alteração e exclusão de dados. O estudo dos dados do WPG levou 20 minutos e começou com a análise dos termos insatisfatórios que mostrou um padrão da pronuncia em interfaces com poucos textos e informações e também na utilização dos Menus Superiores das Páginas

Outras interfaces com o mesmo padrão de desenvolvimento foram classificadas como "Regulares"e "Ruins" e algumas estavam com o menu superior ativado. Entretanto não foi possível identificar, a priori se o conceito se tratava da tela como um todo ou do unicamente do Menu. O conceito "Ótimo"foi pouco aplicado sendo pronunciado por um único avaliador para classificar a página inicial do website.

O terceiro aplicativo analisado foi o PEM utilizado para edição de imagens. Este aplicativo tem diversas funcionalidades e o tempo total de seus testes foi de 57 minutos. A análise foi realizada seguindo as mesmas diretrizes dos dois estudos anteriores e teve uma duração de 30 minutos.

Esta análise apresentou maior complexidade e dúvidas em relação às duas primeiras, principalmente pelo fato do PEM apresentar uma interface com uma densidade informacional muito grande (CYBIS; BETION; FAUST, 2010), ou seja, está contém muitos dados e informações em uma mesma tela levando a uma má estrutura de distribuição de recursos e componentes da aplicação.

O estudo dos dados mostrou que $70 \%$ das abas que agrupam as funcionalidades do aplicativo levaram um conceito "Ruim"e "Regular" e em determinados momentos essas receberam conceitos positivos. A maior dificuldade ocorreu em determinar qual recurso era foco de análise do participante naquele momento. A Figura 49 apresenta uma tela classificada como "Regular/Ruim" em dois testes distintos realizados por dois participantes também distintos. A interface mostra uma tela que permite a montagem de uma folha com diversas fotos, entretanto a grande quantidade de recursos impede a visualização do foco do participante e para qual item foi atribuída a nota. 


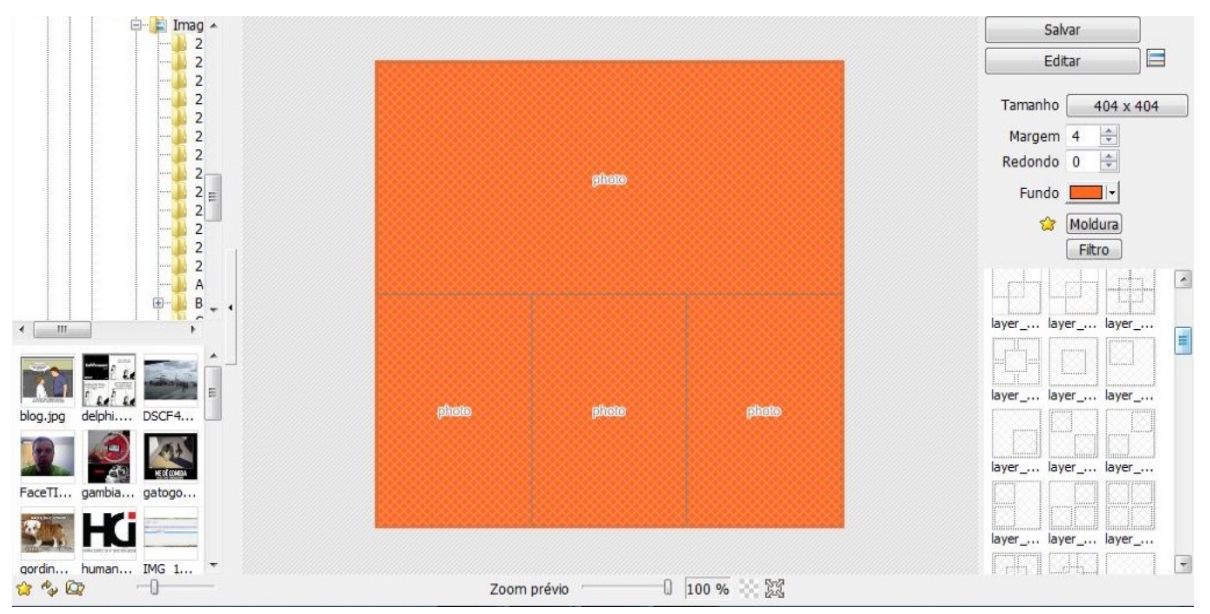

Figura 49 - Tela do PEM com muitos recursos

Outras interfaces classificadas apresentaram notas positivas e/ou negativas, porém por mostrarem telas em destaque assumiu-se que a nota foi atribuída a essas telas. A Figura 50 mostra um exemplo de uma tela em destaque na qual é atribuída a nota Bom.

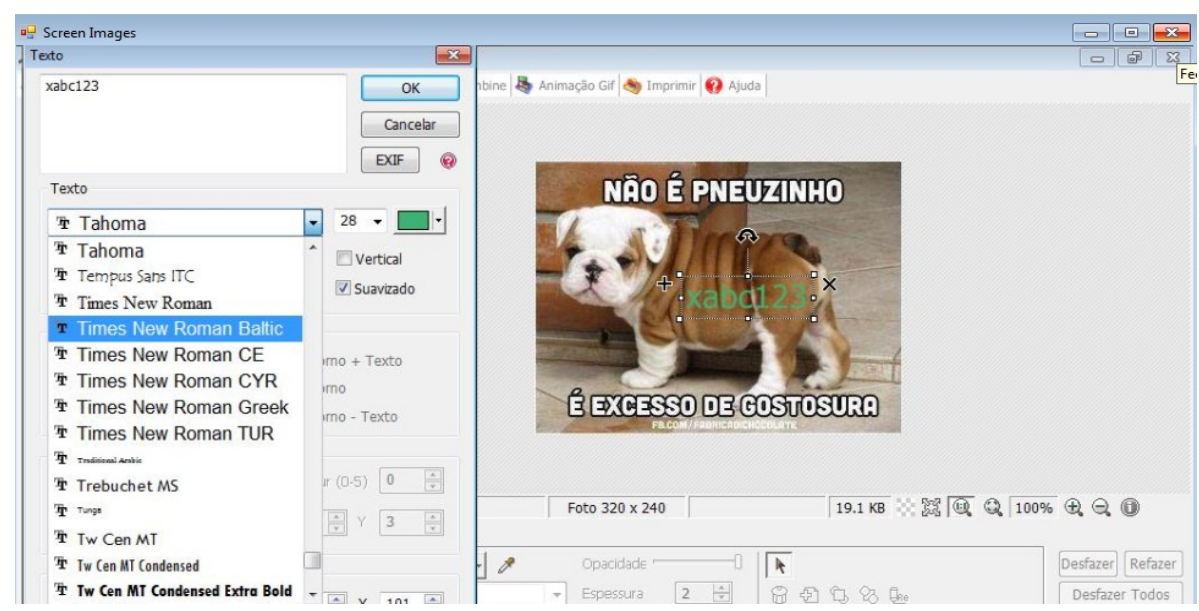

Figura 50 - Tela do PEM classificada como Bom

A análise dos dados somente com palavras pronunciadas foi considerada satisfatória, pois identificar interfaces a serem analisadas em tempo inferior aos tempos totais de teste. Ao mesmo tempo, esta abordagem proporcionou uma ideia de quais interfaces tinham nota positiva ou negativa por parte dos participantes.

As palavras chave pronunciadas também foram consideradas eficientes para análise por se posicionarem como classificadoras claras da opinião dos participantes, ou seja, foi possível identificar se uma pessoa gostou de determinada interface por meio das palavras "Ótimo" e "Bom" e identificar se uma pessoa desaprovou a interface ao ser identificadas pronuncias das palavras "Regular", "Ruim"e "Péssimo". As palavras pronunciadas funcionaram como ferramentas para chamar a atenção do designer quanto a um problema 
ou para algum recursos que foi de extrema satisfação das pessoas.

O gráfico apresentou uma visão de alto nível do resultado do teste, no qual são apresentadas as palavras pronunciadas e o total de cada termo e foi considerado bom por proporcionar um panorama geral da opinião dos participantes com o sistema testado. Com a imagem do gráfico foi possível identificar qual foi o posicionamento dos participantes em relação aos testes obtendo uma visão inicial de uma possível necessidade de revisão detalhada da interface ou da possibilidade de manter e expandir os recursos já existentes.

Entretanto, um ponto negativo identificado nesta abordagem de análise foi a dificuldade em identificar qual era o foco de atuação do usuário nos momentos próximos a pronuncia. Por exemplo, a Figura 50 apresenta uma interface na qual 2 participantes pronunciaram a palavra "Ruim". As interfaces utilizadas no momento e próximo a reação foram facilmente identificadas devido a palavra chave pronunciada, entretanto foi difícil identificar o foco de visão dos participantes considerando que conhecendo qual era direção do rosto e/ou olhos das pessoas no momento do registro poderia reduzir a área de insatisfação. O recurso de acesso as interfaces permitiu visualizar a tela por completo, mas não foi possível saber qual o foco do olhar da pessoa, ou seja, a palavra "Ruim" foi uma opinião a respeito do menu superior ou do menu lateral ou da tela central ou a tela como um todo. Esta situação levaria a necessidade de se questionar o participante para descobrir o alvo da opinião.

Mesmo com esse ponto negativo a análise dos dados utilizando dados de fala foi considerada eficaz para abordagem devido ao fato de reduzir o tempo para identificação de interfaces problemáticas, assim como os momentos anteriores e posteriores a este evento, para aproximadamente $60 \%$ do tempo do teste. Informações das palavras apresentadas em gráfico permitiram uma rápida análise da situação geral do software permitindo assim uma pré análise e um posicionamento de forma geral sobre a qualidade da interação do ponto do vista do usuário.

Na próxima subseção será tratada a análise dos dados somente com imagens.

\subsubsection{Análise Somente com Dados de Imagens}

A segunda abordagem de análise foi realizada utilizando somente os dados de imagens registradas com foco na lista de imagens faciais registradas contendo a imagem, o horário de registro, o intervalo em relação ao início do teste e o percentual de similaridade em 
relação à imagem padrão. As imagens descartadas e o recurso para acessar imagens da tela no momento da reação, momentos antes e após a reação também foram disponibilizados.

O principal objetivo desta abordagem foi verificação da capacidade de identificação de interfaces com possíveis problemas de usabilidade, momentos de insatisfação dos participantes e a geração de insumos para análise da usabilidade utilizando somente a dados de imagens faciais e os recursos disponibilizados pelo ErgoSV Analyzer por meio da funcionalidade "Only Face Images" e assim reduzir o tempo para análise dos dados de teste.

A primeira verificação desta abordagem foi feita utilizando o gráfico apresentado na interface, porém o mesmo se limita a apresentar o percentual de imagens com faces reconhecidas versus imagens descartadas, assim seus dados não permitiram uma identificação da opinião do participante. A tentativa de elaborar um gráfico com dados adicionais foi prejudicada com a falta de dados para criação do mesmo, ou seja, não havia uma forma de classificar a opinião do participante como satisfatório ou insatisfatório.

Após análise insatisfatória do gráfico, o foco se voltou para análise da lista de imagem que continha, dentre demais dados o valor da similaridade. Este dado foi analisado em primeiro momento com objetivo de utilizar o mesmo, de forma individual, para de identificar a opinião do participante. Assim como na análise somente com dados de fala, o objetivo era analisar os dados dos testes em tempo inferior a 1,5 vezes o tempo de cada teste.

A análise utilizando a lista de imagens e seus atributos foi realizada de três formas diferentes:

- utilizando somente os valores de similaridade;

- associando os valores de similaridade com a expressão facial dos participantes;

- utilizando os valores de similaridade abaixo da média.

Os três estudos são explicados a seguir.

1 - Utilizando somente valores de similaridade: Para esta análise foi considerado somente o valor de similaridade como parâmetro para verificar a opinião do participante e, assim, possíveis problemas de usabilidade. O avaliador se concentrou no estudo deste dado de forma isolada.

Entretanto, o valor de similaridade de forma isolada não representou a priori uma opinião do participante, mas somente o percentual de similaridade em relação à imagem 
padrão. Por exemplo, analisando a Figura 51 é possível ver a lista de imagens do $E r$ goSV e seus valores de similaridade, mas não foi possível classificar a priori qual imagem representa um evento satisfatório ou insatisfatório.

\begin{tabular}{|c|c|c|c|}
\hline $\begin{array}{l}\text { Image } \\
\text { ID }\end{array}$ & Time Moment & Interval & Similarity \\
\hline 3861 & $11: 11: 26$ & $00: 00: 00.6216700$ & 0,613484738784366 \\
\hline 3862 & $11: 11: 27$ & $00: 00: 01.6107270$ & 0.883083618659775 \\
\hline 3863 & $11: 11: 28$ & $00: 00: 02.6257850$ & 0,913836791702854 \\
\hline 3864 & $11: 11: 29$ & $00: 00: 03.6758450$ & 0,689768926357053 \\
\hline 3865 & $11: 11: 30$ & $00: 00: 04.7939090$ & 0,634185399194458 \\
\hline 3866 & $11: 11: 31$ & $00: 00: 05.7299630$ & 0.6862517317797 \\
\hline 3867 & $11: 11: 32$ & $00: 00: 06.7370200$ & 0,675332266344521 \\
\hline 3868 & $11: 11: 33$ & $00: 00: 07.7700790$ & 0,657713659647929 \\
\hline 3869 & $11: 11: 34$ & $00: 00: 08.7621360$ & 0,864198202668539 \\
\hline 3870 & $11: 11: 35$ & $00: 00: 09.7671930$ & 0.691100946357001 \\
\hline 3871 & $11: 11: 36$ & $00: 00: 10.8092530$ & 0,687398087302892 \\
\hline 3872 & $11: 11: 37$ & $00: 00: 11.8833140$ & 0,687795614072736 \\
\hline 3873 & $11: 11: 38$ & $00: 00: 12.8603700$ & 0,669130428373319 \\
\hline 3874 & $11: 11: 39$ & $00: 00: 13.8894290$ & 0,660898350743424 \\
\hline 3875 & $11: 11: 40$ & $00: 00: 14.9344890$ & 0,653487440303299 \\
\hline 3876 & $11: 11: 41$ & $00: 00: 15.9965500$ & 0.62105352686007 \\
\hline 3877 & $11: 11: 54$ & $00: 00: 28.3682570$ & 0,674081983810223 \\
\hline 3878 & $11: 11: 55$ & $00: 00: 29.2873100$ & 0,684284763663538 \\
\hline 3879 & $11: 11: 56$ & $00: 00: 30.2933670$ & 0,691951411804397 \\
\hline 3880 & $11: 11: 57$ & $00: 00: 31.3254270$ & 0,900594176893507 \\
\hline
\end{tabular}

Figura 51 - Lista de registro de imagens com valores de similaridade

Olhando um valor de similaridade, por exemplo, 0.883083618659775, não foi possível classificar essa imagem como uma opinião positiva ou negativa, necessitando analisá-la de forma subjetiva, ou seja, selecionar o registro da imagem e efetuar um estudo da expressão apresentada. A incapacidade de identificar as expressões fez com que a análise dos dados fosse realizada visualizando em sequência todas as imagens faciais registradas. Após a análise individual da imagem facial era tomada a decisão de estudar ou não o que o participante fazia no momento. Estas ações levaram a um tempo mínimo de análise de três vezes o tempo do teste, situação já comum neste tipo de análise e que não agregou bons resultados a abordagem.

\section{2 - Tentativa de associar valores de similaridade com a opinião do par-} ticipante: Nesta análise, os valores de similiaridade foram associados a reações faciais específicas. Entretanto, esta ação foi feia manualmente. Todas as imagens de todos os testes foram comparadas com imagens faciais apresentadas no livro de Castilho (2011) que apresenta uma séria de imagens faciais com reações diversas e instruções de como identificar as respectivas expressões em outras imagem. As imagens foram classificadas como: com reação facial clara; com reação facial não identificada e; sem reação facial. A Figura 52(c) apresenta exemplos desta classificação.

De 2305 imagens registradas, apenas 1,7\% das imagens faciais apresentavam reações faciais claras e assim, permitiram ser identificadas e classificadas de acordo uma reação. Após está primeira classificação, as imagens foram classificadas de acordo com a expressão para qual foi associada. A Tabela 16 apresenta o nome das expressões identificadas e os 


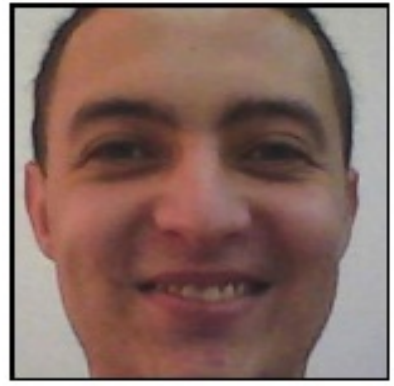

(a) Imagem com expressão facial clara

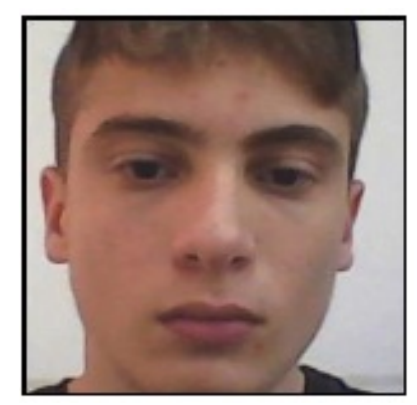

(b) Imagem sem reação facial

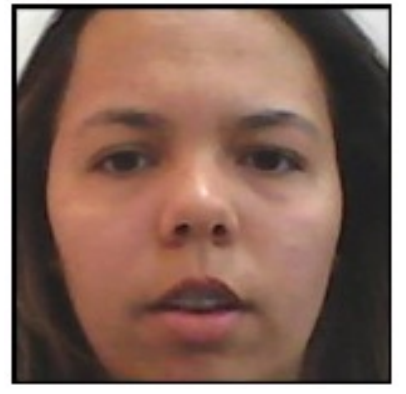

(c) Imagem com reação facial não identificada

Figura 52 - Imagens com expressões faciais relevantes X Não identificáveis

valores de similaridades em relação a imagem padrão do teste das imagens associadas à expressão.

Tabela 16 - Valores de similaridade por expressão facial

\begin{tabular}{l|l}
\hline Expressão Facial & Similaridades (\%) \\
\hline Sorriso & $63,74,76,87,88,90,91,92,94$ e 96 \\
\hline Dúvida & $56,58,67,74,79,81,86$ e 95 \\
\hline Espanto & $47,57,77,82,96$ e 96 \\
\hline Indecisão & 86 e 94 \\
\hline Insatisfação & 93 \\
\hline Pensativo & $86,87,88$ e 90 \\
\hline
\end{tabular}

Os dados apresentados na Tabela 16 mostram que não ocorreu um padrão de valores de similaridade para as expressões, mas sim uma variação significativa da menor similaridade até a maior. Embora algumas expressões tenham apresentado diferenças menores e/ou valores mais próximos, caso da expressão "Pensativo", esta situação não foi comum para outras situações as quais tiveram variações entre 47 e $96 \%$ ("Dúvida"') ou variaram de 63 a 96 \%, no caso da expressão "Sorriso". Como resultado desta classificação, foi possível concluir que não seria possível relacionar um percentual de similaridade com uma expressão facial (ou opinião) considerando todos os testes e todas as expressões.

Uma segunda classificação foi realizada agrupando os valores por teste a fim de verificar se ocorreram padrões de valores de similaridade para um mesmo teste. Esta análise foi feita assumindo que uma pessoa pode não variar, de forma significativa, sua maneira de expressar suas emoções faciais mantendo assim um padrão de valores.

Algumas reações ocorreram de forma isolada (1 reação por teste) e foram descartadas desta análise, pois não permitiriam identificar a variação dos valores das expressões para um determinado teste, reduzindo ainda mais a quantidade de dados. Como o objetivo era 
verificar quanto o valor da similaridade variava em relação à expressão de uma pessoa em um teste, foram utilizadas somente dados de expressões que ocorreram mais de uma vez em um teste. Assim, uma combinação de 5 testes nos quais 7 reações ocorreram mais de uma vez foram analisadas. A Tabela 17 apresenta a relação de testes, tipo de expressão, valores de similaridade e quantidade de ocorrências.

Tabela 17 - Classificação de valores de similaridade por teste

\begin{tabular}{l|l|l|l|l|l}
\hline Teste & Expressão & $\begin{array}{l}\text { Menos } \\
\text { Similar } \\
(\%)\end{array}$ & $\begin{array}{l}\text { Mais Si- } \\
\text { milar }(\boldsymbol{\%})\end{array}$ & $\begin{array}{l}\text { Diferença } \\
\mathbf{( \% )}\end{array}$ & Ocorrências \\
\hline A & Dúvida & 74 & 79 & 5 & 2 \\
\hline B & Indecisão & 86 & 94 & 8 & 2 \\
\hline B & Dúvida & 56 & 58 & 2 & 2 \\
\hline B & Sorriso & 74 & 87 & 13 & 2 \\
\hline C & Espanto & 77 & 96 & 19 & 2 \\
\hline D & Pensativo & 86 & 90 & 4 & 2 \\
\hline E & Sorriso & 88 & 91 & 3 & 2 \\
\hline
\end{tabular}

Esta tabela apresenta que os valores mínimos e máximos das similaridades estão próximos em 3 dos 5 casos analisados apresentando uma situação que poderia levar a uma padronização de valores. Entretanto, no teste número 2, único a apresentar um intervalo de dados para três expressões distintas, é observável uma situação de interseção, no qual o valor 86 é encontrado em 2 casos distintos (Indecisão e Sorriso). A proximidade dos valores de similaridade poderia gerar informações incorretas e interferir seriamente na análise dos dados. Considerando este estudo e este exemplo, teríamos um caso no qual o participante teve uma reação de indecisão representado pela valor de $86 \%$ de similaridade e um outro caso, no qual o usuário teve uma reação de sorriso (satisfação) também representado pelo mesmo percentual de similaridade. Os casos representaram situações divergentes, ou seja, enquanto que no primeiro, o participante tem dúvidas sobre a utilização que poderia implicar em uma análise aprofundada da interface, no segundo caso o participante se mostra satisfeito com o que utiliza que implicaria na manutenção da interface ou na expansão para outros pontos do sistema.

Embora os dados apresentem um padrão de proximidade de valores, quando analisados teste a teste, a aplicação de uma expressão específica para um determinado valor de similaridade seria arriscada devido aos seguintes fatores: primeiramente não foi possível identificar um padrão de valores de similaridade para reações identificadas manualmente; depois, quando identificados os valores, estes ocorreram ao serem agrupados em seus respectivos testes o que obrigaria a equipe de design a efetuar uma calibragem de imagens e 
expressões antes da análise dos testes para posterior aplicação de uma técnica de processamento de imagens visando gerar a informação de similaridade. Da mesma forma que não foi possível identificar um padrão de similaridade, alguns valores representaram mais de uma reação por valor de similaridade o que dificultou a identificação de qual reação seria melhor para qual similaridade; Por fim, a baixa quantidade de reações faciais identificadas dificultou a análise desses dados e não permitiu a geração de informações consistentes e seguras para serem aplicadas no software ErgoSV.

Por fim, esta forma de análise foi considerada ineficaz devido as seguintes situações: Na primeira, quando os valores de similaridade foram agrupados por expressão, foi possível perceber um grande intervalo de similaridade entre o menor valor e o maior valor para um determinada expressão e com isso concluir que não seria possível associar determinada expressão com determinado valores de similaridade. Além disto, várias expressões se enquadram em valores que foram obtidos para expressões diversas, por exemplo, as expressões Sorriso e Espanto tiveram valores de similaridade de $96 \%$.

Quando os valores de similaridade foram agrupados por teste e expressão, foi possível identificar um padrão consistente entre a expressão faciais e o valor de similaridade. Esta relação poderia ser estabelecida no sistema com objetivo de agilizar a identificação de interfaces problemáticas, entretanto necessitaria de uma alimentação e/ou treinamento prévio do ErgoSV para efetuar a comparação com expressões faciais considerando somente da pessoa que utiliza o software no determinado teste e esta situação acarretaria em uma mudanças na fase de pré teste além de alterações no processo de identificação de similaridade do ErgoSV. Por fim, a busca por expressões ficaria reduzida a um usuário e a um único teste e a baixa quantidade de imagens utilizadas para validar esta hipótese não permitiu estabelecer esta regra como padrão para esta abordagem.

Concluí-se portanto, que atribuir um valor de similaridade a uma determinada expressão poderia gerar informações incorretas levando o avaliador a análises e tomadas de decisão erradas e assim comprometer a qualidade do teste e do produto.

3 - Utilizando valores de similaridade abaixo da média: Nesta análise, a hipótese de que um valor de similaridade abaixo da média do teste poderia representar uma movimentação do participante ou uma grande alteração na expressão facial foi análisada pelos avaliadores. Um recursos de destaque para imagens abaixo da média foi implementado no ErgoSV conforme apresenta a Figura 53.

Embora tenha se posicionado como um possível recurso para agilizar a identificação de opiniões, principalmente pelo fato de uma similaridade baixa indicar a movimentação 


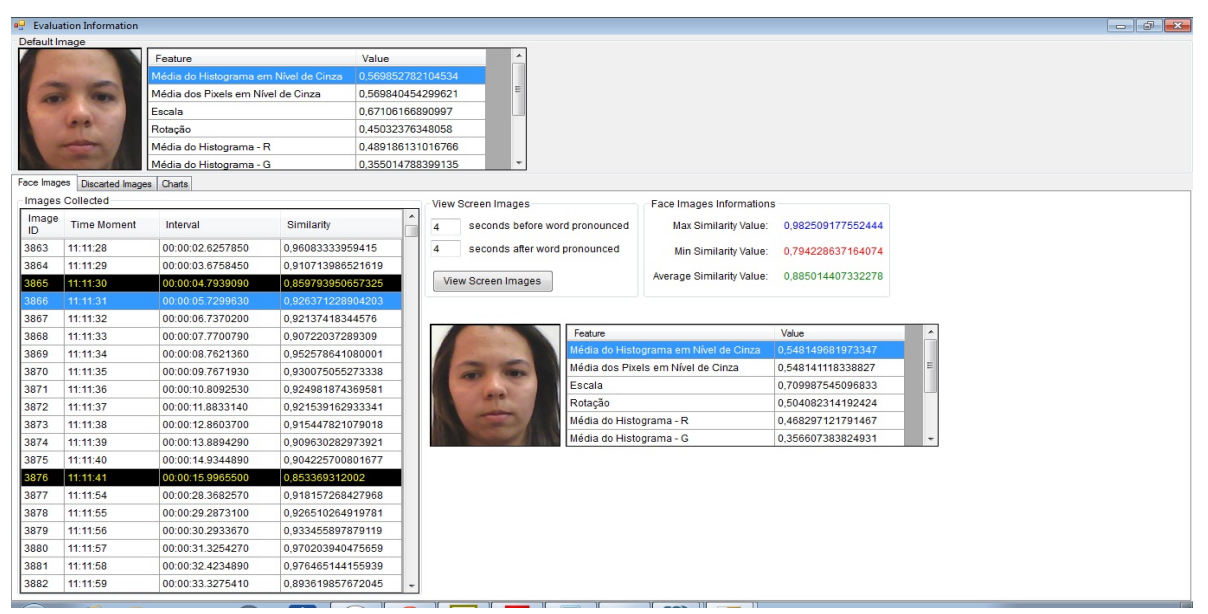

Figura 53 - Tela do ErgoSV com dados de similaridade

abrupta do participante e portanto, uma informação relevante, a utilização de valores de similaridade abaixo da média do teste foi considerada arriscada, pois o baixo valor não significou a priori insatisfação ou problemas por parte do usuário, mas sim que o mesmo se movimentou de forma significativa em relação a imagem padrão. Esta situação poderia levaria a uma análise subjetiva por parte do avaliador que poderia considerar estas imagens como critérios de insatisfação e assim propor correções para interfaces erradas. Além disto, seria possível que o avaliador se atentasse somente a esses registros ignorando assim registros com maior similaridade e que poderia ter informações relevantes.

Todas as formas utilizadas para analisar o teste somente com dados de imagem levou a um único caminho: a análise de todas as imagens de forma individual, sequencial e subjetiva e o aumento o tempo de análise para próximo ou mesmo mais de 3 vezes o tempo do teste. Um tempo de análise semelhante a este não foi considerando ideal para ferramenta pois não agregou melhorias ao processo de análise e identificação de problemas.

Na próxima subseção será apresentada uma análise na qual são unidos dados de fala e de imagens.

\subsubsection{Análise com Dados de Voz e Imagens}

A terceira abordagem de análise foi realizada utilizando a combinação dos dados de fala, imagens faciais e imagens da tela. Como os experimentos anteriores apresentaram maior eficiência na utilização dos dados de fala em relação aos dados de imagens faciais ficou determinado como parâmetro para identificação das opiniões dos usuários as palavras pronunciadas, assim as imagens faciais e de telas foram utilizadas como apoio para enriquecer os dados e melhorar a análise e tomada de decisão. 
A análise seguiu os mesmos processos realizados nas abordagens anteriores, ou seja, primeiro foram identificadas palavras de classificação negativa, seguidas pela palavra de maior classificação positiva (Ótimo) e por último analisadas as palavras "Bom"para situações que exigissem tal estudo.

Identificadas as palavras alvo, foi possível realizar uma análise que começava a partir da palavra pronunciada, que permitia acessar as imagens de tela e, a partir do momento de registro de determinada interface, acessar as imagens faciais.

A estrutura permitiu a criação de uma árvore batizada de "Árvore do Ambiente". Nessa árvore, o nó raiz é a palavra pronunciada pelo participante e guia principal para busca de informações. A partir do nó raiz era possível acessar as imagens da tela que foram utilizadas por cada participante no momento da pronuncia, instantes antes e instante após. Como o avaliador pode indicar o intervalo de tempo de seu interesse para busca de imagens, para cada imagem pode ser relacionada uma ou várias imagens de tela. As imagens da tela eram consideradas outros nós da árvore, este em um segundo nível, ou de profundidade dois. Selecionado uma imagem e indicando um intervalo de tempo, era possível acessar uma série de imagens da face do participante no momento, antes e após determinada tela, estas consideradas nós folhas da árvore. A Figura 54 apresenta o modelo desta abordagem.

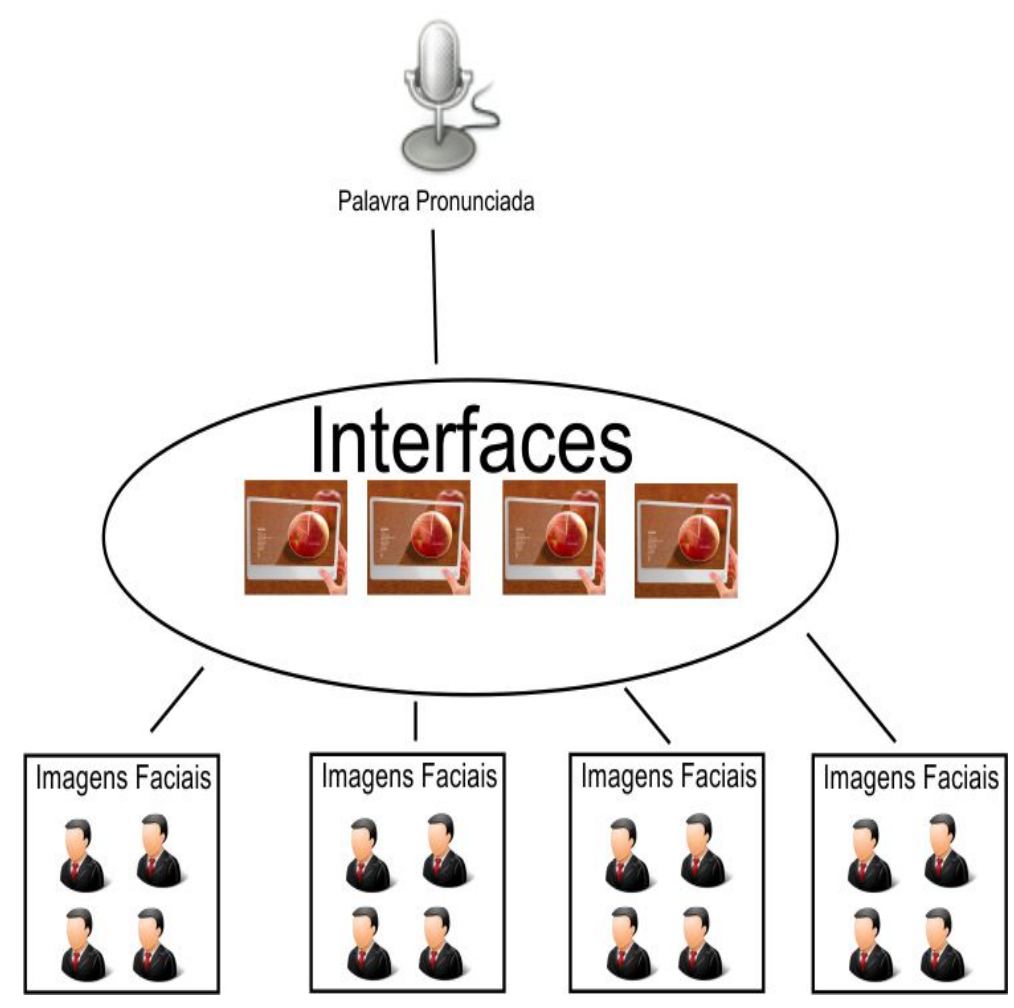

Figura 54 - Árvore do ambiente do teste no momento de uma reação 
O parâmetro para busca de imagens de tela e imagens faciais foi o intervalo especificado pelo participante no momento da análise. Nesta estrutura, considerando uma palavra pronunciada com 05 minutos e 20 segundos de teste e um valor de intervalo de 6 segundos, o ErgoS $V$ buscava todas as imagens de tela registrada entre o tempo de 05 minutos e 14 segundos até o tempo de 05 minutos e 26 segundos. Neste momento não eram exibidas imagens faciais, esta situação ocorria após o a seleção de uma imagem e o acionamento do comando de exibição. Selecionada uma imagem, por exemplo, registrada no momento de 05 minutos e 24 segundos, o $\operatorname{ErgoS} V$ seleciona as imagens faciais em uma intervalo de 6 segundos antes e depois do momento da imagem, ou seja, eram exibidas as imagens faciais registradas entre o tempo de 05 minutos e 18 segundos e 05 minutos e 30 segundos. Juntamente com a imagem facial eram exibidos dados tais como percentual de similaridade e horário de registro, funcionalidade esta já apresentada nos capítulos anteriores.

Uma grande contribuição desta análise foi a relação da interface utilizada pelo participante no momento da reação e a posição de seu resto e de seus olhos. Com isso, foi possível solucionar, a princípio, um problema encontrado na abordagem de análise utilizando somente dados de fala a qual obteve êxito para identificar interfaces com problemas, mas não permitia identificar o foco de visão do usuário.

Considerando a posição do usuário em frente da câmera e a forma como o mesmo olhava a imagem foi possível direcionar qual era o lado, quadrante ou canto para o qual o mesmo olhava no momento da reação. A Figura 55 apresenta um exemplo no qual é exibido uma imagem facial registrada próximo ao momento em que o participante pronunciou a palavra "Regular". Olhando a imagem facial foi possível verificar que o usuário olhava para o canto inferior direito da imagem. Portanto, foi possível assumir que o conceito aplicado se referia às funcionalidades ou características da interface que se encontravam nesta posição da tela.

Em um segundo exemplo, apresentado na Figura 56, o aplicativo ErgoSV registra a pronuncia da palavra "Péssimo", a imagem da tela e da face do participante. Nesta imagem é possível analisar que o usuário olha atentamente para o canto esquerdo do monitor/interface. Isto permitiu assumir que o foco da avaliação se referia a recursos localizados nesta posição.

O tempo da análise dos dados dos testes aumentou em relação à primeira abordagem de análise, porém manteve-se dentro dos $50 \%$ de acréscimo em relação ao tempo total de coleta. O aumento do tempo de análise deu-se por motivo do maior número de dados 


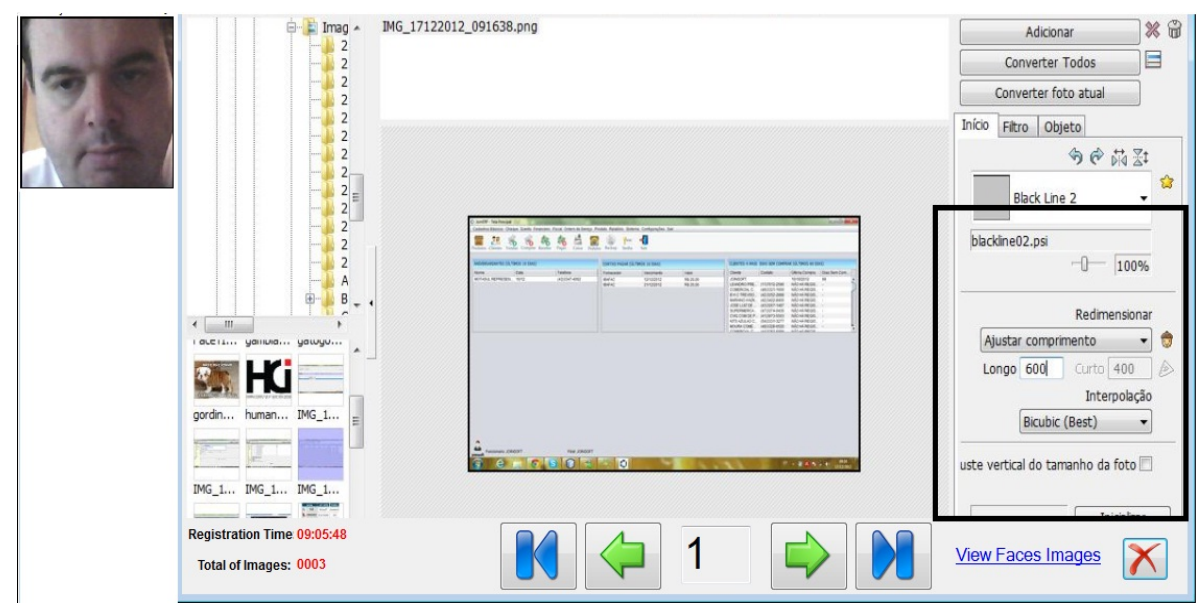

Figura 55 - Imagem facial e imagem de tela com possível local de insatisfação

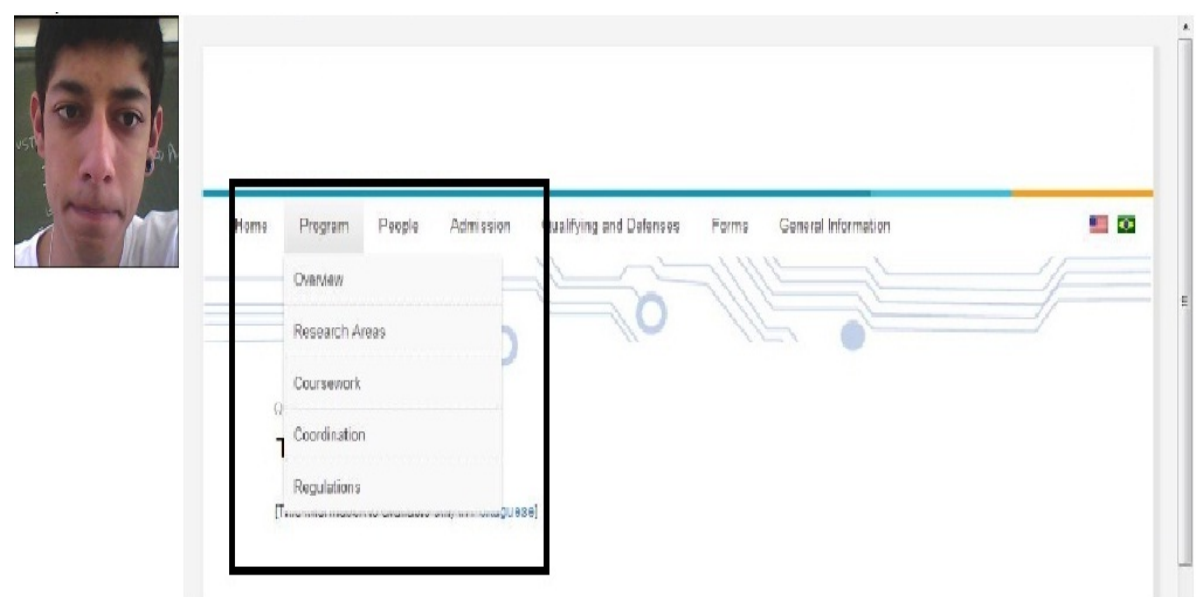

Figura 56 - Imagem facial e imagem de tela com possivel local de insatisfação

para estudo, visto que acrescentou-se dados de imagens faciais e os mesmos requereram um tempo para estudo e detecção de informações relevantes. O tempo dos testes nesta terceira abordagem utilizando palavras pronunciadas, imagens da tela e imagens faciais foi de:

- WCE: 85 minutos;

- WPG 30 minutos;

- PEM 85 minutos;

Por fim, a análise dos dados utilizando a combinação de palavras pronunciadas e imagens faciais apoiadas por imagens da tela foi considerada satisfatória devido ao fato que proporcionou a maior quantidade de informações relevantes e permitiu uma análise com mais detalhada dos dados. Nesta abordagem foi possível identificar a opinião do participante por meio das palavras, quais interfaces ele utilizava no momento e próximo 
aos momentos da reação, assim como as imagens faciais que permitiram, ainda, uma análise do foco de visão do participante reduzindo assim a área de estudo da tela. Esta última situação permitiu resolver o ponto negativo da abordagem que utilizava somente dados de voz que por sua vez indicava qual a interface problemática mas deixava em aberto qual o fato de existir ou não um local específico de uso por parte do participante.

Na próxima seção serão apresentados os resultados da validação, realizados conforme atividades explicadas previamente.

\subsection{Resultados da Validação}

Os experimentos para validação da abordagem foram realizados de três formas diferentes: (1) utilizando somente dados de palavras registradas; (2) utilizando somente dados de imagens faciais registradas; (3) utilizando uma combinação de palavras pronunciadas e imagens faciais. Em todas as formas de análise foram consideradas as imagens das interfaces utilizadas pelos participantes no momento e próximo ao momento da reação.

O objetivo principal era reduzir o tempo de análise dos dados e a identificação de pontos do aplicativo que não estavam de acordo com a satisfação do participante, além de visualizar, por meio de imagens da tela, imagens faciais e da análise das palavras pronunciadas, o ambiente que ocorreu segundos antes e segundos após determinada reação. Um aplicativo foi desenvolvido especialmente para apoiar esta pesquisa e foi batizado de $\operatorname{ErgoSV}$ e apoiou atividades de coleta, processamento e análise dos dados.

\subsubsection{Análise dos dados de voz}

A abordagem de avaliação apresentou resultado satisfatório para os dois casos de análise que utilizaram palavras pronunciadas principalmente para a abordagem que considerou imagens faciais para suporte a análise das palavras.

As análises com dados de voz apresentaram melhores resultados devido ao fato da utilização de palavras chave que representaram conceitos de qualidade definidos de acordo com uma ordem hierárquica, ou seja, uma determinada palavra, peso e classificação bem definida. Este critério facilitou a identificação de quais momentos ocorreram uma reação de insatisfação ou mesmo uma opinião satisfatória.

O gráfico da Figura 57 apresenta quatro dados utilizados como base para análise: 


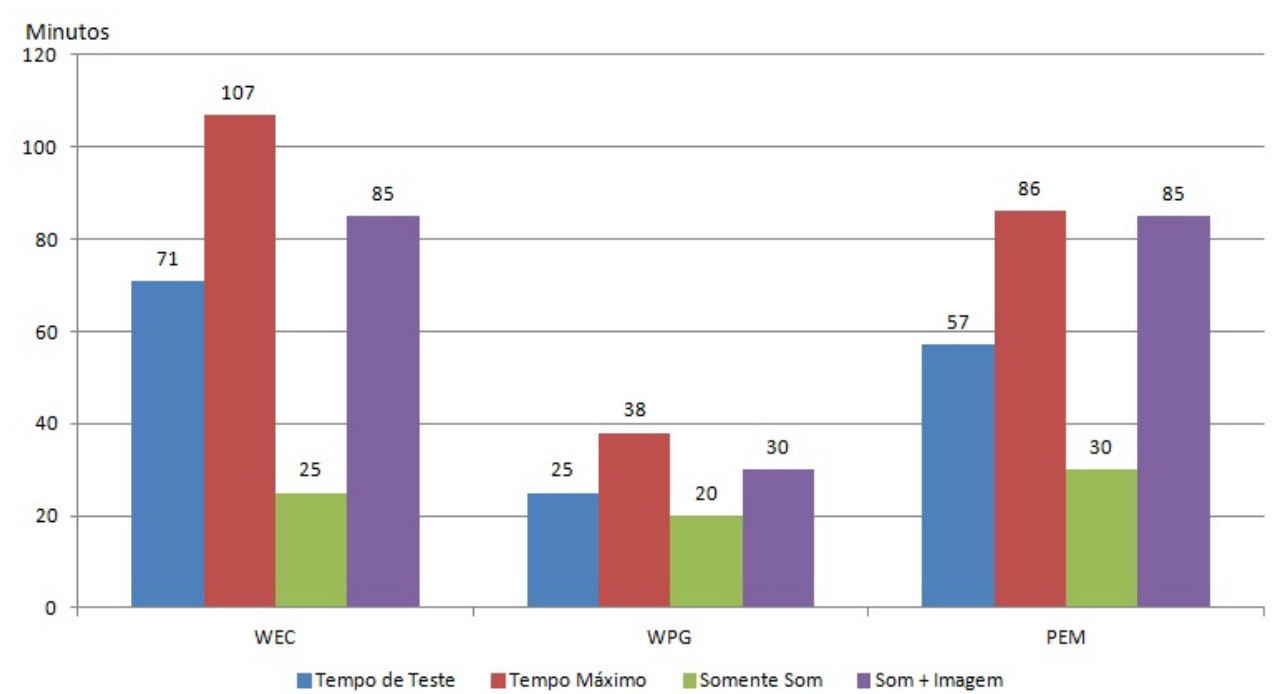

Figura 57 - Comparativo de tempo de análise com dados de fala

- Tempo de Teste: Duração dos testes realizados pelos participantes;

- Tempo Máximo: Tempo máximo estipulado como ideal para análise dos dados

- Somente Som: Tempo de análise utilizando somente dados de palavras pronunciadas;

- Som + Imagem: Tempo de análise utilizando dados de palavras pronunciadas apoiados por dados de imagens faciais.

Com o gráfico, é possível verificar que as duas abordagens de análise permitiram o estudo dos dados em tempo inferior a 1,5 vezes o tempo do teste e consequentemente ao tempo médio padrão apresentado por Nielsen (1993) que refere-se a 2 ou 3 vezes o tempo do teste.

O tempo de análise utilizando os recursos de imagem e som apresentaram um tempo médio maior e em 2 casos (WEC e PEM) os tempos de análise apresentaram um aumento de $80 \%$ em relação a análise somente com dados de voz, enquanto o WPG apresentou um aumento de 50\% no tempo de análise. Este aumento ocorreu devido a necessidade de analisar, juntamente com a palavra e a imagem da tela, a imagem facial do participante a fim de verificar se a mesma proporcionava alguma informação relevante tal como o foco da visão do participante, seu posicionamento e/ou se algo ou alguém chamou sua atenção da pessoa.

Mesmo executando a análise completa (voz + imagem), todos os aplicativos ficaram abaixo do tempo máximo estipulado e, embora bem próximo, abaixo do tempo do teste, 
exceto pela análise do WPG no qual a análise com voz e imagem demorou mais tempo que o teste em si, mas pode ser executada mais rápida que máximo estipulado para análise dos dados nesta pesquisa.

\subsubsection{Análise com dados de imagem}

A análise dos dados utilizando somente os dados de imagens faciais, ao contrário da análise com dados de voz, não se mostrou satisfatório. Três maneiras diferentes de análise foram realizadas a fim de verificar se, de alguma forma, os dados de imagens, de forma isolada, poderia apoiar a análise reduzindo o tempo para identificação de problemas de usabilidade:

1: Na primeira forma foram utilizados somente os valores de similaridade processados pelo $\operatorname{ErgoSV}$ em relação à imagem padrão. Estes dados não permitiram a redução do tempo de análise, pois o valor de similaridade não representava um conceito satisfatório ou insatisfatório. Esta situação levou a necessidade de realizar uma analise de todas as imagens do teste em sequência, semelhante ao processo tradicional, em outras palavras, olhava a imagem facial e efetuava uma análise subjetiva para saber se a imagem proporcionava alguma informação semelhante e, caso necessário, olhava as imagens de tela. Nesta análise foi possível perceber que uma análise da imagem facial demorava no mínimo 4 segundos e como foi necessário estudar todas as imagens de todos os testes o tempo total de análise levou uma média de 4 vezes o tempo total do teste.

Considerando esta primeira análise ineficaz, foi realizada uma associação do percentual de similaridade com uma reação específica. Esta análise foi feita seguindo conceitos de expressões apresentados por Castilho (2011). Entretanto não foi utilizado um sistema automatizado para apoiar a identificação da expressão sendo realizada de forma tradicional.

As expressões foram classificadas de forma geral (considerando todos os testes) e por teste. Porém, o baixo número de expressões faciais diferentes de expressões neutras foi extremamente baixo totalizando apenas 1,7\% do total de imagens com faces reconhecidas.

Assim, na classificação geral foi possível identificar que existiu uma variação muito grande dos valores para determinadas expressões. Por exemplo, houve expressões em que os valores de similaridade variaram entre $45 \%$ e $99 \%$ de uma pessoa para outra ou de uma expressão para outra. Quando classificados por teste ocorreram variações menos significativas quando considerado somente 1 único teste, porém se mantiveram as variações 
quando comparados os valores para outros testes.

Por fim, não foi possível identificar um valor padrão de similaridade para cada expressão devido a dois motivos: primeiro que os valores não apresentaram um padrão quando comparados aos demais testes e caso aplicado ao software não apresentaria dados seguros para análise e comprometeria seriamente a qualidade das informações. Foi possível verificar um padrão de valores de similaridade dentro de um único teste, mas para que pudessem se tornar informações relevantes seria necessária uma calibragem de teste por teste antes de realizar o processamento destes dados, recurso este não implementado no escopo desta pesquisa. Devido a estes dois fatores a associação de valores de similaridade com expressões faciais foi descartada.

A terceira forma de análise utilizada foi o destaque dos registros de imagens contendo valor de similaridade inferior ao valor médio de similaridade de cada teste. Este recurso foi disponibilizado como forma de agilizar os testes, ainda sim, não foi considerado seguro devido ao fato que os valores de similaridade não apresentaram padrões que permitissem identificar a satisfação ou insatisfação do usuário e por isso o simples uso destes parâmetros pode comprometer os dados.

Portanto, a utilização dos dados de imagem de forma isolada para apoiar a análise dos dados e a redução do tempo de estudo do teste não é recomendada devido ao fato que os dados disponibilizados juntamente com a imagem (similaridade, data, hora e intervalo da reação) não são suficientes para auxiliar a análise dos dados, principalmente, por não representarem alguma reação específica do participante e assim forçar uma analisar os dados por completo aumentando. A Figura 58 apresenta uma comparação do tempo de análise dos dados utilizando somente recursos de imagem em relação aos tempos de análise com dados de som.

A seguir serão apresentadas as considerações finais a respeito dos resultados da pesquisa.

\subsubsection{Considerações Finais dos Resultados}

Os tempos dispensados para analise dos dados de voz e imagens registrados permitiram constatar que a utilização do recurso de verbalização utilizando palavras chave foi satisfatória para a abordagem, principalmente por classificar os conceitos fazendo assim que os dados se transformassem em indicadores de qualidade da interface. A união com imagens faciais permitiu melhorar a análise com a redução da área de estudo, pois per- 


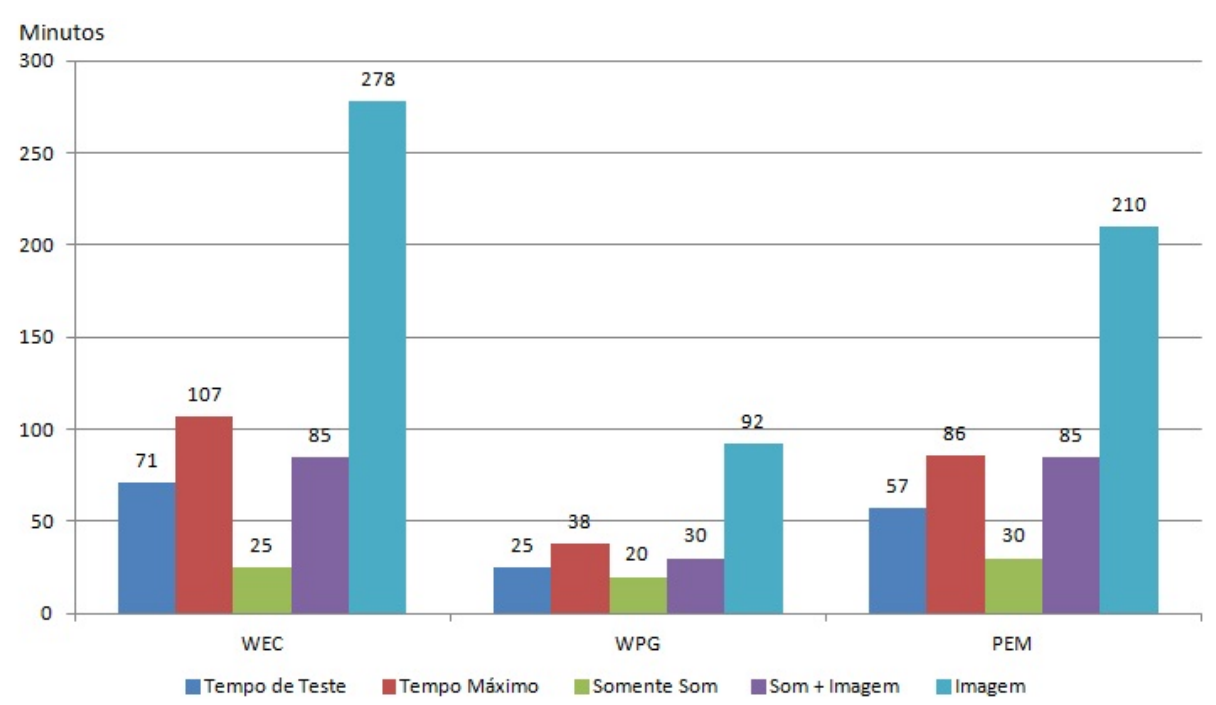

Figura 58 - Comparativo de tempo de análise com dados de fala e dados de imagem

mitiu identificar qual era o foco de visão do participante o que aumentaria a chance de identificar possíveis problemas de usabilidade.

A análise utilizando somente dados de imagem não foi considerada satisfatória devido, principalmente, a falta de dados classificadores que permitisse ao avaliador acessar de forma mais rápida e clara a opinião do participante e assim identificar em menor tempo problemas de usabilidade.

A Tabela 18 apresenta os valores finais de tempo de análise dos dados a qual permitiu maior eficiência da abordagem quando utilizados dados de fala. 


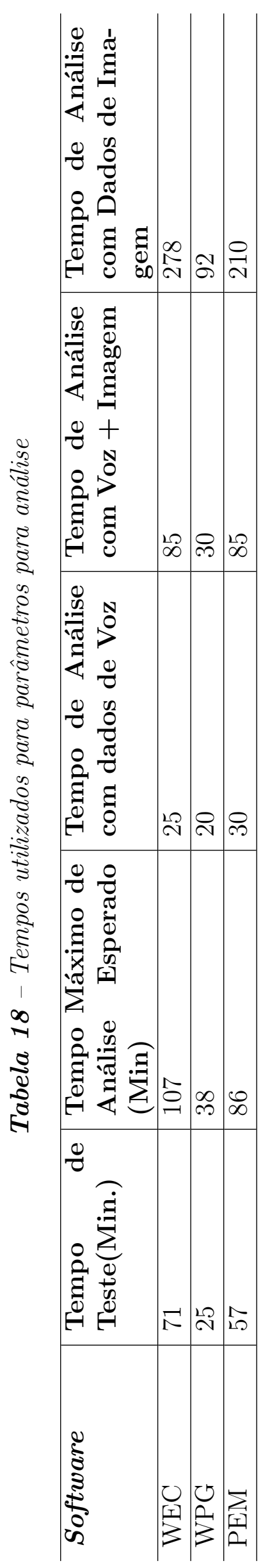


Com base nos resultados apresentados, o sistema ErgoSV será adaptado para permitir a melhor utilização dos recursos considerados satisfatórios. Estas alterações serão realizadas com objetivo de distribuir a aplicação para empresas, instituições de ensino e pesquisa que se interessem pelo seu uso. 


\section{Capítulo 4}

\section{Conclusão}

Este capítulo apresenta a conclusão desta pesquisa que teve como objetivo o desenvolvimento de um ambiente de avaliação da usabilidade utilizando recursos de processamento de imagens e reconhecimento de fala. Como seções deste capítulo são apresentadas as contribuições, limitações, trabalhos futuros e publicações.

\subsection{Contribuições}

Com base nos objetivos apresentados, esta pesquisa proporcionou as seguintes contribuíções:

- Desenvolvimento de um ambiente para avaliação da usabilidade: a abordagem desenvolvida ofereceu recursos para aquisição de dados sobre a opinião por participante utilizando eventos (palavras pronunciadas e imagens faciais) de forma rápida, prática e com pouca intrusividade na atividade de execução do software. A utilização de eventos para gerar insumos para apoiar a identificação de interfaces com problemas de usabilidade e/ou interfaces agradáveis foi considerada totalmente satisfatória devido ao fato que reduziu o tempo para identificação e análise das interfaces. Os experimentos mostraram que o evento de prouncia de palavras (verbalização) utilizando palavras chave se mostrou muito eficiente, pois o significado de cada palavra foi o principal dado utilizado para auxilio na identificação de problemas na interface. A imagens faciais se mostram eficazes quando utilizadas para apoiar a análise com uso de palavras já que auxiliaram na identificação do foco de visão do participante no momento de um evento e assim qual era o recurso em utilização no momento. Por fim, foi possível atingir o objetivo de reduzir o tempo de análise dos dados de um teste de usabilidade para um tempo inferior a 1,5 vezes o tempo do teste, tempo este significativamente menor que o tempo já utilizado na teoria de Nielsen (1993) de 3 a 10 vezes o tempo do teste.

- Necessidade de mais dados para análise de imagens: nesta pesquisa de mestrado foi possível identificar que a simples aquisição de imagens faciais associadas 
ao valor de similiridade com outras imagens não foi suficiente para auxiliar na identificação de problemas de usabilidade devido ao fato que as imagens não se posicionaram como classificadores de satisfação ou insatisfação do participante. Para tal contribuíção se faz necessária a inclusão de algum tipo de classificador tal como a identificação de qual expressão facial foi feita pelo participante.

- Software de monitoramento dos testes: um software batizado de ErgoSV foi desenvolvimento e utilizado na validação da abordagem. O aplicativo pode ser utilizado para monitoramento do teste de usabilidade e para execução de atividades como aquisição, processamento e geração de insumos para apoiar a análise dos dados.

\subsection{Limitações}

O ambiente de teste de usabilidade apresentou as seguintes limitações:

- As palavras chave utilizadas dependem da configuração do dicionário fonético e a forma da realização desta configuração pode ocasionar o não reconhecimento de algumas palavras em determinados sotaques;

- Foi possível notar que os participantes realizaram os testes de forma tensa, provavelmente devido ao fato de estarem participando de um experimento. Embora avisados que não eram alvos do teste, os mesmo permaneceram em sua maioria, com semblante neutro. O semblante neutro dificultou o cálculo de similaridade e a relação dos valores de similaridade com uma expressão faciais específica;

- A instalação do recurso computacional para utilização do ambiente de avaliação depende de configurações específicas do computador ou da utilização de uma máquina virtual para rodar uma versão pré configurada do Microsoft Windows.

\subsection{Trabalhos Futuros}

Os seguinte trabalhos futuros são propostos para esta pesquisa:

- Inclusão de algoritmos para reconhecimento de expressões faciais permitindo assim identificar a opinião do participante por meio do reconhecimento de suas expressões. Logo, este recurso poderá atribuir uma contribuição significativa a análise de dados de imagens de forma isolada; 
- Inclusão de técnicas de mineração de fala e processamento de linguagem natural com objetivo de disponibilizar um recurso para verbalização completa e sem restrições a palavras chave pré-determinadas. Importante ressaltar que este recurso não eliminaria a verbalização por palavras chave;

- Para utilização de palavras chave pretende-se o desenvolvimento de um ambiente visual que permita a escolha de palavras chave a serem utilizadas, suas definições, pesos e seu dicionário fonético;

- Desenvolvimento de um ambiente comercial/educacional para divulgação da abordagem e do software para utilização comercial e para estudo permitindo a interessados efetuar a aquisição da ferramenta, manual de instrução, compartilhar opiniões, sugestões, críticas e melhorias;

- Desenvolvimento de cálculo que considere as características do participante e o publico alvo do teste para calcular a taxas de usabilidade do software;

- Teste do ambiente em outras categorias de sistemas tais como games, sistemas para pessoas com problemas de acessibilidade e sistemas ecológicos a fim de analisar o comportamento do ambiente com sistemas de características específicas;

- Suporte ao recurso de Eye Tracking com objetivo de enriquecer os dados permitindo identificar para quais pontos da tela o participante olhou.

\subsection{Publicações}

Esta pesquisa permitiu a criação de 4 artigos aceitos e publicados em eventos Qualis. As publicações foram:

- Título: The Proposition of ErgoSV: An Environment to Support Usability Evaluation Using Image Processing and Speech Recognition System publicado no IADIS Interfaces and Human Computer Interaction 2012 (IHCI 2012) Conference. Este artigo apresentava a proposta da abordagem desenvolvida ainda sem resultados parciais ou totais, porém deixando claro o objetivo da pesquisa;

- Título: Analyzing face and speech recognition to create automatic information for usability evaluation publicado no Human Computer Interaction International, 2013, Las Vegas. Este artigo apresentava resultados parciais da pesquisa obtidos por meio 
dos primeiros experimentos realizados. O mesmo já apresentava um panorama de qual seria o comportamento e os resultados da abordagem;

- Título: The Proposition of a Framework to Support the Design of Ecological Systems for the Web artigo publicado no Human Computer Interaction International, 2013, Las Vegas no qual era parte da proposta de um framewor de desenvolvimento de sistemas voltados para área ecológica. A abordagem é apresentada como recursos para teste dos sistemas relacionados ao projeto;

- Título: A Teaching Strategy for Usability Evaluation to Human-Computer Interaction Courses aceito e publicado no IV WEIHC - Workshop de Ensino de Interação Humano Computador, artigo no qual a ferramenta é destacada como parte de uma estratégia de ensino de avaliação da usabilidade. O ambiente é utilizado para apoiar a aprendizagem de testes de usabilidade submetendo os alunos a situações reais de projeto, realização e análise dos dados dos testes. 


\section{Referências}

AGUS, T. et al. Characteristics of human voice processing. In: Circuits and Systems (ISCAS), Proceedings of 2010 IEEE International Symposium on. [S.1.: s.n.], 2010. p. $509-512$.

BALAGTAS-FERNANDEZ, F.; HUSSMANN, H. A methodology and framework to simplify usability analysis of mobile applications. Proceedings of 2009 IEEE/ACM International Conference on Automated Software Engineering, 2009.

BERGAMASSO, L. C. C. Recuperação de Imagens por conteúdo utilizando Lógica Fuzzy. Um estudo de caso sobre imagens faciais. [S.l.], 2010.

BOREN, M. T.; RAMEY, J. Thinking aloud: Reconciling theory and practice. IEEE Transactions on Professional Communication, p. 261-278, 2000.

CAMACHO, C. O. de A. Desenvolvimento em Camadas com C Sharp .NET. [S.1.]: Visual Books, 2008. 202 p.

CASTILHO, W. Mentira: um rosto de várias faces. [S.l.]: Matrix, 2011.

CERRATO, M. V. Utilização do ErgoParser em arquivos de log para determinação de métricas de usabilidade de websites. Dissertação (Mestrado) — Escola de Artes, Ciências e Humanidades da Universidade de São Paulo, São Paulo, SP, 2012.

CHENG, S. The research framework of eye-tracking based mobile device usability evaluation. Proceedings of PETMEI 2011, 2011.

COOKE, L. Assessing concurrent think-aloud protocol as a usability test method: A technical communication approach. IEE Trans. Prof. Commun, p. 202-215, 2010.

CYBIS, W.; BETION, A. H.; FAUST, R. Ergonomia e Usabilidade - Conhecimentos, Métodos e Técnicas. [S.1.]: Novatec Editora, 2010.

CYBIS, W. d. A.; SCAPIN, D.; MORANDINI, M. Ergomanager: um sistema gerenciador de interfaces com o usuário para sites web transacionais. In: Proceedings of the 2005 Latin American conference on Human-computer interaction. New York, NY, USA: ACM, 2005. (CLIHC '05), p. 256-267. ISBN 1-59593-224-0. Disponível em: $<$ http://doi.acm.org/10.1145/1111360.1111386>.

DíAZ, P.; SICILIA, M. Ángel; AEDO, I. Evaluation of hypermedia educational systems: Criteria and imperfect measures. Proceedings of the International Conference on Computers in Education (ICCE 02), 2002.

DEFFNER, G. Verbal protocols as a reserach tool in human factors. Proc. Human Factors Soc. 34th Annual Meeting, p. 1263-1264, 1990. 
FERNáNDEZ, N. C. et al. An empirical approach for evaluating the usability of model-driven tools. ScienceofComputerProgramming, 2012.

GOLDBERG, J. H.; WICHANSKY, A. M. Eye tracking in usability evaluation: A practitioner's guide. The Mind's Eye: Cognitive and Applied Aspects of Eye Movement Research, 2003.

GONZALEZ, R. C.; WOODS, R. E. Processamento de Imagens Digitais. [S.1.]: Edgard Blucher Ltda, 2000.

GUEDES, G. T. A. UML 2: uma abordagem prática. [S.l.]: Novatec Editora, 2009.

HAAK, M. J. van den; JONG, M. D. T. de; SCHELLENS, P. J. Retrospective vs. concurrent think alou protocols: testing the usability of an online library catalogue. Behavior \& Information Tecnology, p. 339-351, 2003.

HASAN, L.; MORRIS, A.; PROBETS, S. E-commerce websites for developing countries: a usability evaluation framework. Online Information Review, v. 37, n. 2, p. 231-251, 2013.

HEO, J. et al. A framework for evaluating the usability of mobile phones based on multi-level, hierarchical model of usability factors. Interacting with Computers, 2009.

HERTZUM, M.; HANSEN, K. D.; ANDERSEN, H. H. Scrutinising usability evaluation: does thinking aloud affect behaviour and mental workload? Behavior $\&$ Information Tecnology, p. 165-181, 2009.

HOLLINGSED, T.; NOVICK, D. G. Usability inspection methods after 15 years of research and practice. SIGDOC'07, 2007.

ISO 25010: Software engineering. Software product Quality Requirements and Evaluation (SQuaRE). Software and quality in use models.

JACOB, K. S. K. R. J. Eye tracking in human-computer interaction and usability research: Ready to deliver the promises. The Mind's Eye, 2003.

JIN, B. S. et al. Development of a usability evaluation framework with quality function deployment: From customer sensibility to product design. Human Factors and Ergonomics in Manufacturing, p. 177-194, 2009.

KHAN, M. et al. Empirical validation of usability evaluation framework for haptic systems. Proceedings of International Conference on Computer $\&$ Information Science (ICCIS), 2012.

KIM, H. J.; CHOI, J. K.; JI, Y. Usability evaluation framework for ubiquitous computing device. Proceedings of Third 2008 International Conference on Convergence and Hybrid Information Technology, p. 164-170, 2008.

LETTNER, F.; HOLZMANN, C. Usability evaluation framework automated interface analysis for android applicat ions. EUROCAS T 2011, Part I I, LNCS 6928, p. 560 $567,2011$. 
LETTNER, F.; HOLZMANN, C. Automated and unsupervised user interaction logging as basis for usability evaluation of mobile applications. Proceedings of MoMM2012,, 2012 .

LIMA, J. P. S. de M. et al. Reconhecimento de padrões em tempo real utilizando a biblioteca opencv. Técnicas e Ferramentas de Processamento de Imagens Digitais e Aplicações em Realidade Virtual e Misturada, p. 47-89, 2008.

MCDONALD, S.; EDWARDS, H. M.; ZHAO, T. Exploring think-alouds in usability testing: An international survay. IEEE Transactions on Professional Communication, 2011.

MORANDINI, M. Ergo-Monitor: Monitoramento da Usabilidade em Ambiente Web por Meio de Análise de Arquivos de Log. Tese (Doutorado) - Universidade Federal de Santa Catarina, 2002.

MORANDINI, M. et al. Project and development of ergocoin version 2.0. 2011.

NETO, N.; PATRICK, C.; KLAUTAU, A. Free tools and resources for brazilian portuguese speech recognition. The Brazilian Computer Society, 2010.

NETO, N. et al. Um reconhecedor de voz livre para português brasileiro. August 2010.

NIELSEN, J. Usability Engeneering. [S.1.]: Morgan Kaufmann, 1993.

NUNES, F. de Lourdes dos S. Introdução ao processamento de imagens médicas para auxílio a diagnóstico - uma visão prática. Livro das Jornadas de Atualização em Informática, p. 73 - 126, 2006.

NUNES, F. de Lourdes dos S. Processamento Gráfico para aplicações em saúde. Técnicas, requisitos, ferramentas, desafios e oportunidades. Tese (Doutorado) - Universidade de São Paulo, Agosto 2011. Tese de Livre Docência.

OLIVEIRA, E. de; JAQUES, P. A. Inferindo as emoções do usuário pela face através de um sistema psicológico de codificação facial. IHC2008 - VIII Simpósio Sobre Fatores Humanos em Sistemas, 2008.

PREECE, J.; BORGES, Y.; SHARP, H. Design de Interação, Além da interação homem computador. [S.l.]: Bookman, 2005.

PRESSMAN, R. Engenharia de Software - uma abordagem profissional. [S.l.]: Bookman, 2011.

RAMLI, R.; ZAMAN, H. B. Designing usability evaluation methodology framework of augmented reality basic reading courseware (ar baca sindd) for down syndrome learner. Proceedings of 2011 International Conference on Electrical Engineering and Informatics, 2011.

RAMLI, R. bt M.; JAAFAR, A. bt. e-rue: A cheap possible solution for usability evaluation. 2008.

ROCHA, H. V. da; BARANAUSKAS, M. C. C. Design e Avaliação de Interfaces Humano-Computador. [S.l.]: NIED/UNICAMP, 2003. 
SCAPIN, D.; BASTIEN, C. Ergonomic criteria for evaluating the ergonomic quality of interactive systems. Behaviour and Information Technology, v. 16, 1997.

SHARIAH, M. A. M. A. et al. Human computer interaction using isolated-words speech recognition technology. International Conference on Intelligent and Advanced Systems 2007, 2007.

SILVA, P. et al. An open-source speech recognizer for brazilian portuguese with a windows programming interface. The International Conference on Computational Processing of Portuguese (PROPOR), 2010.

SOUZA, L. B. L. de; SANTOS, J. C. de S.; GULIATO, D. Um extrator de caracterÍsticas baseado em complexidade aplicado À classificaÇÃo tumores de mama. XII Seminário de Iniciação Científica da Universidade Federal de Uberlândia, 2008.

TAMIR, D. E.; MEMBER; MUELLER, C. J. Pinpointing usability issues u sing an effort based framework. IEEE, p. 931-938, 2010.

VARGAS, A.; WEFFERS, H.; ROCHA, H. V. da. A method for remote and semi-automatic usability evaluation of web-based applications through users behavior analisys. 2010.

WRIGHT, R.; CONVERSE, S. Method bias and concurrent verbal protocol in software usability testing. Proceedings of the human factors society 36th annual meeting, p. 1220-1224, 1992. 